\title{
TIm Technology Innovation Management Review
}

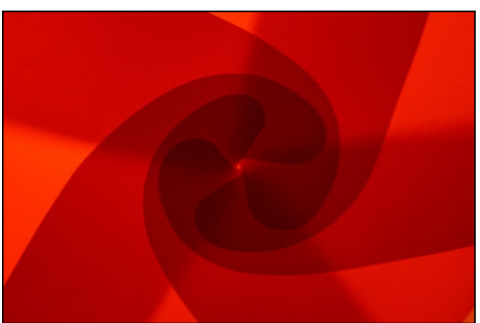

Image credit: Rebecca Siegel (CC-BY)

\section{Action Research}

Welcome to the May issue of the Technology

Innovation Management Review. We welcome your comments on the articles in this issue as well as suggestions for future article topics and issue themes.

Editorial: Action Research

Chris McPhee, Magnus Hoppe, and Erik Lindhult

Scientific Excellence in Participatory and Action Research: Part I.

Rethinking Research Quality Erik Lindhult

Scientific Excellence in Participatory and Action Research: Part II.

Rethinking Objectivity and Reliability Erik Lindhult

How to Develop an Impactful Action Research Program: Insights and

Lessons from a Case Study Victoria Lakiza and Isabelle Deschamps

Employee-Driven Innovation: An Intervention Using Action Research Mats Holmquist and Anna Johansson

Embedded Master's Students Conduct Highly Relevant Research Using

Industry as Their Laboratory Kristin Falk and Gerrit Muller

Q\&A. What Can Action Research Learn from Business Environment Analysis? Bengt Wahlström

Author Guidelines 


\section{Publisher}

The Technology Innovation Management Review is a monthly publication of the Talent First Network.

\section{ISSN}

1927-0321

\section{Editor-in-Chief}

Chris McPhee

\section{Advisory Board}

Tony Bailetti, Carleton University, Canada

Peter Carbone, Ottawa, Canada

Parm Gill, Gill Group, Canada

Leslie Hawthorn, Red Hat, United States

Michael Weiss, Carleton University, Canada

\section{Review Board}

Tony Bailetti, Carleton University, Canada

Peter Carbone, Ottawa, Canada

Parm Gill, Gill Group, Canada

G R Gangadharan, IBM, India

Mohammad Saud Khan, Victoria University of

Wellington, New Zealand

Seppo Leminen, Pellervo Economic Research and Aalto University, Finland

Colin Mason, University of Glasgow, United Kingdom

Steven Muegge, Carleton University, Canada

Jennifer Percival, University of Massachusetts, United States

Risto Rajala, Aalto University, Finland

Punit Saurabh, Nirma University, India

Sandra Schillo, University of Ottawa, Canada

Marina Solesvik, Nord University, Norway

Stoyan Tanev, Carleton University, Canada

Michael Weiss, Carleton University, Canada

Mika Westerlund, Carleton University, Canada

Blair Winsor, Memorial University, Canada

(C) $2007-2019$

Talent First Network

www.timreview.ca

\section{Overview}

The Technology Innovation Management Review (TIM Review) provides insights about the issues and emerging trends relevant to launching and growing technology businesses. The TIM Review focuses on the theories, strategies, and tools that help small and large technology companies succeed.

Our readers are looking for practical ideas they can apply within their own organizations. The TIM Review brings together diverse viewpoints - from academics, entrepreneurs, companies of all sizes, the public sector, the community sector, and others - to bridge the gap between theory and practice. In particular, we focus on the topics of technology and global entrepreneurship in small and large companies.

We welcome input from readers into upcoming themes. Please visit timreview.ca to suggest themes and nominate authors and guest editors.

\section{Contribute}

Contribute to the TIM Review in the following ways:

- Read and comment on articles.

- Review the upcoming themes and tell us what topics you would like to see covered.

- Write an article for a future issue; see the author guidelines and editorial process for details.

- Recommend colleagues as authors or guest editors.

- Give feedback on the website or any other aspect of this publication.

- Sponsor or advertise in the TIM Review.

- Tell a friend or colleague about the TIM Review.

Please contact the Editor if you have any questions or comments: timreview.ca/contact

\section{About TIM}

The TIM Review has international contributors and readers, and it is published in association with the Technology Innovation Management program (TIM; timprogram.ca), an international graduate program at Carleton University in Ottawa, Canada. 


\title{
Editorial: Action Research
}

\author{
Chris McPhee, Editor-in-Chief \\ Magnus Hoppe and Erik Lindhult, Guest Editors
}

\section{From the Editor-in-Chief}

Welcome to the May 2019 issue of the Technology Innovation Management Review. This is the second of two issues on the theme of Action Research, and it is my pleasure to continue our collaboration with guest editors Magnus Hoppe and Erik Lindhult from Mälardalen University in Sweden. Magnus and Erik are also both Board Member of the Swedish Interactive Research Association (SIRA), and Erik is a Board Member of the Swedish Participative Action Research Community (SPARC).

We hope that these two special issues on action research will both provide valuable insights and encourage further contributions in the field. As we are developing plans for future special issues on action research, we encourage potential authors to contact us to express interest in contributing articles.

Furthermore, our regular June issue will include an interview with David Coghlan, Professor Emeritus at the Trinity Business School, Trinity College Dublin, Ireland. David is one of the founding fathers of modern action research, and he will offer his reflections on the present and future of the theory and practice of action research, and he will comment on the patterns and insights he sees in these two special issues of the TIM Review.

Please contact us (timreview.ca/contact) with potential article topics and submissions, and proposals for future special issues. As always, we also welcome general submissions of articles on technology entrepreneurship, innovation management, and other topics relevant to launching and growing technology companies and solving practical problems in emerging domains.

\section{Chris McPhee}

Editor-in-Chief

\section{From the Guest Editors}

In April (timreview.ca/issue/2019/april), we published the first of this pair of special issues on the theme of Action Research. This second special issue can be said to be both a prolongation of the first issue and an expansion of the scope of the first issue. The aim, however, is the same: to express the action research discussion in an accessible manner such that academics, industry, and the public sector can adopt the frameworks, models, and ideas presented by the authors.

First, Erik Lindhult provides two complementary articles that we hope can be used as solid references on the philosophy of action research. They both rests on the notion that action research has an epistemology of its own that challenges traditional views on quality, objectivity, and reliability. We believe that this argumentation is much needed by all who struggle with the demands from scientific dogmas and traditions. As these ideas most likely can be viewed as controversial to many, we are looking forward to continuing the discussion in future issues of the TIM Review, and we hope readers will take up this call for further contributions on action research in this journal.

Erik's first article, "Rethinking Research Quality", reconstructs scientific inquiry from a praxis-oriented understanding of knowledge, pointing to wider opportunities for understanding and achieving research quality. From this point of view, the potential for research quality lies not in corresponding theory with reality but in warranting and enhancing the trustworthiness of achieving human ends. Erik argues that engagement and purposes are integrated in science, recognizing a distinguishing feature of action research in the focus on production of knowledge for worthwhile human purposes. He develops a wider framework for understanding purpose in science and its basis in validity, reliability, and the core characteristics of participatory and action research. The article is also rethinking validity, offering a broader landscape of validation than more traditional approaches. An implication is that good inquiry management is needed in order to mobilize a broader spectrum of purposes, forms of knowledge, and a collaborative capacity for inquiry of stakeholders. 


\title{
Editorial: Action Research
}

\author{
Chris McPhee, Magnus Hoppe, and Erik Lindhult
}

In Erik's second article, "Rethinking Objectivity and Reliability", he goes further in reconstructing research quality by rethinking objectivity and reliability. In addition to achieving objectivity through a passive, distant position and reliability through replication of research results and standardization, the article shows that it is fruitful to consider the "subjective" and active role of researchers and participants as vital in enabling scientific objectivity and reliability. Erik concludes the article by emphasizing that, by rethinking validity, reliability, and objectivity, and recognizing that substantially more active and participatory stances enable scientific excellence, we can expand the repertoire of strategies for promoting research quality and support the mainstreaming of this type of approach in the scientific community.

In the third article, we revisit the empirical grounds of action research via a case study in order to not blind ourselves with theories. In this article, Victoria Lakiza and Isabelle Deschamps from Polytechnique Montréal in Canada describe the mechanisms through which action research can create the desired change and impact in both industry and academia. Through their article, we gain insight into the main steps of a longitudinal action research program in a Canadian manufacturing company. In order to succeed, the authors emphasize the necessities of building trust, understanding the system, becoming part of the team, and iterating. This approach has led them to formulate six success factors revolving around adherence to the developing specifics of the process they are part of as well as a flexible attitude in all aspects of action research work. We venture to conclude from their work that, if you accept that the system is open, you must be open, too, in most aspects, in order to make an action research partnership work for all.

Then, in the fourth article, by Mats Holmquist and Anna Johansson from Halmstad university, we learn how interventions affected employee-driven innovation. Crucial to their approach was to give centre stage to the employees and make managers bystanders. However, even though managers learned about their employees' ideas and appreciated the innovation process, the resulting innovation ideas were not implemented due to other priorities. The authors conclude that the absorptive capacity simply was not there, and they indirectly stress that management need to take a greater responsibility for implementing desired innovations, not just encourage employees to participate in processes for formulating innovation ideas.

Next, Kristin Falk from the University College of Southeastern Norway and Gerrit Muller at the Embedded
Systems Institute in Eindhoven describe how master's students can conduct research in collaboration with industry. The study covers a period of 10 years and over 180 master's projects, where the students were working embedded in industrial companies during half of time of their studies. As results from their projects, about a fourth of the students managed to produce research that qualified for publication in international conferences and journals. The approach guaranteed basing research in real-world problems where Falk and Muller classify $80 \%$ percent of the papers to be within the domain of action research.

Finally, Bengt Wahlström from Mälardalen University in Sweden draws on his 30-plus years of experience of management consultancy to answer the question: "What can action research learn from business environment analysis?" With different examples, he emphasizes that there is not just one knowledge or learning process at work, but several, that need to be addressed while succeeding with consultancy and, thus, these are also important aspects to consider when doing action research. At the centre of this is acknowledging that there is more than one way of gaining access to a company and building a project. Nevertheless, management and those with the power to change need to be involved at some point.

Taken together, we notice some central themes present in the articles of this special issue. The main one, to us, is the idea of the researcher to be or become part of the team that work with the real-world problem the action and knowledge process is supposed to solve. It takes commitment to the cause as well as time in order to become embedded and continuously adapt. Thus, flexibility is key. This logic contrasts with traditional ideas of scientific rigour and control, meaning that action researchers need complementary views on quality, objectivity, and validity, which we hope we have provided through this special issue. These insights might help researchers to reach their ends, but they will not suffice at the practical end. Instead, through the accounts available here, we become aware that action research efforts do not trump organizational power structures. Instead, analyzing the organization, how it is run, and who has the power to change are vital when paving the way for innovations, whether they are developed through action research or not. Action research is thus nothing you should do on a whim. You should not to just plunge into the practice. Instead, you will do better if you study the water first and decide when, where, and how to jump.

\section{Magnus Hoppe and Erik Lindhult Guest Editors}




\section{Editorial: Action Research}

\section{About the Editors}

Chris McPhee is Editor-in-Chief of the Technology Innovation Management Review. Chris holds an MASc degree in Technology Innovation Management from Carleton University in Ottawa, Canada, and BScH and MSc degrees in Biology from Queen's University in Kingston, Canada. He has 20 years of management, design, and content-development experience in Canada and Scotland, primarily in the science, health, and education sectors. As an advisor and editor, he helps entrepreneurs, executives, and researchers develop and express their ideas.

Magnus Hoppe is an Associate Professor at the School of Economics, Society and Engineering at Mälardalen University, Sweden. At the university, he is member of the Faculty Board and leads processes for collaborative research in sustainable development. Magnus holds a PhD in Business Administration from Åbo Akademi University in Finland, where he presented his thesis on organized intelligence work in modern organizations. His current research concerns both private and public organizations and spans intelligence, entrepreneurship, and innovation. A special research interest lies in questioning dominating perspectives that bind our understanding of specific topics, and he now works to establish new ways of talking and thinking about innovation. His aim is to help organizations build new insights that will enhance their ideation processes and strategy building and, thereby, improve their innovative capabilities.

Erik Lindhult (Ph.D.) is a Senior Lecturer in Innovation Management and Entrepreneurship at Mälardalen University in Sweden. He received his doctoral degree in Industrial Management from the Royal Institute of Technology in Stockholm, in the area of Scandinavian dialogue democratic approach to innovation and action research. His main area of research is participatory, collaborative, and democratic innovation and change management, as well as entrepreneurship for a sustainable development of society. His research interests also involve collaborative research methodologies, including action research and interactive research. He has been involved in a wide range of collaborative R\&D projects in the private, public, and cooperative sectors, in areas such as organizational development, incubator and science park development, service innovation, societal entrepreneurship, sustainable innovation, and school development. $\mathrm{He}$ is a board member of the Swedish Participatory Action Research Society (SPARC) and the Swedish Interactive Research Association (SIRA), as well as an expert advisor to the EU SWAFS Horizon 2020 research committee.
Citation: McPhee, C., Hoppe, M., \& Lindhult, E. 2019. Editorial: Action Research. Technology Innovation Management Review, 9(5): 3-5. http://doi.org/10.22215/timreview/1236

Keywords: action research, participatory research, participative, innovation 


\title{
Scientific Excellence in Participatory and Action Research: Part I. Rethinking Research Quality
}

\author{
Erik Lindhult
}

\author{
In memory of Björn Gustavsen
}

\begin{abstract}
"Action research is not only one of a number of 'branches' or") competing 'schools of thought' but actually a main school... action research finds its legitimacy in an ability to deal with the traditional tasks of research in a way which is superior to other schools of thought.
\end{abstract}

Björn Gustavsen (1938-2018)

Professor and Action Researcher

In Gustavsen (1992)

\begin{abstract}
A core impetus of participatory and action research is making science relevant and useful for solving pressing problems and improving social conditions, and enabling stakeholders to participate in research and development processes. There are claims in the community of participatory and action research of the potential for heightened scientific excellence, but at the same time, there are critiques in the mainstream community that more engaged, even activist, stances threaten scientific norms or that position these type of research approaches outside the field of science, for example, as issues of application. In the search of clarification of the scientific identity and the specific qualities of participatory and action research, scholars have been moving away from and sometimes have rejected traditional conceptions of quality. This leads to confusion about how to relate to the discourse on research quality and scientific excellence in mainstream science. Integration in this discourse is important in order to attain academic legitimation in prevailing institutions of science, for example, in applications for funding, in seeking to publish research, and in the acceptance of dissertations based on participatory and action research. The purpose of this article is to contribute to this integration by reconstructing the way traditional quality concepts - validity, reliability, and objectivity - can be fruitfully used in expanded frameworks for quality where scientific excellence of participatory and action approaches are visible and where mainstream science approaches also can be harboured. In this conceptual article, reconstruction of understanding of scientific inquiry is first made based on a praxis-oriented epistemology inspired by pragmatism. Through rethinking truth as trustworthiness, new proposals for the conceptualization and frames for research quality and scientific excellence are introduced. Second, a framework for understanding purpose in science and its basis in validity, reliability, and the core characteristics of participatory and action research is developed. Third, the turn to action, practice, and participation enables plural ways of knowing and ways that knowledge claims can be validated and made trustworthy. The article concludes that participatory and action research offers a broader landscape of purpose and validation than more traditional approaches to science. In a subsequent article, reliability and objectivity, and their use in participatory and action research, will be clarified.
\end{abstract}




\section{Scientific Excellence in Participatory and Action Research: Part I. Rethinking Research Quality Erik Lindhult}

\section{Introduction}

The quality discourse in the scientific community is today both institutionalized and many-faceted based both on dominant perspectives, often emanating from positivist accounts, and, during recent decades, expanded qualitative approaches for doing scientific research. This has provided broadened and varied views on research quality in qualitative research (Denzin \& Lincoln, 2011), partly also opening up the quality research arena for participatory and action research approaches (Guba \& Lincoln, 1989; Lincoln \& Guba, 1985; Merriam \& Tisdell, 2016). In this wider variety of research approaches and understanding of science, conceptions of quality are in flux. Furthermore, the quality discourse does not yet fully recognize and incorporate the special characteristics and purposes in participatory and action research approaches and tradition. In this varied community and loose tradition, "action research" is a main appellation used (Bradbury-Huang, 2015; Reason \& Bradbury, 2001a, 2008); other more or less frequent connotations are "participatory action research" (Fals-Borda, 1979; Fals-Borda \& Rahman, 1991; Whyte, 1991), "participatory research" (Brown \& Tandon, 1983; Hall et al, 1982), "interactive research" (Nielsen \& Svensson, 2006; Svensson et al., 2007), "collaborative inquiry/research" (Heron, 1996), and "engaged scholarship" (Van de Ven, 2007). A core impetus of this intersecting variety of research approaches is making science relevant and useful for solving pressing problems and improving social conditions. An equally important impetus is enabling stakeholders to participate in research and development processes. It points to two basic norms in organizing and managing research that can capture defining characteristics: a focus on action and practice and a focus on interaction, participation, and collaboration. Active and interactive research roles and relations in scientific inquiry are distinguishing design parameters compared to mainstream science, where passive and distant positions are generally the norm.

There are opportunities for doing better, higher-quality research combining rigour and relevance that are not fully recognized and focused on (Greenwood, 2002; Gustavsen, 1992). However, quality in this type of research is unclear and has different meanings (Checkland \& Howell, 1998; Coghlan \& Shani, 2014; Eikeland, 2006, 2008, 2012; Feldman, 2007; MacIntosh \& Bonnet, 2007; Martí \& Villasante, 2009; Susman \& Evered, 1978). There is also a view that scientific excellence tends to be compromised, at risk, or of lower scientific standards in participatory and action research (Bradbury-
Huang, 2010; Bryman, 2016; Levin, 2012). The purpose of this article is to develop an argumentation on how quality in participatory and action research can be interpreted with a special focus on how to understand and thus redefine central concepts such as validity, reliability, and objectivity. I will, in this first of two articles, develop quality frameworks for participatory and action research based on a broader set of purpose in science and a wider understanding of validity and validation. Reliability and objectivity in participatory and action research will be the focus of a subsequent article (Lindhult, 2019).

It should be noted that these quality concepts are contested and are sometimes rejected both in the qualitative research domain as well as in participatory and action research. This motivates proposals of alternative concepts of quality in the search for more adequate understanding of what is excellent in participatory and action research. In finding its own identity, a more separatist approach is recognizable, pointing to dimensions different from other approaches and requiring its own qualities and standards (Bradbury \& Reason, 2001; Reason \& Bradbury, 2001b). For example, Peter Reason, a leading researcher in the debate on the quality of action research and the search for its identity, points to four such characteristic dimensions: 1) worthwhile practical purposes, 2) democracy and participation, 3) many ways of knowing, and 4) emergent developmental forms. These represent "a broad range of criteria beyond those of the empirical research paradigm" (Reason, 2006). In addition to Reason (2006), to my mind, one of the most elaborate attempts is made by Herr and Anderson (2015; but there are others, e.g., Coghlan \& Shani, 2014), who point out that their notion of quality "departs radically from those of both quantitative and qualitative research". But they want to retain the language of validity for strictly strategic reasons. Objectivity and reliability are not part of this strategic move (I will deal with these concepts in the subsequent article). Although they do not intend to "speak with an authoritative academic voice" about research quality for participatory and action research, they still want to provide an authoritative voice for successfully completing dissertations, that is, works that have to be accepted in academia, legitimized in this traditional institution for science. Thus, academic legitimation is their strategic goal in entering the traditional battlefield of scientific quality by formulating alternative qualities for participatory and action research (e.g., democracy) in the cloak of validity: dialogic validity, outcome validity, catalytic validity, democratic validity, and process validity. They are offering these criteria in the hope being "widely 


\section{Scientific Excellence in Participatory and Action Research: Part I. Rethinking Research Quality Erik Lindhult}

cited and summarized in mainstream research texts (...) may provide the legitimation needed to get a dissertation through a less than totally sympathetic dissertation committee" (Herr \& Anderson, 2015). To what extent this tactic will succeed is still open; Herr and Andersson (2015) see their offering of validity criteria as "tentative and in flux". This might seem daunting for people attracted to use participatory and action research approaches, but the situation of quality conceptions in flux also goes for the whole quality research field with the use of the traditional concepts as contested (Denzin \& Lincoln, 2011; Leung, 2015; Merriam \& Tisdell, 2016).

I agree that the institutionalization tactic propagated by Herr and Anderson (2015) is a fair point and that it might work well in the long run. My integrational aim is instead based on a stronger claim: to speak in an authoritative scientific voice in the sense of providing convincing arguments for more fruitful conceptualization of validity, objectivity, and reliability that can provide good support and space for participatory and action research and having persuasive force in the ongoing academic debate on research quality. This reconstruction is required to develop the status of participatory and action research as a not only acceptable, but also fully recognized and respected, family members in the community of scientific approaches in the academic community - and society at large.

\section{Reconstructing understanding of scientific inquiry and traditional quality concepts}

In order to clarify scientific excellence in participatory and action research, I will pinpoint epistemologically favourable dimensions that participatory and action research approaches to inquiry can realize in effective, high-quality research practices. It is a contribution to clarify the ability of participatory and action research "to deal with the traditional tasks of research in a way which is superior to other schools of thought" (Gustavsen, 1992). It builds on advancement in understanding of the epistemological significance of action and praxis pointing to an extended and pluralist epistemology (Heron, 1996). This requires rethinking of the philosophy and practice of science, and this rethinking often finds support in different dimensions of pragmatic- or practice-inspired philosophy (i.e., Dewey, 1939; Habermas, 1971, 1984, 1987; Rorty, 1979; Schön, 1983; Santos, 2014; Wittgenstein, 1984; Foucault, 1980). I will here clarify the relation between science, inquiry, knowledge, and truth with the aid of John Dewey, particularly his emergent crystallization of his theory of inquiry in his later years (Dewey, 1929, 1939).
Dewey is criticizing the spectator orientation and the subjectivism of established epistemology, where knowledge and the conceptions of truth are based on the metaphor of mental mirroring of objects in a given, external reality (Dewey, 1929; Rorty, 1979, 1998). Dewey argues that the development of knowledge cannot be done purely mentally, just inside one's head. "Men have to do something to the things when they wish to find out something; they have to alter conditions" (Dewey, 1929). "A known object exists as the consequences of directed operations, not because of conformity of thought or observation with something antecedent" (Dewey, 1929). When we are able to drive a car, ride a horse, get a new product to work in a stable way, that is, secure intended and valued consequences projected as possibilities by our ideas that direct our action, we possess knowledge, we show intelligence. Knowledge is not in this view accurate conceptual mirroring of a given reality, but instead it is of a reality constructed and harnessed to human ends. That is, data, ideas, propositions, and laws are means of knowing, not its objects (Dewey, 1929).

This points to an actor- and praxis-oriented view where knowledge is the capacity to act to transform conditions to accomplish human aims and goods. Table 1 depicts core dimensions in a spectator-oriented and praxis-oriented epistemologies and points to opportunities for research quality in a praxis orientation to knowledge and scientific inquiry.

Participatory and action research may be backed by a spectator orientation to knowledge, for example, as enabling field experiments as the first generation of action research used in its scientific legitimation. Overall, it does not, in this orientation, receive much epistemological support but rather is perceived as disturbing the research object through more active and collaborative roles and relations. The scientific qualities, according to the standard use of mainstream quality concepts, tend to disfavour participatory and action research: validity as the extent to which models, theories, or concepts correspond to features of reality; reliability as consistency in measuring different dimensions (i.e., mirroring) of research objects; and objectivity as avoiding any "subjective" intrusion. Furthermore, participatory and action research is, from a spectator view, seen as "activist" in bringing in non-scientific values of human needs, utility, participation, and democracy into the understanding of science.

First, participatory and action research comes more into its own in a movement from a spectator orientation 


\section{Scientific Excellence in Participatory and Action Research: Part I. Rethinking Research Quality Erik Lindhult}

Table 1. Spectator- and praxis-based epistemological orientations

\begin{tabular}{|c|c|c|c|}
\hline & Spectator Orientation & Praxis Orientation & $\begin{array}{l}\text { Research Quality Potential in } \\
\text { Praxis-Oriented Approaches }\end{array}$ \\
\hline $\begin{array}{l}\text { Character of } \\
\text { knowledge }\end{array}$ & $\begin{array}{l}\text { Faithful depiction of given } \\
\text { reality (truth as } \\
\text { correspondence) }\end{array}$ & $\begin{array}{l}\text { Competent reconstruction of } \\
\text { situations to realize human } \\
\text { goods }\end{array}$ & $\begin{array}{l}\text { Trustworthiness in achieving } \\
\text { human ends }\end{array}$ \\
\hline $\begin{array}{l}\text { Human interests } \\
\text { and purpose }\end{array}$ & $\begin{array}{l}\text { Basic research ideally free from } \\
\text { interests (other than advancing } \\
\text { knowledge and individual } \\
\text { curiosity) }\end{array}$ & $\begin{array}{l}\text { Inherent in } \\
\text { knowledge/knowing as a } \\
\text { competent activity }\end{array}$ & $\begin{array}{l}\text { Purposive, trustworthy } \\
\text { resolution of concerns, praxis } \\
\text { improvements, and } \\
\text { transformations }\end{array}$ \\
\hline \multirow{2}{*}{$\begin{array}{l}\text { Relation to } \\
\text { stakeholders / those } \\
\text { affected }\end{array}$} & Research on... & Research with... & \multirow{2}{*}{$\begin{array}{l}\text { Mobilize and pool distributed } \\
\text { forms of knowledge and } \\
\text { research capacity }\end{array}$} \\
\hline & $\begin{array}{l}\text { Subjects as study objects / data } \\
\text { source ("respondents") }\end{array}$ & $\begin{array}{l}\text { Subjects as participants in } \\
\text { research }\end{array}$ & \\
\hline \multirow{2}{*}{$\begin{array}{l}\text { Position of } \\
\text { research }(\text { ers })\end{array}$} & Detached, passive & Engaged, (inter)active & \multirow{2}{*}{$\begin{array}{l}\text { Situated, mutual learning } \\
\text { processes among participants in } \\
\text { different roles }\end{array}$} \\
\hline & Ideally outside research context & $\begin{array}{l}\text { Researchers can have various } \\
\text { positions and roles }\end{array}$ & \\
\hline $\begin{array}{l}\text { Knowledge } \\
\text { development about } \\
\text { research object }\end{array}$ & $\begin{array}{l}\text { Depicting knowledge objects as } \\
\text { they "are" }\end{array}$ & $\begin{array}{l}\text { Constructing / creating } \\
\text { research objects }\end{array}$ & $\begin{array}{l}\text { Trustworthy design of new or } \\
\text { improved objects to enhance } \\
\text { human value }\end{array}$ \\
\hline
\end{tabular}

to a praxis orientation toward knowledge and scientific inquiry. The character of knowledge is a less faithful depiction of a given reality (truth as correspondence) instead of a competent reconstruction of situations to realize human goods. Knowledge is an outcome of competent and controlled inquiry, of intelligence: "Were we to define science not in the usual technical way, but as a knowledge that accrues when methods are employed which deal competently with problems that present themselves, the physician, engineer, artist, craftsman, lay claim to scientific knowing" (Dewey, 1929). The potential for research quality is not in mirroring reality but in warranting and enhancing the trustworthiness of achieving human ends. Like with a global positioning system (GPS) in an automobile, which extends the driver's sense of direction as a form of knowledge, the point is not to mirror reality exactly. The precision of a GPS is normally not more than in the range of 10 to 100 metres, but this is sufficient for the purpose (when combined with the driver's training and recognition of road signs and landmarks) and has satisfactory trustworthiness. The insights and tacit skills of the situated actors is combined with the embedded rule-based expertise of the GPS equipment in warranting judgments in ongoing inquiry and future action.
Second, in a spectator orientation, knowledge and inquiry are ideally free from the interference of human interests, which can compromise research quality, a core quality of "basic" research. In a praxis orientation, purposes and ends in trustworthy resolution of concerns and problems, praxis improvements, and transformations are inherent in knowledge and inquiry as competent activity. It calls for consideration of a wider spectrum of purposes as inherent in different forms of scientific inquiry. As Dewey says, "If the living, experiencing being is an intimate participant in the activities of the world to which it belongs, then knowledge is a mode of participation, valuable in the degree in which it is effective. It cannot be the idle view of an unconcerned spectator... knowing has to do with reorganizing activity, instead of being something isolated from all activity, complete in its own account." (Dewey, 1946). For example, by extending your knowing through using a GPS, you reorganize your modes of transportation (incorporating consulting the GPS system to enhance your sense of orientation), making it more effective in achieving new and enhanced ends.

Third, in relation to stakeholders and others affected, that is actors in and in relation to the context of the 


\section{Scientific Excellence in Participatory and Action Research: Part I. Rethinking Research Quality Erik Lindhult}

problem domain receive enhanced status beyond being study objects and data sources ("respondents"). Instead of research on subjects, a praxis orientation in science shifts more to research with subjects as participants in research. It calls for an extended epistemology where the knowledgeability of actors is coming into focus and the way it can enhance scientific excellence by mobilizing and pooling distributed forms of knowledge and research capacity. Fourth, the position of research and researchers in a spectator orientation is detached and passive, ideally outside research context in order to avoid any epistemologically compromising interaction. In a praxis orientation, the inquirer is not standing outside the problematic situation like a spectator. They are engaged in it and in transaction with it. Researchers can have various positions and roles. They can be a researcher with a particular responsibility for high-quality inquiry but also as physician, engineer, artist, or craftsman, as Dewey is saying. The epistemologically transformed relation to actors in and related to the research context and the situated positionality of the inquirers opens up opportunities for scientific excellence through situated, mutual learning and inquiry processes among participants in different roles in co-producing knowledge. Here, open communication on equal terms among participants is a way to unleash different forms of knowing and inquiry and avoid dominance of a particular understanding of knowledge and knowledge interests (Gustavsen,1986; Habermas, 1984, 1987; Kemmis, 2008; Santos, 2014). It points to participatory and discursive democracy as a philosophical and practical point of departure for scientific, high-quality inquiry (Gustavsen, 1992, 2017; Lindhult, 2015).

Fifth, if we look around us, we see that reality is to a large extent shaped and crafted by people through inquiry and knowledge creation, such as communication and transportation praxes and systems. Thus, knowledge development about research objects cannot just be depicting knowledge objects as they "are". Through scientific inquiry, research objects, such as cars, GPS systems, the Internet, and social innovations such as sharing and caring systems, are to a large extent created. Thus, there are opportunities for scientific excellence in trustworthy design and innovation of new or improved objects to enhance human value and achieve new projected ends. As Kurt Lewin said, indicating a wider view of research quality, "creating, not predicting, is the most robust test of validity-actionability" (Kaplan, 1998).

Generally, a praxis-oriented relation to inquiry urges us to move from a contemplative and spectator orientation towards a creative and participatory orientation to inquiry (Reason, 2006; Reason \& Bradbury, 2001a). Instead of the traditional conceptualization of truth as correspondence, it is appropriate to use trustworthiness to indicate a plural, fallibilistic, and praxis-oriented view of knowledge. It is the degree to which claims or constructions are worthy of our trust that forms a basis for further inquiry and action. Validity, reliability, and objectivity are different qualities of trustworthiness of claims to knowledge. I will show how these quality notions in mainstream research methodology are also fruitful in participatory and action research. In line with the purpose, this first article thus addresses a wider spectrum of purposes and interests for the understanding of research quality in scientific inquiry, as well a wider variety of truth-developing and justification practices that can warrant trustworthiness of assertions and proposed actions.

\section{Worthwhile Purposes in Science}

What is science for? Beyond doubt, science has created considerable benefits for people, organizations, and communities. The questioning of received learning and spaces for open, systematic searches for its advancement is fundamental in scientific activity (Alvesson \& Sandberg, 2013). However, the purpose beyond advancing scientific funds of knowledge is often seen as an extra-scientific concern, something entering in secondary phases when scientific knowledge is to be applied for improving practice and generating innovation. But, purposes and aims can be seen as a constitutive feature of what is defined as good research. A point of action and participatory research is that the purpose of scientific activity is more than curiosity and more than basic research, traditionally seen as research free from any consideration of purposes and interests. One distinguishing feature of action research is the focus on production of knowledge for worthwhile human purposes. Not only is trustworthiness part of research quality but so is "purpose-worthiness". Thus, basic research is rather basic in the sense of focusing on the fundamental needs and challenges of people, organizations, and societies. Collaborative and participatory research, as a consequence of being collaboration between different stakeholders with various knowledge interests, need to consider purposes beyond academic interests in advancing knowledge in particular disciplines of science. As Habermas (1971) points out, knowledge is constituted by human interests in managing and controlling conditions, in understanding, communication, and concertation in social situations, and in empowerment and emancipation from unnecessary powers and hardships. 


\section{Scientific Excellence in Participatory and Action Research: Part I. Rethinking Research Quality Erik Lindhult}

The broadening of the framework for quality can be connected to Habermas' widened conceptualization of truth, implying that knowledge claims are made and redeemed in a broader range of dimensions, not only truth as correspondence with reality, but also efficiency/utility, normative rightness, and authenticity/truthfulness (Habermas, 1984, 1987).

Engagement and purpose have deeper groundings that are also integrated in science. Ontologically, we human beings are always already situated and engaged, or projected, as Heidegger (1962) says, in the world, constituted by needs as well as and challenges, dangers, and opportunities experienced and imaginatively envisioned. Epistemologically, knowledge is something that accrues and can be claimed to the extent that problems and problematic situations can be dealt with competently and, thus, worthwhile purposes can be trustworthily approached and situations can be improved (Dewey, 1939). Participatory and action research is to an important extent, integrating elements of science of design (Simon, 1996) and professional practice (Schön, 1983), where ideation and experimentation to construct new, artificial objects to achieve goals are core dimensions in inquiry. Goals seeking is also an integral part.

\section{A Wider Spectrum of Aims and Qualities}

There are different dimensions of quality depending on the main character of aims focused on in inquiry efforts, as shown in Table 2. I argue that participatory and action research often wavers between different types of aims. The discussions of "purpose worthiness" tend to be lacking in elaboration in participatory and action research, according to Bradbury and Reason (2001). Often, some type of aim is emphasized while other aims are downplayed or neglected. This may be acceptable as long as it is made in a conscious way that is appropriate to the project and circumstances at hand. It is also often difficult to distinguish between different aims in practice, but I stress the importance of maintaining the distinctions in order to make appropriate quality judgments. For example, participatory and action research, coming out of a context where more radical social transformation is called for in order to improve the situation of underprivileged groups (e.g., the southern tradition, see Brown \& Tandon, 1983), generally has a stronger emphasis on normative-political aims. An important emphasis is that people should do their own research in order to democratize knowledge production and as part of their self-liberation. On the other hand, academic research aims tend to be placed in the background where it often seems to be enough that the knowledge that people produce is judged to be useful by the people themselves in their struggle for liberation. While this is an important and neglected dimension of scientific/research quality that participatory and action research quite rightly is emphasizing, there are also other quality dimensions of this aim.

Table 2 indicates and exemplifies the way quality understanding, as well as the role of action, practice, and practitioners, is shifting depending of areas of purpose in knowledge production. High-quality, scientific knowledge can be developed in scientific inquiry aimed at realization of different purposes, but quality is perceived differently. The academic type of purposefulness is familiar, referring to advancement of knowledge in a field of study, which in the dominant linear model is autonomous basic research going further to application and innovation in society. Where there is integration in this process, it is clearly beneficial for society, but there are also critics. Alvesson, Gabriel, and Paulsen (2017) argue that there has been decline in the quality of social science research, with a proliferation of meaningless research of no value to society. The assumption is that academics are doing research in order to get published, not to say something socially meaningful. This view leads to the rise of nonsense in academic research, which represents a serious social problem leading to extensive waste of resources and costs to tax payers. This indicates that participatory and action research, with a focus on worthwhile purposes, has a role in restoring meaning and value in social science by integrating academic research with human development. Alvesson, Gabriel, and Paulsen's (2017) analysis particularly focus on the less worthwhile personal purpose in prevailing system of knowledge production, something that also requires structural transformation related to the normative-political domain in order to enhance social value created in the system.

In the practical domain, actual change for solving problems and improving conditions is crucial for scientific quality in realizing value, and workable, robust solutions. Often, practitioners have important roles in creating, testing, and assessing knowledge claims embedded in new practices and methods. In this domain, usefulness and efficiency of solutions are focused on, that is, what Weber (1978) calls rationality in relation to given value frameworks (zweckrationalität). In the normativepolitical domain, the domain of Weberian value rationality (wertrationalität), frameworks for valuation and structures of power are also questioned. Quality and knowledge generation are, in this domain, focused on the extent to which these frameworks and structures 


\section{Scientific Excellence in Participatory and Action Research: Part I. Rethinking Research Quality Erik Lindhult}

Table 2. Purpose domains and quality dimensions in participatory and action research

\begin{tabular}{|c|c|c|c|c|}
\hline \multirow[b]{2}{*}{ Dimensions } & \multicolumn{4}{|c|}{ Area of Purpose } \\
\hline & Academic & Practical & Normative-political & Personal \\
\hline $\begin{array}{l}\text { Orientation to } \\
\text { participatory } \\
\text { and action } \\
\text { research with a } \\
\text { focus on } \\
\text { different aims }\end{array}$ & $\begin{array}{l}\text { Focus of non-action- } \\
\text { oriented research, also } \\
\text { part of most } \\
\text { participatory and } \\
\text { action research } \\
\text { orientations }\end{array}$ & $\begin{array}{l}\text { Pragmatic-oriented } \\
\text { participatory and action } \\
\text { research, Scandinavian } \\
\text { action research, } \\
\text { positivist or action } \\
\text { research, e.g., } \\
\text { Lewin/organization } \\
\text { development tradition }\end{array}$ & $\begin{array}{l}\text { Critically oriented action } \\
\text { research (also partly } \\
\text { postmodernist and } \\
\text { constructionist or action } \\
\text { research), mainly } \\
\text { participatory action } \\
\text { research (Freire, Fals- } \\
\text { Borda) }\end{array}$ & $\begin{array}{l}\text { Life-oriented action } \\
\text { research, practitioner- } \\
\text { oriented action research, } \\
\text { human inquiry (Reason) }\end{array}$ \\
\hline $\begin{array}{l}\text { Value } \\
\text { (relevance) }\end{array}$ & $\begin{array}{l}\text { Advancement of } \\
\text { knowledge in a field of } \\
\text { study, application of } \\
\text { findings, dissemination }\end{array}$ & $\begin{array}{l}\text { Innovation of product / } \\
\text { process, new } \\
\text { understanding, new } \\
\text { alternatives, self- } \\
\text { development }\end{array}$ & $\begin{array}{l}\text { Democratization, } \\
\text { liberation, social or } \\
\text { wealth development, } \\
\text { justice, support of } \\
\text { political process, } \\
\text { rationalization }\end{array}$ & $\begin{array}{l}\text { Personal / life } \\
\text { development, } \\
\text { professional } \\
\text { development, personal } \\
\text { value/moral } \\
\text { development }\end{array}$ \\
\hline Validity & $\begin{array}{l}\text { Valid theories, data, } \\
\text { knowledge claims }\end{array}$ & $\begin{array}{l}\text { Workable, efficient } \\
\text { solutions and praxis }\end{array}$ & $\begin{array}{l}\text { Moral-political } \\
\text { transformation } \\
\text { (rationalization) }\end{array}$ & $\begin{array}{l}\text { Authenticity, good life } \\
\text { for individuals and those } \\
\text { concerned, and one's } \\
\text { community }\end{array}$ \\
\hline Reliability & $\begin{array}{l}\text { Reproducible and } \\
\text { accountable research } \\
\text { process }\end{array}$ & $\begin{array}{l}\text { Robust solution, stable } \\
\text { praxis }\end{array}$ & $\begin{array}{l}\text { Sustainability of } \\
\text { transformation }\end{array}$ & $\begin{array}{l}\text { Skill and personal } \\
\text { excellence, security, } \\
\text { limited risks involved, } \\
\text { enabling context }\end{array}$ \\
\hline $\begin{array}{l}\text { Role of action } \\
\text { and practice }\end{array}$ & $\begin{array}{l}\text { Application and quality } \\
\text { test of knowledge } \\
\text { claims }\end{array}$ & $\begin{array}{l}\text { Instrumental for change, } \\
\text { experimentation, } \\
\text { development and } \\
\text { validation change } \\
\text { hypotheses, } \\
\text { implementation and } \\
\text { dissemination of } \\
\text { solutions }\end{array}$ & $\begin{array}{l}\text { Ethical-political struggle } \\
\text { for improvement of } \\
\text { human conditions, } \\
\text { development and } \\
\text { validation of } \\
\text { transformative } \\
\text { hypotheses }\end{array}$ & $\begin{array}{l}\text { Self-reflection, self- } \\
\text { realization, identity } \\
\text { formation; first-person } \\
\text { inquiry }\end{array}$ \\
\hline $\begin{array}{l}\text { Role of } \\
\text { practitioners }\end{array}$ & $\begin{array}{l}\text { Data sources for } \\
\text { inquiry, respondent / } \\
\text { use validation }\end{array}$ & $\begin{array}{l}\text { Innovators, change } \\
\text { agents, participants in } \\
\text { inquiry, users, } \\
\text { beneficiaries }\end{array}$ & $\begin{array}{l}\text { Subjects and actors of } \\
\text { struggle for } \\
\text { emancipation and } \\
\text { realizing values / ideals }\end{array}$ & $\begin{array}{l}\text { Partners in self- } \\
\text { development and co- } \\
\text { inquiry }\end{array}$ \\
\hline
\end{tabular}

can be questioned and influenced and the extent to which alternatives can be envisioned and generated, and can sustainably transform conditions. There are many areas and contexts where dominant value frameworks and related power structures need to be questioned and challenged as part of and enabled by processes of scientific knowledge production, from recognition of and satisfying needs of marginalized groups to valuation and power shifts in today's digital transformation of industry and society in order to achieve sustainable communities and a sustainable planet. Here, the role of action, practice, and practitioners in knowledge generation is crucial to knowledge generation in many ways, for example, by acting differently to expose and challenge ingrained norms and power structures and by forming alliances that can test 


\section{Scientific Excellence in Participatory and Action Research: Part I. Rethinking Research Quality Erik Lindhult}

transformative hypotheses and effect change. As Dewey (1939) says, in social inquiry, behavioural changes and participation of the concerned are inherent in enacting and testing claims to knowledge beyond describing existing conditions.

Personal value is rarely mentioned as central in the research community, but, as I see it, it is most central to and is even a prerequisite for the other value dimensions (Marshall, 2016; Reason, 2006). The subjective is a necessary starting point for any research. It is recognized as an important research "instrument" in interpretative-oriented research. The "I" of science, the actor in research, is an important ingredient in any research activity (Brown, 1996) and its capacity for excellence. If knowledge is to be developed, someone, often several people in collaboration, have to learn something new and significant. Based on this dimension, value creation is linked to what Reason and Bradbury (2001b) call "the flourishing of individual persons and their communities". Validity gains meaning from authenticity, in other words, learning and development that the individual feels "at home" in, recognizes, and can identify with in relation to values and ideals. Reliability is the meaning of security - security and health in development - with limited personal risks. The action dimension based on personal value for the involved can involve competence and career development, self-reflection, self-realization, and identity formation. Practitioners' importance and role gain the character of equal partners in development and learning, where the priority of what is considered valuable development and learning often varies between those involved.

A similar differentiation of aims of inquiry often referred to is the distinction made between "for me" (the personal value and development), "for us" (the people wanting praxis improvement), and "for them" (those outside the context of change, requiring consideration of the wider significance of achievements) (Reason \& Torbert, 2001). In addition, there is a broader politicalethical definition of aims including such values as freedom, democracy, and justice, for example, "us" as part of a group aiming to improve the underprivileged status of certain groups such as workers, impoverished people, and people with disabilities based on values institutionalized in the community at large. A basic point of participatory and action research is that quality can be achieved from the point of view of different types of aims and thus a broader range of interested parties in a mutually beneficial way.
The ideal is that these different interests can be furthered by the same activities (Clark, 1976), for example, experimentation that is enabling creativity and learning, generation of new knowledge (e.g., concerning an understanding of a problem or a transformative hypothesis), and forceful action for resolution of problems and transforming situations. In each context or project, the combination of purpose must also integrate interests of parties and stakeholders to a sufficient degree so that a common ground can be established based on mutual agreement and shared understanding. Note that good inquiry management is needed to achieve such mutually beneficial aims in a workable and efficient way. Aims and purposes do not combine harmoniously and automatically; it requires organization and management by those responsible for participatory and action research initiatives. This is a basic challenge in managing participatory and action research so as to empower different parties, to critically reflect on existing power relations and their implications and possible transformation, and to build collaborative power among stakeholder for common participatory and action research enterprises and ventures (Gaventa \& Cornwall, 2008; Hafting \& Lindhult, 2013).

\section{Rethinking Validity}

Creating trustworthiness is a pluralistic enterprise and so is validity. Validity means reaching sound and grounded claims to knowledge. Traditionally, this has been the domain of conceptions and practices of truth. I will draw on different perspectives on and theories of truth to identify different approaches to validation of knowledge, which can also be seen as different designs of inquiry systems (Churchman, 1971). These perspectives are also used in everyday assessment of knowing in practice, such as sensing, testing, consulting with others or with texts, discussing, integrating pictures of evidence, and debating people with different views (Lindhult, 2008). The different perspectives are also related to different forms of knowledge (e.g., practical and theoretical, tacit and explicit, physical and cultural) and procedures of inquiry. Quality, as well as the understanding of action and participation in inquiry, is also dependent on orientations to inquiry, for example, positivist, interpretative, critical, constructivist, pragmatic (Johansson \& Lindhult, 2008; Lindhult, 2002). The quality dimensions achieve different emphasis and conceptualization depending on dominant orientation. For example, a good representation (positivist orientation) is able to match propositions with data about reality (correspondence view of validity), a good interpretation 


\section{Scientific Excellence in Participatory and Action Research: Part I. Rethinking Research Quality Erik Lindhult}

(interpretative orientation such as hermeneutics) is able to integrate different meaning making elements into a whole (coherence view of validity), while a good critical hypothesis (critical orientation) is able to unmask coercive power relations and can be vindicated through discourse free from distorting power influences (discursive view of validity). Participatory and action research provides particular opportunities for validation compared to other approaches to inquiry. At the same time, participatory and action research also has its particular validity weaknesses and risks. A core issue of inquiry management is to exploit these opportunities and, at the same time, minimize weaknesses. As an orientation for inquiry management and judgment of quality, Table 2 gives an overview of different dimensions of validation and its relation to participatory and action research.

\section{Correspondence validation}

Correspondence validation is the dominant conception of truth and validity in science. It is a process where ideas about research objects are matched to empirical material, action, and experience. It is an interaction between guiding assumptions and research constructs, its operationalization in concrete research activities, and its extended networks of directly experienced and interpreted implications and consequences. Construct validity is used to assess the extent to which concepts and models (i.e., constructs) can faithfully depict objects of knowledge and their characteristics. Internal validity is evidenced by patterns of dynamics and causal relations in the area of study while external validity is evidenced by patterns that can be inferred to similar areas and contexts or more generally. These forms of validation can also be dealt with through the other validation procedures described in Table 2.

The assumption of generality of knowledge assessed in external validation is often played down in qualitative research as well as in participatory and action research (Coghlan, 2016). The assumption of generality, inspired by ideals from natural science, as not only a quality of knowledge but a standard of knowledge, tends to downgrade social and cultural knowledge to an imperfect and "anecdotal" status. It is already mentioned by Bacon (1960), a founder of modern science, as type of idol, an illusion of the mind, in adhering to false analogies and assuming greater order and regularity in the world than is actually the case. Still the wider import and validity of knowledge is an important quality dimension. Greenwood and Levin (2006) are tuning down external validity to "transcontextual credibility": the way knowledge can have validity in different contexts. Parti- cipatory and action research provides opportunities for access to measurement/testing possibilities, where matching concepts and objects of knowledge can be developed and more grounded conceptualization can lead to increased construct validity. Internal validation can be increased by mobilizing a broader range of knowledgeable individuals. In the domain of some design sciences, such as various engineering and professional disciplines, external validation can be rather high (e.g., medical treatment) or product development (e.g., think of the rather broad validation in the uses of mobile communication systems). But evidence from action research shows that pure copying as a mechanism for generalization seldom works. It assumes that knowledge structures could be successfully standardized and "frozen" in practices, methods, and tools with a degree of context independence or robustness. But, external knowledge elements often tend to be used in combinatorial, associational, and inspirational ways in developing contextual solutions appropriate for each situation, such as in a new organization of work suitable for a particular workplace. Furthermore, participation in the creation of sustainable, local solutions among those concerned is often required to mobilize local knowledge and build necessary commitment (Gustavsen, 1992).

Lincoln and Guba (1985) reconceptualize external validation as transferability. This shifts the responsibility for validation from the developer of knowledge more to the user of it in others' situations and contexts. A precondition is that the researchers have documented the knowledge to a sufficient degree (i.e., they have a sufficiently "thick" description) so that other users are able to understand and integrate it in their own inquiry. What is more general might be the generative mechanisms used (e.g., procedures of inquiry, dialogic procedures) to create solutions to problematic situations rather than generality of certain knowledge elements in particular solutions. The attractiveness of a correspondence view is partly conditioned on the dominant spectator and visual metaphor of knowledge focused on correct mirroring of a given reality. Then, active and collaborative research roles tend to be seen as irrelevant to or at risk of disturbing and corrupting the "true" relation of concepts and mental models on the one hand and data about objects given in reality on the other. With a more pragmatic and praxis orientation to science, correspondence is more something created by competent inquiry in the relation secured between ideas and their consequences. Then other dimensions of validation described below are put in play, giving more credibility and greater leeway for participatory and action research to enact scientific validation. 


\section{Scientific Excellence in Participatory and Action Research: Part I. Rethinking Research Quality Erik Lindhult}

\section{Coherence validation}

Coherence validation focuses on how different empirical, interpretative, and conceptual elements can be integrated and thus mutually reinforce one another in a meaningful and reasonable whole, such as a theory or conceptual framework. This is the main validity dimension in interpretative research in developing interpretations that can function as meaning nexus in understanding (see, e.g., Dilthey, 1979), which is also evident in methods of triangulation of various data sources or assessments, for example, in case research, and in systemic explanations. Participatory and action research provide opportunities for considerable richness and variety of experience/data and meaning relations as well as can take advantage of interpretative capacities of stakeholders, but may also lead to overburden by richness of experience and meaning, and to fragmentation rather than validation. On the other hand, objects of knowledge do not only display harmonious unity but also differences, anomalies, tensions, and conflicts, which can point to additional and deeper understanding of a plural reality and a more critical perspective on coherence validation, for example, in reflexive interpretative work (Alvesson \& Sköldberg, 2018).

\section{Discursive validation}

Discursive validation is a significant opportunity and aim in collaborative and participatory research approaches in mobilizing different expertise and forms of knowing of a broader range of people. This is in line with emphasizing dialogic and democratic validity in participatory and action research (Herr \& Anderson, 2015; Reason, 2006). Discursive validation as a procedure also occurs in the research methodological literature, for example, in the form of feedback of printed interviews (e.g., in respondent validation or "member checks"). The starting point is then often that the researcher has produced some text or material that the practitioners are invited to react to and comment on, and thus validate. The ideal within participatory and action research is also that researchers and practitioners together can make experiences, generate data, analyze and produce conclusions, or even that practitioners themselves do research about their reality (often called practitioner research), often with the support of experienced researchers. Discursive validation is something that can be continuous in the interaction and affect different phases and parts of the work, and thus affect the outcomes of inquiry. Practitioners can reflect on and give views on experiences and events in the inquiry process. It is important that there are good forums in the collaborative processes where validating dialogue can be carried out. There is often a need for continuous work to build such forums in the form of open, democratic dialogue and exchange between participants. Here, one can see the research role as a "publican role", an audience- or public-supportive role that aims to open up communicative spaces (Kemmis, 2008) and create a basis for dialogue on equal terms between different parties involved (Gustavsen, 1992; Lindhult, 2005; Pålshaugen, 2002). It means organizing interactive and collaborative learning processes generating high-quality knowledge for all participants. A dominance-free communication in the spirit of Habermas (1984) between competent and concerned persons, who, through discussion, strive for coordinated understanding and practical agreements. This relates to the idea of open, public, critical conversation between equal citizens as a way of sifting out "truth" and utilizing common intelligence to find solutions to societal problems.

Wider discursive validation is a central ambition within participatory and action research. It clearly provides additional opportunities for validation but also leads to a number of difficult issues in itself. The researcher may be given a privileged expert role and is considered by their academic affiliation to have a better knowledge or analytical ability. It creates trusting relationships that can make it more difficult to openly and critically discuss different issues (Svensson et al., 2007). The discourse and language use of the research community, as well as the interests of knowledge, can be widely different from the practice's discourse and language use, which leads to translation problems as well as negotiation rather than dialogue. What should be validated, who should participate, and how it can be carried out in a satisfactory way, are often not so easy to clarify. An agreement based on the combined expertise of actual participants may lack some important insight and learning. Time and motivation are often limiting factors for broader participation, there are often status differences and unequal recognition of expertise, as well as limited opportunities for different parties to familiarize themselves with issues relevant to the research. But, with all its limits, it is a procedure commonly used in the scientific community. The point in participatory and action research is to extend its uses to include additional parties in society.

\section{Practical validation}

Practical validation involves trying out ideas, approaches, theories, hypotheses, and solution proposals in practice and seeing how they "work" and create, or do not create, expected or novel effects (Dewey, 1939). This type of validation is included in the experimental focus of action research (Lewin, 1946), in the field experiment 


\section{Scientific Excellence in Participatory and Action Research: Part I. Rethinking Research Quality Erik Lindhult}

idea, as well as in experience-based learning (Schön, 1983). It is a common view on how action research is conducted and is incorporated in action research cycle models (Coghlan \& Brannick, 2014, McNiff et al., 1996; Stringer, 1999). Practical validation in live settings is a significant comparative advantage in action and participatory research, both in developing and testing knowledge claims and in realizing practical usefulness and transformation. To the extent that validation in real-life practice is necessary for particular knowledge claims to gain sufficient trustworthiness, all research needs to emulate aspects of action and participatory research - or else be based on less scientific everyday trial-and-error learning often seen as outside the domain of science. In line with a practical view on validation, Gustavsen (2014) emphasizes "participative constructivism" as a point of departure in validating "the ability of those concerned to themselves create and shape the society in which they live. It is these broadly framed movements that represent the primary generalization of action research knowledge, not textually expressed claims to generality, nor the specific measures applied to broaden and strengthen the movements." Thus, the shift and movement in practice is important in validation. As Dewey (1939) points out, in social inquiry (e.g., investigation of the validity of ways of organizing health care for rehabilitation of mental illness), it is not only agreement in discourse that is needed but also consonance in practices of organizing and practically validating the workability of models. To wait for some actors to try out new models is an option, but Dewey (1939), as well as Simon (1996), in developing a science of design, saw in the focus on experimentation also designing research situations where new models and artefacts are developed and tested and new experience systematically developed as important for valid scientific advance. It should be noted that general shifts in practice are indicators of practical validation based on inquiry and the learning of people involved, but are dependent on the standards of inquiry used. Both trustworthy claims and misconceptions can be diffused in practice depending on the degree to which inquiry is competent, that is, to what extent it lives up to scientific standards. In principle, the basic norms and practices for good knowledge creation and competent inquiry do not differ between scientific and everyday inquiry, only the degree to which they are used (i.e., situated problem and purpose formulation, development and test of suggestions for resolution, reasoned argumentation, systematic creation of evidence in experience, good use of available knowledge and inquiry capacity, consideration of alternative hypotheses for resolution, control of bias, openness for review and further inquiry, etc.) (Dewey, 1903/1976, 1939). Still, even the best inquiry can fail.

\section{Intuitive, dialectical, and perspectivist validation}

I see the four validation procedures described above as the most common in validating knowledge claims. To show a broader spectrum, I would like to mention three other validation approaches. Intuitive validation is based on knowledgeable persons who have a rich and extensive experience base from a particular activity, which provides the basis for a refined judgment in the domain of experience. A difficulty for outsiders is to examine the basis for an intuitive assessment. Track records of earlier judgments and how long the person has built up their knowledge base and judgment, as well as how close the area the person has worked are proxies. It is recognized in qualitative research in using length of time in the field interacting with and participating in research situation as indicator of validity. Articulation of the tacit knowledge base and the basis for the assessments through dialogue and reflection, so that these also become available and critically accessible by others (Nonaka, 1994; Schön, 1983), is also a "truth tactic".

The other two, dialectical and perspectivistic validation, both assume that reality is multifaceted. Dialectical validation means letting knowledge claims be confronted with their opposites in order to call in their possibilities and limitations and possibly achieve a synthesis of the opposites at a higher level. Hegelian logic is here a point of reference. Perspectivist validation is instead based on the assumption that it is the richness of perspectives that enables approaching a greater validity. Because several parties are involved in the research process, and that it is often closer to real situations with their openness to different interpretations and perspectives instead of assuming a predetermined theoretical view, such validation within participatory and action research is promoted. Both of these validation procedures increase the polyphony of various voices in the research, which is a general trend in participatory and action research. Such validation can be problematic in that it reveals ambiguities and conflicts that need to be addressed and can lead to a confusing cacophony of voices. At the same time, communicative openness is something that, on the basis of these dimensions of validation, is inevitable to approach a high-quality understanding of science.

Table 3 condenses the discussion on different validation dimensions. My hope is it can provide an overview of different validation opportunities and their relation to participatory and action research as a guide for organizing and managing research practices for validating different knowledge claims. 


\section{Scientific Excellence in Participatory and Action Research: Part I. Rethinking Research Quality Erik Lindhult}

Table 3. Validity dimensions and validation practices

\begin{tabular}{|c|c|c|c|}
\hline Validity Dimension & Measures & $\begin{array}{l}\text { Potential Advantage of } \\
\text { Participatory and Action Research }\end{array}$ & $\begin{array}{l}\text { Potential Weakness of } \\
\text { Participatory and Action Research }\end{array}$ \\
\hline Correspondence & $\begin{array}{l}\text { Construct development, } \\
\text { observation, measurement }\end{array}$ & $\begin{array}{l}\text { Measurement / testing } \\
\text { possibilities, grounded } \\
\text { conceptualization }\end{array}$ & Disturbing research domain \\
\hline Coherence & $\begin{array}{l}\text { Triangulation, } \\
\text { interpretation (unified } \\
\text { pattern), framing }\end{array}$ & $\begin{array}{l}\text { Richness and variety of experience } \\
\text { / data and meaning relations }\end{array}$ & $\begin{array}{l}\text { Overburdened by richness of } \\
\text { experience / meaning, } \\
\text { fragmentation }\end{array}$ \\
\hline Discursive & $\begin{array}{l}\text { Respondent validation, } \\
\text { member check, democratic } \\
\text { dialogue (communication } \\
\text { free of domination) }\end{array}$ & $\begin{array}{l}\text { Broader discursive validation } \\
\text { among concerned / competent } \\
\text { parties }\end{array}$ & $\begin{array}{l}\text { Arranging good forums difficult } \\
\text { (e.g., democratic, free of } \\
\text { domination, inclusive), dissensus }\end{array}$ \\
\hline $\begin{array}{l}\text { Practical } \\
\text { (workability) }\end{array}$ & Test by application / use & $\begin{array}{l}\text { Experimentation possibilities in } \\
\text { field / live context }\end{array}$ & $\begin{array}{l}\text { Limited control of and influence on } \\
\text { conditions }\end{array}$ \\
\hline Intuitive & $\begin{array}{l}\text { Judgment of experienced } \\
\text { person / expert }\end{array}$ & $\begin{array}{l}\text { Access to a broader spectrum of } \\
\text { experienced persons / expertise }\end{array}$ & $\begin{array}{l}\text { Difficult to examine intuitive } \\
\text { judgments }\end{array}$ \\
\hline Dialectic & $\begin{array}{l}\text { Comparative test of } \\
\text { competitive knowledge } \\
\text { claims }\end{array}$ & $\begin{array}{l}\text { Broader access to diverse views and } \\
\text { experiences }\end{array}$ & Polarization and conflict \\
\hline Perspectivistic & $\begin{array}{l}\text { Using plurality of } \\
\text { perspectives }\end{array}$ & $\begin{array}{l}\text { Multiple embodied perspectives } \\
\text { through participants, polyphony }\end{array}$ & $\begin{array}{l}\text { Cacophony, dominance of some } \\
\text { perspective }\end{array}$ \\
\hline
\end{tabular}

\section{Conclusion}

In this article, I have reconstructed the understanding of scientific excellence and research quality in participatory and action research in order to set out a clearer and more secure path for its scientific development. First, a reconstruction of understanding of scientific inquiry has been made based on a praxis-oriented epistemology inspired by pragmatism. Science is not only faithfully depicting existing objects of research but is, to a significant extent, creating them, which implies a movement towards "participatory constructivism" (Gustavsen, 2014). I have particularly focused on proposals of a wider role of purpose and a plural character of validation in participatory and action research.

I am aware that my proposals for reconstruction are upsetting basic assumptions of "scientificness" inherited from the Greeks and further institutionalized in the 16th and 17th century scientific revolution (Toulmin, 1990, 2001; Toulmin \& Gustavsen, 1996) based on a spectator view of knowing and a copying focus of inquiry. In mirroring reality, it is quite reasonable to stay free from values, purposes, and interests and avoid "activist" stances that participatory and action research is perceived to be using. If ultimate validation is correspondence with given reality, alternative validation tends to be seen as secondary or preliminary to this ultimate validation. That people agree on and act according to a claim may be indication of its truth, but is not really truth before correspondence has been established. But, if actionability is part of knowledge and truth as trustworthiness, then the purposes that action is to further and engagement of involved is inherent in science.

A framework for understanding purpose in science and its basis in validity, reliability, and the core characteristics of participatory and action research is developed. Participatory and action research require considering a broader spectrum of purpose. I do not claim that this framework is unique. It is offered as indicative of important domains of purpose that are as far as unavoidable to consider in scientific inquiry. I hope that the framework can support proposals in participatory and action research project development, and the judgement of "purpose worthiness" as combination and balance between 


\section{Scientific Excellence in Participatory and Action Research: Part I. Rethinking Research Quality Erik Lindhult}

different domains of purpose in a research context comprising several parties and stakeholders. "Purpose-worthiness" of research can be considered with the help of the spectrum of forms and practices of validation described in the article. The turn to action, practice, and participation enables plural ways of knowing and ways that knowledge claims can be validated and made trustworthy. This broader landscape of validation and the way participatory and action research can enable different forms of validation are described and elaborated. These forms of validation can be embedded and enabled in various research and development practices.

Both frameworks are pointing to and clarifying the broader terrain of research quality in participatory and action research, in which specific projects can be positioned to produce appropriate and high-quality achievements, and pinpoint and try to deal with quality deficiencies and risks. My aim has been to contribute to an integration with mainstream discourse through clarifying the way traditional quality concepts can be fruitfully used in an expanded framework for quality where scientific excellence of participatory and action research is visible and both participatory and action research and mainstream science approaches can be harboured. In a following article (Lindhult, 2019), reliability and objectivity and their use in participatory and action research will be clarified and the way rethinking and reconstructing these traditional quality concepts can support mainstreaming of participatory and action research in scientific community. My integrational aim is not only to clarify a specific epistemology and understanding of scientific excellence for participatory and action research but to offer it as also fruitful for the scientific community at large as an input to a wider debate on the character of scientific inquiry, scientific excellence, and research quality.

\section{About the Author}

Erik Lindhult $(\mathrm{PhD})$ is a Senior Lecturer in Innovation Management and Entrepreneurship at Mälardalen University in Sweden. He received his doctoral degree in Industrial Management from the Royal Institute of Technology in Stockholm, in the area of Scandinavian dialogue democratic approach to innovation and action research. His main area of research is participatory, collaborative, and democratic innovation and change management, as well as entrepreneurship for a sustainable development of society. His research interests also involve collaborative research methodologies, including action research and interactive research. He has been involved in a wide range of collaborative $R \& D$ projects in the private, public, and cooperative sectors, in areas such as organizational development, incubator and science park development, service innovation, societal entrepreneurship, sustainable innovation, and school development. He is a board member of the Swedish Participatory Action Research Society (SPARC) and the Swedish Interactive Research Association (SIRA), as well as an expert advisor to the EU SWAFS Horizon 2020 research committee. 


\section{Scientific Excellence in Participatory and Action Research: Part I. Rethinking Research Quality Erik Lindhult}

\section{References}

Alvesson, M., \& Sandberg, J. 2013. Constructing Research Questions: Doing Interesting Research. Los Angeles: SAGE. https://dx.doi.org/10.4135/9781446270035

Alvesson, M., \& Sköldberg, K. 2018. Reflexive Methodology: New Vistas for Qualitative Research (3rd ed.). London: SAGE Publications Ltd.

Alvesson, M., Gabriel, Y., \& Paulsen, R. 2017. Return to Meaning: A Social Science with Something to Say. Oxford: Oxford University Press.

Bacon, F. 1960. The New Organon. Indianapolis, IN: Bobbs-Merrill.

Bradbury-Huang, H. 2010. What Is Good Action Research? Why the Resurgent Interest? Action Research, 8(1): 93-109.

https://doi.org/10.1177/1476750310362435

Bradbury-Huang, H. (Ed.). 2015. The SAGE Handbook of Action Research (3rd ed). Los Angeles: SAGE.

Bradbury, H., \& Reason, P. 2001. Conclusion: Broadening the Bandwith of Validity: Issues and Choice-Points for Improving Quality of Action Research. In P. Reason \& H. Bradbury (Eds.), Handbook of Action Research. Participative Inquiry \& Practice: 447-456. London: Sage Publication Ltd.

Brown, J. R. 1996. The I in Science. Oslo: Scandinavian University Press.

Brown, L. D., \& Tandon, R. 1983. The Ideology and Political Economy of Inquiry: Action Research and Participatory Research. The Journal of Applied Behavioral Science, 19(3): 277-294. https://doi.org/10.1177/002188638301900306

Bryman, A. 2016. Social Research Methods (5th ed.). Oxford: Oxford University Press.

Checkland, P., \& Holwell, S. 1998. Action Research: Its Nature and Validity. Systemic Practice and Action Research, 11(1): 9-21. https://doi.org/10.1023/A:1022908820784

Churchman, W. 1971. The Design of Inquiring Systems: Basic Concepts of Systems and Organization. New York: Basic Books.

Clark, A. (Ed.) 1976. Experimenting with Organizational Life: The Action Research Approach. New York: Plenum.

Coghlan, D. 2016. Retrieving a Philosophy of Practical Knowing for Action Research. International Journal of Action Research, 12(1): 84-107.

Coghlan, D., \& Brannick, T. 2014. Doing Action Research in Your Own Organization. London: SAGE.

Coghlan, D., \& Shani, A. B. 2014. Creating Action Research Quality in Organization Development: Rigorous, Reflective and Relevant. Systemic Practice and Action Research, 27(6): 523-536. https://doi.org/10.1007/s11213-013-9311-y

Denzin, N. K., \& Lincoln, Y. S. 2011. The SAGE Handbook of Qualitative Research (4th ed.) Thousand Oaks, CA: SAGE.

Dewey, J. 1903/1976. Studies in Logical Theory. In J. A. Boydston (Ed.), 1976, The Middle Works of J. Dewey, 1899-1924, Volume 2 (1902-1903): 293-378. Carbondale, IL: Southern Illinois University Press. (Original work published in 1903.)

Dewey, J. 1929. The Quest for Certainty: A Study of the Relation of Knowledge and Action. New York: Minton, Balch \& Company.
Dewey, J. 1939. Logic: The Theory of Inquiry. London: George Allen \& Unwin Ltd.

Dewey, J. 1946. Problems of Men. New York: Philosophical library.

Dilthey, W. 1979. Selected Writings. Cambridge: Cambridge University Press.

Eikeland, O. 2006. Validity of Action Research and Validity in Action Research. In K. A. Nielsen \& L. Svensson (Eds.), Action and Interactive Research: Beyond Practice and Theory: 193-240. Maastricht: Shaker Publishing.

Eikeland, O. 2008. The Ways of Aristotle: Aristotelian Phronesis, Aristotelian Philosophy of Dialogue, and Action Research. Berlin: Peter Lang.

Eikeland, O. 2012. Action Research: Applied Research, Intervention Research, Collaborative Research, Practitioner Research, or Praxis Research? International Journal of Action Research, 8(1): 9-44.

Feldman, A. 2007. Validity and Quality in Action Research. Educational Action Research, 15(2): 21-32.

https://doi.org/10.1080/09650790601150766

Fals-Borda, O. 1979. Investigating Reality in Order to Transform It: The Columbian Experience. Dialectical Anthropology, 4(1): 33-56. https://doi.org/10.1007/BF00417683

Fals-Borda, O., \& Rahman, M. (Eds.). 1991. Action and Knowledge: Breaking the Monopoly with Participatory Action-Research. New York: The Apex Press.

Foucault, M. 1980. Power/Knowledge: Selected Interviews and Other Writings 1972-1977. Brighton, UK: Harvester Press.

Gaventa, J., \& Cornwall, A. 2008. Power and Knowledge. In P. Reason \& H. Bradbury (Eds.), The SAGE Handbook of Action Research (2nd ed.): 172-189. Los Angeles: SAGE. https://dx.doi.org/10.4135/9781848607934.n17

Greenwood, D. 2002. Action Research: Unfulfilled Promises and Unmet Challenges. Concepts and Transformation, 7(2): 117-139. https://doi.org/10.1075/cat.7.2.02gre

Greenwood, D., \& Levin, M. 1998. Introduction to Action Research. Thousand Oaks, CA: SAGE.

Guba, E., \& Lincoln, Y. 1989. Fourth Generation Evaluation. Newbury Park: SAGE.

Gustavsen, B. 1986. Social Research and Participative Dialogue. In F. Heller (Ed.), The Use and Abuse of Social Science: 143-156. London: SAGE.

Gustavsen, B. 1992. Dialogue and Development: Theory of Communication, Action Research and the Restructuring of Working Life. Assen/Maastricht: Van Gorcum.

Gustavsen, B. 2014. Social Impact and the Justification of Action Research Knowledge. Journal of Action Research, 12(4): 339-356. https://doi.org/10.1177/1476750314534455

Gustavsen, B. 2017. Action Research and the Promotion of Democracy. International Journal of Action Research, 13(2): 101-111.

Habermas, J. 1971. Knowledge and Human Interests. Boston, MA: Beacon Press.

Habermas, J. 1984. The Theory of Communicative Action, Vol I. London: Polity Press. 


\section{Scientific Excellence in Participatory and Action Research: Part I. Rethinking Research Quality Erik Lindhult}

Habermas, J. 1987. The Theory of Communicative Action, Vol II. London: Polity Press.

Hafting, T., \& Lindhult, E. 2013. Developing Collaborative Power in Working Life: Linking American Pragmatism and Action Research. In M. Kelemen \& N. Rumens (Eds.), American Pragmatism and Organisation: Issues and Controversies: 205-222. Surrey, UK: Gower/Ashgate.

Hall, B., Gillette, A., \& Tandon, R. 1982. Creating Knowledge: A Monopoly? Participatory Research in Development. Toronto: International Council for Adult Education.

Heidegger, M. 1962. Being and Time. New York: HarperCollins.

Herr, K., \& Anderson, G. L. 2015. The Action Research Dissertation: A Guide for Students and Faculty. Thousand Oaks, CA: SAGE.

Heron, J. 1996. Co-operative Inquiry: Research into the Human Condition. London: SAGE.

Johansson, A. W., \& Lindhult, E. 2008. Emancipation or Workability? Critical versus Pragmatic Scientific Orientation in Action Research. Action Research, 6(1): 95-115. https://doi.org/10.1177/1476750307083713

Kaplan, R. S. 1998. Innovation Action Research: Creating New Management Theory and Practice. Journal of Management Accounting Research, 10: 89-118.

Kemmis, S. 2008. Critical Theory and Participatory Action Research. In P. Reason \& H. Bradbury (Eds.), The SAGE Handbook of Action Research (2nd ed.): 121-138. Los Angeles: SAGE. https://dx.doi.org/10.4135/9781848607934.n14

Leung, L. 2015. Validity, Reliability, and Generalizability in Qualitative Research. Journal of Family Medicine and Primary Care, 4(3): 324-327.

https://dx.doi.org/10.4103/2249-4863.161306

Levin, M. 2012. Academic Integrity in Action Research. Action Research, 10(2): 133-149. https://doi.org/10.1177/1476750312445034

Lewin, K. 1946. Action Research and Minority Problems. Journal of Social Issues, 2(4): 34-46. https://psycnet.apa.org/doi/10.1111/j.1540-4560.1946.tb02295.x

Lincoln, Y., \& Guba, E. 1985. Naturalistic Inquiry. Newbury Park, CA: SAGE.

Lindhult, E. 2002. The Quality of Action Research. In Proceedings from the 2nd HSS Research Conference, May 9-11, 2001, Halmstad University, Sweden.

Lindhult, E. 2005. Management by Freedom: Essays in Moving from Machiavellian to Rousseauian Approaches to Innovation and Inquiry. Doctoral Thesis in Industrial Economics and Management. Stockholm: KTH Royal Institute of Technology.

Lindhult, E. 2008. Att bedöma och uppnå kvalitet i interaktiv forskning. In B. Johannisson, E. Gunnarsson, \& T. Stjernberg (Eds.), Gemensamt kunskapande - den interaktiva forskningens praktik. Växjö, Sweden: Växjö University Press.

Lindhult, E. 2015. Towards Democratic Scientific Inquiry? Participatory Democracy, Philosophy of Science and the Future of Action Research. In E. Gunnarsson, H. P. Hansen, \& B. Steen Nielsen (Eds.), Action Research for Democracy - Intervening in the Current Crisis: New Ideas and Perspectives from Scandinavia. London: Routledge.
Lindhult, E. 2019. Scientific Excellence in Participatory and Action Research: Part II. Rethinking Objectivity and Reliability. Technology Innovation Management Review, 5(9): 22-33. http://doi.org/10.22215/timreview/1238

MacIntosh, R., \& Bonnet, M. (Eds.) 2007. Special Issue on International Perspectives on Validity in Action Research. Management Research News, 30(5).

Marshall, J. 2016. First Person Action Research. Los Angeles: SAGE Publications.

Marti', J., \& Villasante, T. R. 2009. Quality in Action Research: Reflections for Second-Order Inquiry. Systemic Practice and Action Research, 22(5): 383-396. https://doi.org/10.1007/s11213-009-9136-X

McNiff, J., Lomax, P., \& Whitehead, J. 1996. You and Your Action Research Project. London: Routledge.

Merriam, S. B., \& Tisdell, E. J. 2016. Qualitative Research: A Guide to Design and Implementation. San Francisco, CA: Jossey-Bass.

Nielsen, K. A., \& Svensson, L. 2006. Action Research and Interactive Research. Beyond Practice and Theory. Maastricht, Netherlands: Shaker Publishing.

Nonaka, I. 1994. A Dynamic Theory of Organizational Knowledge Creation. Organization Science, 5(1): 14-37. https://doi.org/10.1287/orsc.5.1.14

Pålshaugen, Ö. 2002. Discourse Democracy at Work: On Public Spheres in Private Enterprises. Concepts and Transformation, 7(2): 141-192. https://doi.org/10.1075/cat.7.2.03pal

Reason, P. 2006. Choice and Quality in Action Research Practice. Journal of Management Inquiry, 15(2): 187-203. https://doi.org/10.1177/1056492606288074

Reason, P., \& Bradbury, H. (Eds.) 2001a. Handbook of Action Research: Participative Inquiry \& Practice. London: SAGE.

Reason, P., \& Bradbury, H. 2001b. Introduction: Inquiry and Participation in Search of a World Worthy of Human Aspiration. In P. Reason \& H. Bradbury (Eds.), Handbook of Action Research: Participative Inquiry \& Practice: 1-14. London: SAGE.

Reason, P., \& Bradbury, H. 2008. The SAGE Handbook of Action Research (2nd ed). Los Angeles: SAGE. https://dx.doi.org/10.4135/9781848607934

Reason, P., \& Torbert, W. R. 2001. The Action Turn: Toward a Transformational Social Science. Concepts and Transformations, 6(1): 1-37.

https://doi.org/10.1075/cat.6.1.02rea

Rorty, R. 1979. Philosophy and the Mirror of Nature. Princeton, NJ: Princeton University Press.

Rorty, R. 1998. Truth and Progress: Volume 3: Philosophical Papers. Cambridge: Cambridge University Press.

Santos, B. 2014. Epistemologies of the South: Justice against Epistemicide. London: Routledge.

Schön, D. 1983. The Reflective Practitioner: How Professionals Think in Action. Aldershot, UK: Avebury.

Simon, H. A. 1996. The Sciences of the Artificial (3rd ed). Cambridge, MA: MIT Press. 


\section{Scientific Excellence in Participatory and Action Research: \\ Part I. Rethinking Research Quality Erik Lindhult}

Stringer, E. 1999. Action Research (2nd ed). Thousand Oaks, CA: SAGE.

Susman, G. I., \& Evered, R. D. 1978. An Assessment of the Scientific Merits of Action Research. Administrative Science Quarterly, 23(4): 582-603.

https://doi.org/10.2307/2392581

Svensson, L., Ellström, P.-E., \& Brulin, G. 2007. Introduction - On Interactive Research. International Journal of Action Research, 3(3): 233-249.

Toulmin, S. 1990. Cosmopolis: The Hidden Agenda of Modernity. New York: MacMillan.

Toulmin, S. 2001. Return to Reason. Cambridge, MA: Harvard University Press.

Toulmin, S., \& Gustavsen, B. (Eds.) 1996. Beyond Theory: Changing Organizations through Participation. Amsterdam: John Benjamins Publishing.

Van de Ven, A. 2007. Engaged Scholarship: A Guide for Organizational and Social Research. Oxford: Oxford University Press.

Weber, M. 1978. Economy and Society, Volume I. An Outline of Interpretative Sociology. Berkeley: University of California Press.

Whyte, W. (Ed.) 1991. Participatory Action Research. Newbury Park, CA: SAGE.

Wittgenstein, L. 1984. Über Gewissheit. Werkausgabe band 8. Frankfurt am Main: Suhrkamp.

Citation: Lindhult, E. 2019. Scientific Excellence in

Participatory and Action Research: Part I. Rethinking

(cc) BY

Research Quality. Technology Innovation Management

Review, 9(5): 6-21.

http://doi.org/10.22215/timreview/1237

Keywords: action research, participatory research, quality 


\title{
Scientific Excellence in Participatory and Action Research: Part II. Rethinking Objectivity and Reliability
}

\author{
Erik Lindhult
}

\author{
In memory of Björn Gustavsen
}

"Given all the complex relationships that research has to enter into" under present forms of production of knowledge, the demand for objectivity has probably never been higher and more critical than at present... There is no argument available, no position we can enter, no words we can use, that ensure objectivity irrespective of what we actually do when we carry out our tasks. In this sense research is in the same position as, say, a referee in a football match: he is under continuous scrutiny from the public who will immediately notice if he breaks with the idea of objectivity. If such breaks occur, the referee will not be much helped by arguing that he has a philosophy of objectivity that the public does not understand. Objectivity becomes, in other words, a set of practical requirements. When research is actually performing its tasks it is in the same kind of situation.

Björn Gustavsen (1938-2018)

Professor and Action Researcher

In Gustavsen (2003)

The purpose of this article is to deal with the following question: Can the concepts of reliability and objectivity be reconceptualized and reappropriated to enable understanding of scientific excellence in participatory and action research? The article shows that it is fruitful to consider the "subjective" and active role of researchers as vital in enabling scientific objectivity and reliability. As an expansion from a replication logic, reliability can be conceptualized as adaptive, goal-seeking, dynamically regulated processes enabled by effective organization of interactive and participatory learning processes where all participants can contribute to learning and correction in inquiry. Instead of erasing subjectivity, objectivity can be enabled by critical subjectivity, intersubjectivity, practical wisdom, impartial norms of inquiry, and open democratic dialogue. Reliability and objectivity in this understanding can be enabled by participatory and action research through skilful performance of research practices such as reflective conversations between parties, dialogue conferences, experimentation, and experiential learning as part of action-research cycles, etc., which are common in participatory and action research initiatives and projects. By rethinking validity, reliability, and objectivity, recognizing the substantially more active and participatory stances enables scientific excellence, it can expand the repertoire of strategies for promoting research quality, and it helps to mainstream this type of approach in the scientific community. 


\section{Scientific Excellence in Participatory and Action Research: Part II. Rethinking Objectivity and Reliability Erik Lindhult}

\section{Introduction}

In the varied, not to say confusing, discussion of quality in participatory and action research, the use of reliability and objectivity as notions to understand the topic is largely missing (Herr \& Anderson, 2015; Reason, 2006). In a companion article that forms the first part of this conceptual review and development of quality concepts for participatory and action research (Lindhult, 2019), I focused on validity, which has some presence in the literature and debate. This is less the case for the concepts of objectivity and reliability. But, is objective and reliable scientific activity not relevant or not appropriate in participatory and action research? Why are the concepts missing or rejected?

One reason is the dominance of positivist and empiricist scientific paradigms and ideologies and a spectator view of knowledge (Dewey, 1929), which motivate efforts to faithfully mirror the lawful patterns of reality (Rorty, 1979). Such views make participatory and action research look too "subjectivist" and "activist" to be objective and reliable, and they lead participatory and action researchers to look for what they see as more viable and appropriate standards. Some have followed the qualitative camp, turning towards more lenient versions in the context of more dynamic, changing, and contingent circumstances, such as reviewability (i.e., enabling a reviewer to follow the trail of research in the documentation) instead of reliability. Qualitative researchers tend to play down objectivity in face of the important role of subjectivity in unavoidable interpretative dimensions of social science.

The purpose of this article is to address the following question: Can the concepts of reliability and objectivity be reconceptualized and reappropriated to enable understanding of scientific excellence in participatory and action research? I believe it is fruitful to take a step further to consider the "subjective" and active role of researchers as vital in enabling scientific objectivity and reliability.

\section{Robust research practices: Rethinking objectivity and reliability}

Inquiry needs to be trusted to consistently develop and secure knowledge claims with limited risk of failure and too much deviance from acceptably trustworthy outcomes. Here, reliability and objectivity as quality concepts have important guiding roles in inquiry. Reliability is predominantly conceptualized as reaching the same outcomes in repeated use of research instruments and operations, often seen as human senses empowered, or even better, replaced, by measurement tools. If humans are more or less part of instruments and operations of research, for example as interpretative philosophies are arguing is necessary in interpretative research operations, standardization of instruments (e.g., interview protocols and procedures) is recommended to avoid variation and the corrupting influence of subjectivity. Objectivity is impartiality and being (to a satisfactory degree) free from bias of inquirers that can risk trustworthiness. It is traditionally conceptualized as being free from any influence coming from the subjects of inquiry (that is, free from "subjectivity"), something that is properly achieved by distancing the researcher from any participation in the research domain and from any interaction with the research object.

I believe discarding objectivity and reliability as many qualitative as well as participatory and action researchers tend to do is unfruitful and based on a too-limited view on the meaning and use of the concepts. It is taking its point of departure in less fruitful conceptualization out of an overzealous desire to root out any presence of actors of inquiry influencing the processes and methods. It is often influenced by assuming a spectator view of knowing and a positivistically influenced understanding of inquiry. Through appropriate clarification and rethinking of the concepts, including its ontological and epistemological assumptions, they can become open for involving actors and their characteristics in ways that can enhance, not only compromise, research quality.

\section{Objectivity}

A core issue is the role of the "subjective" in making science robust and valid for producing high-quality knowledge. Objectivity is traditionally seen as erasure of subjectivity, for example as "self-distancing" and "disinterestedness" or, more explicitly, "the holding in abeyance, or erasure, of the individual mind's desires, interests, assumptions, and intents while that mind is in the process of knowing the material world" (Solomon, 1998). Objectivity is typically associated with reality and truth and has the general connotation of solidity, trustworthiness, accuracy, impartiality, etc. The general connotation for many uses of subjectivity includes unreliability, bias, an incomplete (personal) perspective, etc., typically indicating the possibility of error. Objective knowledge, knowledge of reality as it is, is what is attained when all subjective factors are 


\section{Scientific Excellence in Participatory and Action Research: Part II. Rethinking Objectivity and Reliability Erik Lindhult}

rooted out. But science can only be performed through subjects, implying that fully objective knowledge in this view is impossible for us humans. As Kant (1998) said, pure objectivity, knowledge of the thing in themselves (Das Ding an sich), is impossible because we necessarily sense the world through basic categories of the mind such as space and time. We always wear our blue-tinted spectacles and we cannot take them off, as he eloquently expressed it. The implication is that our subjective, mentally ingrained space-time categories hinder us from attaining full objectivity in seeing reality as it truly is. The spectator, mirroring image of knowledge (Dewey, 1929; Rorty, 1979) is quite evident, but our mental mirrors are inherently flawed.

\section{The role of the subject in advancing science}

There are other points of departure for understanding objectivity. We can build on cues for rethinking from Francis Bacon as an early originator of the visions and ideology of modern science. Influenced by humanist scepticism, Bacon "was entirely preoccupied with the specific problems he perceived as hindrances to the advancement of knowledge and the implementation of objectivity in the sciences" (Zagorin, 2001). His main contribution was his identification and elaboration of "idols" - fallacies of the human mind - and the outline of reasonable practices (invention of arts of "induction" in developing notions to interpret nature) for the orderly advancement of learning from experience to successively more reliable axioms with wider import (Bacon, 1960). Approaching objectivity means tempering and minimizing the influence of our idols and using our capacities in applying reasonable norms and practices of inquiry for creating high-quality knowledge.

Bacon had a more practice-based, pragmatic view of knowledge creation in line with Dewey (1939a). Knowledge production is less understood as a logical exercise or "God's eye", fly-on-the-wall unobtrusive registration of sense impression mirroring a given reality. It is rather an active, creative, and organized achievement of inquiring actors in developing and securing more reliable connections between notions and experience, better value and workability in practice, and new or enhanced resolution of problematic situations. To know is to be able to think and do in richer, novel, and improved ways, thus scientific research is enabling and empowering for betterment of human condition, as Bacon emphasized. A point in participatory and action research is that research actors and participants can significantly support reliability and objectivity, not only corrupt it by their "subjective" influence. Making claims valid, reliable, and objective in relation to arguably worthwhile purposes often requires significant skills, competence, and virtues of the inquiring subjects. Scientific production is based on relevant competencies and capacities to maintain norms of good inquiry by inquiring actors and their communities.

\section{Threats to objectivity: Bacon's idols}

Objectivity requires actors and includes their effort to diminish the influence of factors that may undermine good norms and practices of inquiry. Here, Bacon's (1960) idols, fallacies of the human mind, are important to deal with in freeing the inquirer from these obstacles to the trustworthy advancement of scientific learning.

The first type of idol, the idols of the tribe, is common to the human species. It is a range of limitations and deficiencies of the human mind rooted in an anthropocentrism of projecting will, passion, and experience into distorted, reified images of things. People are creating "wishful sciences" by more readily believing to be true what they wish were true, and sticking to these opinions despite countervailing evidence, something today reinvented as "knowledge resistance". Their senses are often weak, incompetent, and erring in face of the authority of established superstitions and seemingly self-evident principles. Like Dewey (1939a), he saw an experimental attitude and practice as the way to properly establish the authority of experience and both freeing and disciplining the mind for securing advancement of learning.

The second type of idol, those of the cave, are errors due to the peculiarities and variety of impressions of each particular individual, every one of whom is dwelling in his own cave of interests and opinions. The information revolution, starting with the technology of printing that Bacon took early advantage of, has been, no doubt, a vehicle for general learning and enlightenment. But, surprisingly, it has also led to the construction of new caves, today pinpointed in newly invented notions such as "filter bubbles" and "information silos". Through modern "intelligent" technology, Internet "trolling", and social media, personalized information is created that is reproducing one-sided and even false opinion where people can, as Bacon say, be obedient to their own fancies.

The third type of idol is the most troublesome, according to Bacon: the idol of the forum (or market place), where "commerce and consort" can create and spread 


\section{Scientific Excellence in Participatory and Action Research: Part II. Rethinking Objectivity and Reliability Erik Lindhult}

false or ill-defined notions and language that can twist understanding away from experience. The development of the interpretative sciences has, since Bacon, developed science as an enterprise not only for the interpretation of nature but also for the interpretation of culture where words and language form an important dimension of knowledge. But, the challenge of the "deceits" of language seem even more pronounced today in contemporary, more relativist (e.g., post-modern) philosophies questioning that there is something outside the dynamics of language and discourse that can stabilize linguistic expressivity. The development of post-truth cultures is enlarging relativism by embedding it in social fields. People in these settings do not really care about linking words and narratives to experience and evidence but instead are twisting words and narratives according to their personal interests. Bacon's suggestion that notions need to be successively invented and carefully applied through experimentation to order experience is an important part of his proposed inductive method, but this seems like a weak remedy. However, it may be in accordance with established scientific practices today as well as with the logic of experiential and reflective learning (Kolb, 2015; Schön, 1983) often referred to in participatory and action research.

The fourth type is the idol of the theatre, which consist of the different dogmas coming from false systems of philosophy or deficient principles in the sciences which gives rise, like stage plays, to fictions and unreal worlds. The positivist philosophy of science and the spectator view of knowledge, with its mirroring fiction that I have been criticizing, is an illustration of this type of fallacy of which Bacon had the lengthiest discussion.

\section{Developing the subject to improve objectivity}

Although Bacon was optimistic in inventing new inductive practices for the advancement of science, he did not believe this would be accomplished by doing away with the subjective fallacies. He believed that "the first two classes of idols were hard to eradicate and the other two classes could not be eradicated at all. The most that could be done with the latter..., was to point them out so that their insidious effect on the mind could be identified and overcome" (Zagorin, 2001). The optimistic belief that enlightenment, education, science, and the information revolution should free the human mind from its fallacies has not been generally confirmed, but instead seems today to be more in line with Bacon's more wary view. Thus, Bacon did not argue for avoiding subjectivity, which still is a dominant ideal in today's objectivity understanding. Objectivity, instead of neutrality, stamping out subjectivity, and detachment from research context is based on developed forms of subjectivity that is able to temper Baconian idols and maintain norms of good inquiry. It is a move from naïve to critical subjectivity (Herr \& Anderson, 2015; Reason, 1994) that enables one to, through self-reflexivity, critically examine one's own biases and put in place procedures, such as peer reviewing by critical friends, which can support more impartial and truth seeking, that is, objective, inquiry. Bacon himself is also proposing critical procedures as a remedy. For example, for cave fallacies and today's filter bubbles, which tend to lock people into information sources that strictly conform to their own world view and allow onesided views to thrive, Bacon suggests; "follow the rule that whenever their minds seized upon something with special satisfaction, they should consider it suspect and take special care to keep their minds balanced and clear" (Zagorin, 2001).

To be objective is to develop and make satisfactory claims to knowledge that are not dependent on who is making the claim or on peculiarities of the organization of inquiry. It has a moral dimension of inquiry as fair, impartial, and unbiased. It is in accordance with Gustavsen's (2003) image of a referee in a football match in the introductory quotation, where the referee has to maintain objectivity in face of an often-biased situation. Objectivity is crucial in maintaining the norms and rules of the game, and the trust of the actors in the fairness of the game. This is equally important in science. One way to deal with subjectivity is to include more subjects in inquiry (Westbrook, 1995), like the team of referees in a football game. Objectivity is then recognized as intersubjectivity (Lindhult, 2008), something that accrues when there is consonance among subjects emerging from an interaction between them. This is supported by social, communal, and practice-based epistemology and inquiry orientation often used in participatory and action research (Coghlan, 2016). It is social in the sense of recognizing the distribution of expertise and inquiry capacities in society, and through its important communal dimensions. We are standing on the shoulders of others (building on their insights as well as misconceptions!), and we are interacting indirectly or directly with others in the co-production of knowledge. Through active and collaborative research roles, the best available expertise of various forms of knowledge and research practices and skills of inquiry can be mobilized. It is also social in the sense of creating spaces and furthering norms of 


\section{Scientific Excellence in Participatory and Action Research: Part II. Rethinking Objectivity and Reliability Erik Lindhult}

questioning and thinking and acting differently from established knowledge, authorities, and traditions through collaborative critical reflection, as well as integrating contributions through public discussion (Foucault, 1984; Kant, 1991). This is expressed in the motto Sapere aude! (Dare to be wise!) that Kant saw as epitomizing Enlightenment ideology.

Knowledge is practice-based in the sense of good, scientific inquiry being based on the skillful and competent performance of effective and efficient research practices and methods appropriate in context and for chosen purposes. Moreover, in the sense that inquiry requires action to change and transform situations and problems to develop, test, and validate knowledge claims and resolve issues (Dewey, 1939a). Here participatory and action research is closely allied to science of design, the science of the artificial (Simon, 1996), opening up for a participatory worldview (Heron, 1996) where we are creators of knowledge to approach human purpose, not only discoverers of existing patterns in reality. Simon emulates Dewey's (1939a) definition of scientific inquiry in his oft-cited definition of a designer as everyone "who devises courses of action aimed at changing existing situations into preferred ones" (Simon, 1996). Like Bacon, Simon argues that knowledge of nature and knowing in human operation combine in the goal-oriented design of artifacts as resolutions to issues or realization of imagined opportunities. In this way, science constitutes the empowering of people for development of human betterment. But, while Bacon focused on "interpretation of nature", design sciences related to various professions and disciplines, such as engineering, management, creative arts, innovation and design research, and social reform (Dewey, 1929; Schön, 1983; Simon, 1996), are devoted to imagining, constructing, and innovating physical and social artifices that can realize human visions and goals. Here the "wishful sciences" that Bacon condemned have a scientific status on par with other sciences to the extent that they advance the sciences of design.

\section{Objectivity through practical wisdom}

I believe objectivity, here, fruitfully means the development of good judgment, Aristotelian phronesis (practical wisdom), a capacity for considered, balanced judgment in situations mediating and integrating different considerations (e.g., different interpretations and stakeholder concerns) when participating in research contexts (Lindhult, 2004). Phronesis is, according to Aristotle, experience-based judgement: "a true and reasoned state of capacity to act with regard to the things that are good or bad for man" (Aristotle, 1980; see Eikeland [2008] for an Aristotelian clarification and defence of action research). It involves determining ends and the means of attaining them in particular situations. As Lewin says in a seminal article outlining action research (Lewin, 1946), without consideration of ends, it is like a boat without navigation moving round and round in circles. Wisdom as practical integrates intelligence with virtue in acting according to norms of good judgment and inquiry. Instead of seeing the only alternative to the traditional focus on neutrality and value freedom as being value laden and partial, objectivity here means impartiality in balancing and integrating different values, interests, and purposes in context of research situations with various parties and stakeholders.

A strength in participatory and action research is that objectivity as good judgment and practical wisdom is more a mutual and common accomplishment, not judgment by one or a few "wise guys", where distributed expertise and judgment is pooled and balanced through discussion (Eikeland, 2006; Gustavsen, 1986; Pålshaugen, 2002). Thus, objectivity is based on good organization and institutions of inquiry involving broader collaboration of inquirers. It is a kind of political skill in the Aristotelian sense of public discussion (see also Habermas [1989] and the tradition of discursive/deliberative democracy) with an action orientation towards common advantage, where truth seeking is one important good. Objectivity requires also that people are open to adopting a scientific attitude to life. An inclusive and participatory orientation on who is allowed to partake, share in, and contribute to the scientific community might temper the post-truth cultures evident today and reinforce the unity of science that Dewey saw as a cooperative alliance among engaged professionals and citizens (Dewey, 1938). For example, the focus on Responsible Research and Innovation and Inclusive Innovation is today furthering such an orientation in order to make science more responsive to societal challenges (Owen et al., 2012; Schillo \& Robinson, 2017). Here, democratic dialogue as a leading element and infrastructure in inquiry to pool and develop practical wisdom is a suitable norm (Gustavsen, 1992).

\section{Reliability}

Let us turn to reliability as a quality concept. Whereas objectivity is focused on dealing with different contextual factors of inquiry, reliability ensures that the process of inquiry is on a safe road to valid outcomes - "truths". Reliability refers to research processes, practices, and methods that have a degree of stability in outcomes according to different reviewers and assessment practices, 


\section{Scientific Excellence in Participatory and Action Research: Part II. Rethinking Objectivity and Reliability Erik Lindhult}

and in varied research contexts. It is an achievement of good practices of inquiry in that it enhances the degree of trustworthiness of knowledge claims. It is more than replication logic. A more general and adequate understanding of reliability is robustness and consistency in the process of inquiry so that inquiry operations can lead to expected, intended, or desired outcomes with limited risks of unexpected negative consequences.

The ideal of research is not only observing and mirroring from a distance. This metaphor hides the researchers own active and necessary conceptual and practical construction of research situations and objects in order to create knowledge. It means constructing research situations and performing practices where ideas operationalized can be connected, through these practices, to consequences assessed based on expectations and purposes in inquiry. For example, to arrange research situations to be unobtrusive of subjects of research often requires considerable constructive capacities not just passive, distant mirroring. Creating relationships with subjects such that they feel at ease with the presence of researchers or research instruments requires communicative skills, ethical behaviour to build trust, and authorization by parties involved. Arranging, conducting, and analyzing interviews are basic research practices that require entrepreneurial, reliable, and skillful action from problematization, sampling, access, and creation of scientific social relation to validation and publication of findings on the clarification and resolution of problem academically and (for some, but not all, research approaches) practically.

Research objects are, in important ways, constructed and reconstructed in the transaction between the inquirer and the objects of inquiry as Dewey (1929) points out. Careful formation of notions was central in Bacon's invention of the scientific art of induction. In science as design, not only notions but also many other artifacts as objects of knowledge are constructed where reliability is not only based on stable causal structures and conditions but on how actors cause things to happen and bring them about through creativity and skillful "directed operation" (Dewey, 1929). That is, reliability is an accomplishment through control of consequences and stabilizing, skillful practices so that a high-quality service, an accurate weather foresight, an open, democratic meeting, or an organization free from bullying and racism can be continuously constructed. Susman and Evered (1978) see here a scientific role for participatory and action research in developing "practics" - know-how and action principles or guides for dealing with different situation - for example, in solving problems, enable organizational learning, or mediating and progressively integrating between parties (Follett, 1930).

Reliability is also relevant in dynamic research processes that are difficult to replicate but that are understood as reviewability in tracking the process from initiation to outcomes. Like an auditor, a reviewer can authenticate the findings by following the process and decision trail of the inquiry (Lincoln \& Guba, 1985), for example by checking if the findings are consistent with reported data. (Lincoln and Guba [1985] call this dependability.) This calls for good process documentation, for example, through journalling (Coghlan \& Brannick, 2014). This does not discard replication logic but adapts and weakens it to be applicable to more context- and subject-dependent knowledge areas. It also turns more to process rather than results (replication of outcome) in understanding reliability, still with a focus on what external reviewers can do to assess and enhance reliability.

Furthermore, qualitative as well as participatory and action researchers argue for a degree of reliability in various research models, methods, procedures, and tools designed to overcome, or at least temper, Baconian fallacies in human understanding. This view is embedded, for example, in the wealth of recommendations for doing good interview research, and in the common action research cycle model (i.e., plan, act, observe, and reflect, then repeat). The point of research methodologies is to make fullest use of our capacities for understanding, learning, and inquiry by offering more generic methodological knowledge and providing support for reasonable decisions for appropriate and skillful use in different contexts. Continuous improvement aids inquiry to become more competent in achieving worthwhile purposes through sifting out comparatively better practices and making better situational choices. This is in line with Bacon's methodological proposal he called induction, but with a stronger emphasis on construction, invention, and creation in skillful organization of inquiry.

\section{Reliability and learning}

Reliability is not only inherent in methods, but also in the organization of learning (Lindhult, 2008). If knowledge is to be created, somebody, often a number of interacting individuals in a network or community, needs to learn and express this learning in communicative 


\section{Scientific Excellence in Participatory and Action Research: Part II. Rethinking Objectivity and Reliability Erik Lindhult}

form. Reliability as a particularly distinctive feature of participatory and action research lies in the organization of inquiry as a mutual and interactive learning process (Svensson et al., 2007). Learning and knowledge production support the need for continuously occurring emergent issues and problems to be dealt with and resolved in the inquiry process, and in relation to purposes and their achievement (process validity according to Herr and Anderson [2015]). Purposes are approached and realized, implying consistency in aims (a dimension of what Herr and Anderson [2015] call catalytic validity).

Reliability is also supported through learning in relation to purposes, assumptions, and changing research situations so that inquiry is adaptive and self-correcting - a form of double-loop learning (Argyris \& Schön, 1978). It can also be supported by the participatory process in the sense of emergent, evolutionary inquiry as a dynamic process of interaction that is navigated and stabilized based on coordinated understanding and practical agreements. The most robust guide for scientific advancement is practicing open democratic dialogue as operational directives (Gustavsen, 1992). It means openness for contribution of all on equal terms, a democratic aspect of quality of inquiry (Herr \& Anderson, 2015; Lindhult, 2015). It gives freedom to experiment and try out different lines of inquiry, where dialogue is the medium for critical assessment and sifting out the most trustworthy claims to knowing among the proposed candidates in dialogical contestation and argumentative review (Habermas, 1984). It is also a medium for tempering the idols of our forceful, but fallible, human understanding. Anyone can get it wrong or be unable to see the full picture of an issue or a proposed solution. In line with the social epistemology mobilized in participatory and action research, experience, knowledge, reasoning capacity, perspectives, and creativity are distributed, where open democratic dialogue provides opportunities for pooling resourcefulness and capacities of many through a kind of practical, interactive, communicative, and expansive rationality (Habermas, 1984; Hatchuel, 2002; Schön, 1983; Simon, 1996). Inquiry as open, emergent, creative, and dialectical processes among inquirers can no doubt be a challenge for reliability and objectivity in the short run, but dialogical and participatory procedures has a capacity for learning and self-correction in a longer time perspective.

Table 1 summarizes the shift and reconceptualization of objectivity and reliability proposed in supporting quality in participatory and action research.

\section{Reliability and validity}

Reliability and validity are related in the sense that they both support trustworthiness. Reliability as consistency and stability in a process of inquiry is normally an indicator of validity and can be seen as a validity dimension in itself. On the other hand, striving for reliability can diverge from or even corrupt validity. It is not only the common Baconian fallacy of focusing on what can be reliably measured despite its questionable validity. Consistency, like in the temperature measurement of a thermometer, might hide systematic and systemic deviances, such as technical errors in the instrument, limited skills in using it, or ignorance of situational factors such as windiness, which leads to lower validity in results. In a social context, power structures repressing some views and voices, negative feedback dynamics in a system reproducing unwanted conditions, or isomorphisms in an organizational field driving conformity might lead to spurious trustworthiness. A dominant (positivist) belief in the existence of and the scientific search for universal, Newtonian laws of human behaviour given in reality supports an ideological interest in status quo (e.g., the quite universal lower status of women compared to men can be trustworthily "proven"), instead of an interest in transformation, emancipation, and betterment of human conditions through scientific and collaborative, constructive efforts (e.g., a more equal society). Critical approaches to social science urge us to recognize a fundamental choice of scientific engagement between supporting status quo (with much better chances to attain reliability and objectivity according to traditional standards) or emancipation from structures and relation of domination restricting individual and social improvement and transformation (requiring reconceptualized understanding of scientific excellence).

Furthermore, less reliability in method and process might open up possibilities for greater validity in results in the sense of varied and rich understanding of an issue and possible ways to deal with it (Merriam \& Tisdell, 2016). For example, participatory and action research frequently contribute to quality by opening up opportunities for inquiry into new, unheard, sometimes silenced, voices, experiences, and viewpoints adding to (or disrupting) the dominant learning in a field or context. It might create a more unstable, even conflictual and chaotic, process, but it might also lead to important research qualities and enhanced validity. In addition, courage to break with the urge for rigour might encourage creativity by thinking and acting differently, leading to more interesting and valuable research results in relation to knowledge interests and purposes of inquiry (Alvesson \& Sandberg, 2013). 


\section{Scientific Excellence in Participatory and Action Research: Part II. Rethinking Objectivity and Reliability Erik Lindhult}

Table 1. Reliability and objectivity reconceptualized and expanded

\begin{tabular}{|c|c|c|c|}
\hline & “Normal” Research & $\begin{array}{l}\text { Reconstruction in } \\
\text { Qualitative Research }\end{array}$ & $\begin{array}{l}\text { Action Research / } \\
\text { Participatory Research }\end{array}$ \\
\hline $\begin{array}{l}\text { How researchers can create } \\
\text { reliability }\end{array}$ & 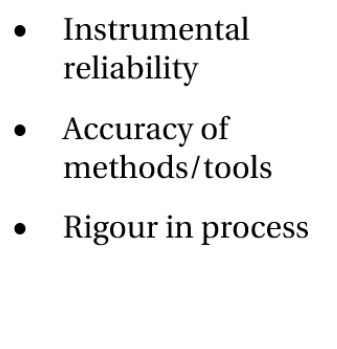 & $\begin{array}{l}\text { - } \begin{array}{l}\text { Documentation of process } \\
\text { and choices (e.g., project log) }\end{array} \\
\text { - } \quad \begin{array}{l}\text { Data is consistent with results } \\
\text { (dependability) }\end{array} \\
\text { - } \quad \text { Critical reflection } \\
\text { - } \quad \text { Standardization and training } \\
\text { for minimizing subjectivity }\end{array}$ & $\begin{array}{l}\text { - } \\
\text { reliabilive, goal-seeking } \\
\text { regulated process } \\
\text { - } \\
\text { Effective organizing } \\
\text { interactive and } \\
\text { participatory learning } \\
\text { processes }\end{array}$ \\
\hline $\begin{array}{l}\text { How stakeholders / external } \\
\text { actors can contribute to } \\
\text { reliability }\end{array}$ & $\begin{array}{l}\text { - Replication of the } \\
\text { study }\end{array}$ & $\begin{array}{ll}\text { - } & \text { Process review } \\
\text { - } & \begin{array}{l}\text { Auditability (e.g., audit } \\
\text { trailing) }\end{array}\end{array}$ & $\begin{array}{l}\text { - Contribute to learning } \\
\text { and correction in inquiry } \\
\text { as (extended/actual) } \\
\text { participant }\end{array}$ \\
\hline Objectivity & $\begin{array}{ll}\text { - } & \text { Neutrality } \\
\text { - } & \text { Non-biased } \\
\text { - } & \text { Detached position }\end{array}$ & $\begin{array}{l}\text { - } \text { Reflexivity } \\
\text { - Description of subjects / pre- } \\
\text { understanding } \\
\text { - Confirmability of findings }\end{array}$ & $\begin{array}{ll}\text { - } & \text { Critical subjectivity } \\
\text { - } & \text { Intersubjectivity } \\
\text { - } & \text { Practical wisdom } \\
\text { - } & \text { Impartial norms of } \\
\text { inquiry } \\
\text { - } \\
\quad \text { Open democratic } \\
\text { dialogue }\end{array}$ \\
\hline
\end{tabular}

Quality through enabling and organizing learning, dialogue, and democracy

All research processes start with some "subjective" factors as it is necessarily humans involved and driving knowledge-creation projects. Humans are both knowledgeable and ignorant, and they necessarily use their pre-understanding for interpreting and constructing a knowledge object. It provides pre-judgment as a resource and at the same time prejudice, as Gadamer (1975) is integrating in the German word Vorurteil. But, in line with Bacon, it does not mean to wholly root out subjective factors such as passion, imagination, skills, creativity, and feelings (Brown, 1996), but rather to use them properly. Scientists need to be passionate, entrepreneurial, and disciplined in establishing good norms (and enabling effective and efficient practices) of inquiry that can purposefully and trustworthily advance human learning. In this sense, all science scholarships must be engaged and use persuasive powers and expertise to initiate, enable, manage, and navigate research processes and organize inquiry to objectify and ensure the reliability of the processes and validate their outcomes.
The reconceptualization of the quality concepts opens up different ways for all participants in participatory and action research to contribute to quality and have a shared responsibility for process and results, for example, by contributing to good interaction and dialogue, reviewing emergent findings, or providing adaptivity to aims. The goodness of inquiry processes seems to be particularly emphasized in participatory and action research with its focus on participation, good dialogue, learning, and experimentation. It is the character of the inquiry process that gives this type of approach its distinctive qualities. It is assumed that these dimensions both support more participatory, inclusive, and democratic science and also increase validity and quality in its operation and outcomes. For example, Herr and Anderson (2015) emphasize "process validity" as an important quality criterion, and most of their other suggested criteria, such as dialogic, democratic, and catalytic validity have important process, and thus reliability, dimensions.

Florin and Lindhult (2015) identify nine norms of excellence as shared responsibility in collaborative inquiry: 


\section{Scientific Excellence in Participatory and Action Research: Part II. Rethinking Objectivity and Reliability Erik Lindhult}

focused on freedom of inquiry, dialogic and democratic processes, shared value, participatory governance, extended epistemology and capacity, self-reflection, building common ground, quality and viability, and efficient methodology. These norms of excellence are constitutive features of inquiry, guidance for and indicators of the successful performance of it, as well as a basis for fair/ethical treatment of involved parties.

There are rich and varied suggestions for reliable research practices and methods that can enable these norms of excellence in the expanding research literature on participatory and action research. It can be seen as an extension and refinement from mainstream methodology literature, which often is deficient or displaying a lacuna in supporting participatory and active research roles. For example, interviewing, often seen as scientific when one party is extracting data in a distant and passive mode for research from other parties, can be shifted in power balance to more mutual and active roles for both parties where interviewing is expanded to reflective conversation, dialogic workshops, and collaborative experimentation with new frames and practices. It becomes a collaborative learning process where all share and all contribute, approaching the vision and ideal of creative democracy (Dewey, 1939b). There is ample room for integrating and further developing the existing repertoire, for example, of meeting and workshop designs for scientific inquiry that can integrate academic, problem solving, and practice improvement in different phases of the processes from problematization to collaborative problem solving, innovation, and transformation. This serves as a collaborative call in response to Gustavsen's (2017) view that "there is a need for a thorough working over of research practices" to bring participatory and action research further. It resonates with Susman and Evered's (1978) proposal of participatory and action research as an enabling science for developing "practics" that lead to action guides for releasing human potential, creating human artifacts, and transforming social systems that we are part of in line with envisioned and agreed purposes.

\section{Conclusion}

This article, and its companion (Lindhult, 2019), has showed how scientific excellence in participatory and action research can be fruitfully understood through the basic quality concepts used in mainstream science, when these concepts are clarified and reconceptualized. The aim is integrational: to advance the inclusion of participatory and action research not only as a peripheral school in the family of sciences, but also, as
Gustavsen argues, as a main school through "an ability to deal with the traditional tasks of research in a way which is superior to other schools of thought" Gustavsen (1992). I have made an effort to show the way that participatory and action research has comparatively advantageous ways to realize the traditional quality standards of validity, objectivity, and reliability in aiming for scientific excellence. I hope this can build understanding and confidence in the community of participatory and action researchers and spur further discussions on quality in the research community at large.

I have focused on conceptual reconstruction. The advantage of using established concepts for describing and assessing quality is that the discussion can integrate and be part of long existing discourses on research quality. The disadvantage is that the diversification in perspective and approaches in science developed since the 1970s has also questioned the continued use of these traditional concepts, where some would argue that it is better leaving these traditional quality concepts behind and talk about quality in other more appropriate ways. It is easy to be co-opted by traditional views on science when using traditional concepts through which scientists describe what they do. Better then, it is argued, to change to another quality vocabulary. My argument is that the reconstruction above is made in a way that it can accommodate different views on science, and it particularly incorporates the important action and practice dimensions of participatory and action research. All types of scientific approaches need to confront the fundamental issues that these quality concepts are dealing with: trustworthiness through a satisfactory degree of validity, objectivity, and reliability.

On the other hand, institutionalized use of traditional concepts means the discourse on quality is not on the same terms but often is a kind of guerilla war on dominant conceptual understanding. In trying to understand the traditional concept in new more suitable ways for participatory and action research, the risk is that it is confusing and difficult to understand because of the existing ingrained understanding. In the experience of this author, traditional textbook understanding can easily make people impregnable from other understandings of quality. For example, the role of participatory and action research in basic textbooks like Bryman (2016) is rudimentary, or near to awkward. Probably because of such textbook authors, participatory and action research can be seen as peripheral, deficient, or awkward from the point of view of their conception of excellent research. On the other hand, another widely 


\section{Scientific Excellence in Participatory and Action Research: Part II. Rethinking Objectivity and Reliability Erik Lindhult}

used introductory textbook in the qualitative research field, by Merriam and Tisdell (2016), has included in its new fourth edition a short introduction to action research, which it describes as approaches "that have become increasingly popular in the last few years".

In making conceptual moves in traditional discourses on scientific excellence, I have tried to clarify in what ways participatory and action research, in comparison with other research approaches, has certain quality opportunities and benefits, and also limitations and shortcomings. It can expand the repertoire of strategies for promoting validity and reliability developed in the qualitative research field (e.g., see the eight strategies identified by Merriam and Tisdell [2016]) when more active and participatory stances are recognized as enabling scientific excellence. At the same time, one should not conceal the fact that, many times, it is not so easy to realize them in a concrete research practice. There is also a need to pay attention to inherent limitations and deficiencies within participatory and action research, for example, that participation is time consuming, sometimes frustrating, and can create political tensions, and that, in many contexts, it is not the most suitable type of research approach. Collaborative and action research takes into account a broader spectrum of knowledge forms and value dimensions, but it increases the complexity of the research role and research work. In addition, attempts to satisfy the knowledge needs of several parties can often lead to more work and more dilemmas.

In order to fully integrate participatory and action research in the scientific community, there is a need to recognize the valuable role of the researcher as learner, as collaborator, and as participant in knowledge creation and improvement. To is a need to recognize the role of collaborative, active, and participative dimensions in science and learning in general in the scientific inquiry process. There is also an important need to go on reconceptualizing science as well as doing science in different ways, showing that other understandings and practices of science and ways of being scientific are worthwhile and fruitful (Eikeland, 2012). Collaborative and action research in the process of mainstreaming may opt for integration and hybridization with other research approaches, designs, and methods in many different ways in the motley tapestry of science.
Through the mainstreaming of participatory and action research, it will be less of a black sheep in the family of social science methodology, and maybe also somewhat less a "saving angel" bringing relevance and democracy to an ivory-towerish and elitist academic community. But participatory and action research can start to feel more at home and welcomed in the academy as one among a plurality of relatives, be it close sisters and brothers or more distant cousins. The choice of participatory and action research will be more based on situated judgement in each research program and project on the comparative advantage of participatory and action research as research design, often in the grey zone of relative degrees of participatory, action, and practice orientation.

\section{About the Author}

Erik Lindhult $(\mathrm{PhD})$ is a Senior Lecturer in Innovation Management and Entrepreneurship at Mälardalen University in Sweden. He received his doctoral degree in Industrial Management from the Royal Institute of Technology in Stockholm, in the area of Scandinavian dialogue democratic approach to innovation and action research. His main area of research is participatory, collaborative, and democratic innovation and change management, as well as entrepreneurship for a sustainable development of society. His research interests also involve collaborative research methodologies, including action research and interactive research. He has been involved in a wide range of collaborative R\&D projects in the private, public, and cooperative sectors, in areas such as organizational development, incubator and science park development, service innovation, societal entrepreneurship, sustainable innovation, and school development. He is a board member of the Swedish Participatory Action Research Society (SPARC) and the Swedish Interactive Research Association (SIRA), as well as an expert advisor to the EU SWAFS Horizon 2020 research committee. 


\section{Scientific Excellence in Participatory and Action Research: \\ Part II. Rethinking Objectivity and Reliability Erik Lindhult}

\section{References}

Alvesson, M., \& Sandberg, J. 2013. Constructing Research Questions: Doing Interesting Research. Los Angeles: SAGE. https://dx.doi.org/10.4135/9781446270035

Argyris, C., \& Schön, D. 1978. Organizational Learning: A Theory of Action Perspective. Reading, MA: Addison Wesley.

Aristotle. 1980. The Nicomachean Ethics. Oxford: Oxford University Press.

Bacon, F. 1960. The New Organon. Indianapolis, IN: Bobbs-Merrill.

Brown, J. R. 1996. The I in Science. Oslo: Scandinavian University Press.

Bryman, A. 2016. Social Research Methods (5th ed.). Oxford: Oxford University Press.

Coghlan, D. 2016. Retrieving a Philosophy of Practical Knowing for Action Research. International Journal of Action Research, 12(1): 84-107.

Coghlan, D., \& Brannick, T. 2014. Doing Action Research in Your Own Organization. London: SAGE.

Dewey, J. 1929. The Quest for Certainty: A Study of the Relation of Knowledge and Action. New York: Minton, Balch \& Company.

Dewey, J. 1938. Unity of Science as a Social Problem. In J. A. Boydston (Ed.) (2008), John Dewey, The Later Works, Volume 13. Experience and Education, Freedom and Culture, Theory of Valuation, and Essays: 271-280. Carbondale, IL: Southern Illinois University Press.

Dewey, J. 1939a. Logic: The Theory of Inquiry. London: George Allen \& Unwin Ltd.

Dewey, J. 1939b. Creative Democracy: The Task Before Us. In J. A. Boydston (Ed.) (2008), John Dewey, The Later Works, Volume 14 224-230. Carbondale, IL: Southern Illinois University Press.

Eikeland, O. 2006. Validity of Action Research and Validity in Action Research. In K. A. Nielsen \& L. Svensson (Eds), Action and Interactive Research: Beyond Practice and Theory: 193-240. Maastricht: Shaker Publishing.

Eikeland, O. 2008. The Ways of Aristotle: Aristotelian Phronesis, Aristotelian Philosophy of Dialogue, and Action Research. Berlin: Peter Lang.

Eikeland, O. 2012. Action Research: Applied Research, Intervention Research, Collaborative Research, Practitioner Research, or Praxis Research? International Journal of Action Research, 8(1): 9-44.

Florin, U., \& Lindhult, E. 2015. Norms and Ethics: Prerequisites for Excellence in Co-production. Paper presented at HSS-2015, SIRA/SPARC Track on Participatory Research, May 28-29, 2015, Kalmar, Sweden.

Follett, M. P. 1930. Creative Experience. London: Longmans, Green and Co.

Foucault, M. 1984. What is Enlightenment? In P. Rabinow (Ed.), The Foucault Reader: 32-50. New York: Pantheon Books.

Gadamer, H.-G. 1975. Truth and Method. New York: Crossroad.

Gustavsen, B. 1986. Social Research and Participative Dialogue. In F. Heller (Ed.), The Use and Abuse of Social Science: 143-156. London: SAGE.
Gustavsen, B. 1992. Dialogue and Development: Theory of Communication, Action Research and the Restructuring of Working Life. Assen/Maastricht: Van Gorcum.

Gustavsen, B. 2003. New Forms of Knowledge Production and the Role of Action Research. Action Research, 1(2): 153-164. https://doi.org/10.1177/14767503030012003

Gustavsen, B. 2017. Action Research and the Promotion of Democracy. International Journal of Action Research, 13(2): 101-111.

Habermas, J. 1984. The Theory of Communicative Action, Vol I. London: Polity Press.

Habermas, J. 1989. The Structural Transformation of the Public Sphere: An Inquiry into a Category of Bourgeois Society. Cambridge, MA: The MIT Press.

Hatchuel, A. 2002. Towards Design Theory and Expandable Rationality: The Unfinished Program of Herbert Simon. Journal of Management and Governance, 5(3/4): 260-273.

https://doi.org/10.1023/A:1014044305704

Herr, K., \& Anderson, G. L. 2015. The Action Research Dissertation: A Guide for Students and Faculty. Thousand Oaks, CA: SAGE.

Heron, J. 1996. Co-operative Inquiry: Research into the Human Condition. London: SAGE.

Kant, I. 1991. Political Writings. Cambridge: Cambridge University Press.

Kant, I. 1998. Critique of Pure Reason. Cambridge: Cambridge University Press.

Kolb, D. A. 2015. Experiential Learning (2nd ed). Upper Saddle River, NJ: Pearson Education.

Lewin, K. 1946. Action Research and Minority Problems. Journal of Social Issues, 2(4): 34-46. https://doi.org/10.1111/j.1540-4560.1946.tb02295.x

Lincoln, Y., \& Guba, E. 1985. Naturalistic Inquiry. Newbury Park, CA: SAGE.

Lindhult, E. 2004. Achieving Quality in Action Research: A Matter of Judgment. Paper presented at the 20th EGOS Colloquium, July 1-3, 2004, Ljubljana, Slovenia.

Lindhult, E. 2008. Att bedöma och uppnå kvalitet i interaktiv forskning. In B. Johannisson, E. Gunnarsson, \& T. Stjernberg (Eds.), Gemensamt kunskapande - den interaktiva forskningens praktik. Växjö, Sweden: Växjö University Press.

Lindhult, E. 2015. Towards Democratic Scientific Inquiry? Participatory Democracy, Philosophy of Science and the Future of Action Research. In E. Gunnarsson, H. P. Hansen, \& B. Steen Nielsen (Eds.), Action Research for Democracy - Intervening in the Current Crisis: New Ideas and Perspectives from Scandinavia. London: Routledge.

Lindhult, E. 2019. Scientific Excellence in Participatory and Action Research: Part I. Rethinking Research Quality. Technology Innovation Management Review, 5(9): 6-21. http://doi.org/10.22215/timreview/1237

Merriam, S. B., \& Tisdell, E. J. 2016. Qualitative Research: A Guide to Design and Implementation. San Francisco, CA: Jossey-Bass. 


\section{Scientific Excellence in Participatory and Action Research: Part II. Rethinking Objectivity and Reliability Erik Lindhult}

Owen, R., Macnaghten, P., \& Stilgoe, J. 2012. Responsible Research and Innovation: From Science in Society to Science for Society, With Society. Science and Public Policy, 39(6): 751-760.

https://doi.org/10.1093/scipol/scs093

Pålshaugen, Ö. 2002. Discourse Democracy at Work: On Public Spheres in Private Enterprises. Concepts and Transformation, 7(2): 141-192.

https://doi.org/10.1075/cat.7.2.03pal

Reason, P. 1994. Three Approaches to Participatory Inquiry. In N. Denzin, \& Y. Lincoln (Eds.), Handbook of Qualitative Research: 324-339. Thousand Oaks, CA: SAGE.

Reason, P. 2006. Choice and Quality in Action Research Practice. Journal of Management Inquiry, 15(2): 187-203. https://doi.org/10.1177/1056492606288074

Rorty, R. 1979. Philosophy and the Mirror of Nature. Princeton, NJ: Princeton University Press.

Schillo, R. S., \& Robinson, R. M. 2017. Inclusive Innovation in Developed Countries: The Who, What, Why, and How. Technology Innovation Management Review, 7(7): 34-46.

https://doi.org/10.22215/timreview/1089

Schön, D. 1983. The Reflective Practitioner: How Professionals Think in Action. Aldershot, UK: Avebury.

Simon, H. A. 1996. The Sciences of the Artificial (3rd ed). Cambridge, MA: MIT Press.

Solomon, J. R. 1998. Objectivity in the Making: Francis Bacon and the Politics of Inquiry. Baltimore, MD: Johns Hopkins University Press.

Susman, G. I., \& Evered, R. D. 1978. An Assessment of the Scientific Merits of Action Research. Administrative Science Quarterly, 23(4): 582-603.

https://doi.org/10.2307/2392581

Svensson, L., Ellström, P.-E., \& Brulin, G. 2007. Introduction - On Interactive Research. International Journal of Action Research, 3(3): 233-249.

Westbrook, R. 1995. Action Research: A New Paradigm for Research in Production and Operations Management. International Journal of Operations \& Production Management, 15(12): 6-20.

https://doi.org/10.1108/01443579510104466

Zagorin, P. 2001. Francis Bacon's Concept of Objectivity and the Idols of the Mind. The British Journal for the History of Science, 34(4): 379-393.

https://doi.org/10.1017/S0007087401004411

Citation: Lindhult, E. 2019. Scientific Excellence in Participatory and Action Research: Part II. Rethinking

Objectivity and Reliability. Technology Innovation

Management Review, 9(5): 22-33.

http://doi.org/10.22215/timreview/1238

Keywords: action research, participatory research, objectivity, reliability 


\title{
How to Develop an Impactful Action Research Program: Insights and Lessons from a Case Study Victoria Lakiza and Isabelle Deschamps
}

\author{
(6 Experience without theory is blind, but theory without ") \\ experience is mere intellectual play.
}

Immanuel Kant (1724-1804)

Philosopher

\begin{abstract}
Action research holds great potential for helping bridge the gap between research and practice. By working closely together, researchers and practitioners can develop tangible customized solutions based on research findings. It becomes possible to go beyond generic best practices that might need adaptation for successful implementation and use, or that may not apply at all in some contexts. In this article, the mechanisms through which action research can create the desired change and impact in both industry and academia are illustrated by describing the relevance and contribution of the main steps of a longitudinal action research program in a Canadian manufacturing company. The authors share four guiding principles and six success factors that were revealed intuitively in the course of this multi-year research program. Their hope is to contribute to a better understanding of how it is possible to develop an adaptive action research methodology to increase the potential for research relevance and organizational change.
\end{abstract}

\section{Introduction}

The research-practice gap is a major missed opportunity for both academia and industry. On one hand, "theorists often write trivial theories" (Weick, 1989) as they are more concerned with methodological strictures than usefulness (Lindblom, 1987). On the other hand, no matter how relevant the work of theorists is, practitioners often disregard it as too theoretical to be applicable in their own precise situation. Rousseau (2006) refers to the research-practice gap as "the failure of organizations and managers to base practices on best available evidence". It results in a combination of two limitations of traditional research:

1. Difficulties experienced by researchers in translating research findings into tangible solutions in industry.

2. The incapacity of managers in using research findings to improve their organizations.

The implication of practitioners in the research can help narrow this gap (Schein, 1999). This can be done through action research (Saunders et al., 2011). The goal of action research is not to test hypotheses or develop generalizable results (Hlady-Rispal, 2016; Saunders et al., 2011). Rather, it serves to deepen researchers' understanding of complex human interactions and helps them develop new research propositions and conceptual frameworks to be tested and validated in future research (Saunders et al., 2011). In doing so, action research not only serves the research community but also builds bridges to close the research-practice gap by working on the two limitations mentioned above, as follows:

\section{Better translation of research findings into tangible} solutions. Action research can have a powerful impact on the relevance of research and the transformation of organizations. By working in collaboration with practitioners on specific challenges they encounter, the proposed solutions are likely to be better adapted to the company's needs and constraints, taking into account the mechanisms necessary for their successful implementation. In addition, their adoption rate is likely to be higher, as having participated in their development, the employees might feel more comfortable in implementing and using them. 


\section{How to Develop an Impactful Action Research Program: Insights and Lessons from a Case Study Victoria Lakiza and Isabelle Deschamps}

\section{Better use of research findings by the managers. Ac-} tion research involves the recipients of the research results directly in the research program itself. As participants of the research process, the managers become more familiar with the research language and more open to experiment with and even implement some new practices.

Although action research presents clear benefits to close the research-practice gap, there is little information available on how to design an action research intervention that can be truly beneficial for researchers and practitioners. The goal of this article is to provide a tangible example of how this can be done by sharing mechanisms of the design of a longitudinal action research program. This article describes the main steps of the action research program in a Canadian manufacturing company along with guiding principles and success factors that were used to make it a success by creating the desired change and impact in industry and academia.

The case company is briefly presented in the next section and followed by a summary of the methodology used in the action research project. Four guiding principles were developed based on the applied research experience and two decades of practitioner background of the senior research supervisor (the second author of this article) and were used to design a research project relevant for the case company. These guiding principles are described in the subsequent section of this article. What follows is a description of how these principles were applied over the course of the three-year case study and what were the success factors. The contributions of this article are discussed in the Conclusion.

\section{Case Company}

The case company is a specialized manufacturer providing customized and specialized products to a wide range of industries. Since its founding in 1950, the company has grown organically, namely through the acquisition of competitors. The founder was the company's main driver of innovation for most of its history before retiring less than a decade ago. While he brought the entrepreneurial spirit, the second generation, which is still in charge, focused on operations and acquisitions. The third generation, which is currently joining the top management ranks, is trying to rejuvenate the company's innovation capabilities. These efforts are in response to a steady decline in sales in well-established markets and product lines, which prompted the company to embark on a major rejuvenation jour- ney. This journey included a revised and more explicit innovation strategy. In this context, the research team was solicited to support the innovation and product development team in several aspects of the development and implementation of innovation management processes, practices, and tools. It resulted in a three-phase longitudinal action research program (Lakiza, 2018).

\section{Methodology}

The research program on innovation management was performed over three phases, each with a one-year duration and a total of seven field researchers and one academic supervisor. Each of the seven research projects had a dual objective: 1) knowledge transfer from academia to industry and 2) knowledge development from the field back to the literature. For the research program to be truly fruitful in both regards, it had to be adaptive, both to the discovery made by the researchers and to the learning journey of the management team. Consequently, the orientation and focus of interest, variables and organizational dynamics of interest, literature background, research objectives, and management deliverables were all revisited between each research phase.

The examples illustrated in this article come from one of the three researchers of phase II, the first author of this article. This specific research project was on the relationship between the company's organizational culture, its performance measurement systems, and its innovation capabilities. As part of the dual objective, the researcher also had the mandate of proposing key performance indicators (KPIs) to measure the success of the company's innovation endeavours.

This research project was conducted by two practitioners: the supervisor and the researcher herself have 10 years of experience in change management. Hence, this research was driven by problems observed in the company under study during Phase I of the research program, with the main interest of achieving an in-depth understanding of complex organizational dynamics. The inductive, theory-building approach was chosen for this research program as it is more appropriate in such circumstances (Saunders et al., 2011). It implies an intimate understanding of the research context and a more flexible research structure (Saunders et al., 2011).

With a goal of developing new understanding based on field observations, the grounded theory research strategy was chosen as it is appropriate for an iterative 


\section{How to Develop an Impactful Action Research Program: Insights and Lessons from a Case Study Victoria Lakiza and Isabelle Deschamps}

interpretative process with the goal of making sense of data and raising it to a higher conceptual level (Saunders et al., 2011). This strategy can provide particularly rich results in a context where there is a desire to close the research-practice gap by testing different theoretical approaches in practice, observing their consequences, and adjusting the approach to the specific context of a case company.

An inductive approach with the goal of making sense of the data requires solid triangulation to corroborate research findings within a study (Bryman, 2016). Multiple sources of evidence are also required to build a robust case study with reliable outcomes (Saunders et al., 2011; Stake, 2000; Yin, 2013). For these reasons, seven data collection methods were used in this research project: a review of prior data, document review, interviews, workshops, a questionnaire, observations, and meetings. The use and relevance of each of the data collection methods are explained in the success factors section.

Qualitative field research such as this one involves continuous iteration between data collection and data analysis (Strauss \& Corbin, 1998). Hence, there is no specific beginning to data analysis (Stake, 2000), which evolves continually informing the next data collection steps trough coding and memoing typical of the grounded research methodology (Holton, 2010).

\section{Guiding Principles}

When doing field research full time at a specific company, it can be difficult to know how to find the right balance between being a researcher and being part of the action. To do so, the researchers followed four guiding principles that were coined based on the combination of their previous research and industry experience: build trust, be part of the team, understand the system, and iterate. These principles helped the research stay on track with regards to both learning objectives: helping develop new theoretical knowledge useful for research and transferring relevant management knowledge to support the company in developing their innovation capabilities.

\section{Build trust... to increase openness}

The first and most important thing to do when joining a company as an action researcher is to build trust. Trust is what allows the researcher to witness a company's reality from within, providing them with a richer data set than what is possible to obtain by traditional surveying techniques. When a relationship of trust is estab- lished with the company's employees and other key stakeholders, they will elaborate more on the subjects of interest, thus answering crucial questions that the researcher did not know they had to ask. The employees will also feel more comfortable in providing genuine feedback on the researcher's recommendations thus helping develop more appropriate solutions. Moreover, when the employees believe that they themselves contributed to the proposed solutions, they are more likely to fully collaborate in implementing and appropriating the solutions resulting from the research partnership. They might also be more open to knowledge transfer from academia that otherwise often has the reputation of being "too theoretical to work in the real world".

Building trust takes time. Moreover, it takes time to understand organizational dynamics and their evolution (Hlady-Rispal, 2016). Thus, to capitalize on action research, it is better to take as much time as possible. Longitudinal research can help limit threats to the reliability of the research findings by reducing participant error and bias, as well as observer bias (Robson, 2002; Saunders et al., 2011). It also helps mitigate several threats to the validity of the research findings such as history, instrumentation, and maturation (Robson, 2002; Saunders et al., 2011).

\section{Be part of the team... to understand the culture}

A company's culture has an important impact on the success of its projects and the suitability of any best practices (Brodeur et al., 2017; Katzenbach \& Harshak, 2011; Katzenbach et al., 2019; Tellis et al., 2009). The culture is often more visible through its informal channels where one must pay attention to its "quiet, sometimes hidden, manifestations" (Schein, 2009). When people feel observed, their actions may be influenced by what they think the observer wants to see or what they believe will make them look better (Robson, 2002). The researcher must become part of the team to be able to access more genuine behaviours and data. Seeing candid interactions among stakeholders helps understand the paradigms that influence their actions (Katzenbach et al., 2019). It becomes possible to uncover deeper root causes of the various challenges an organization is facing. These challenges may be unexpected and different from existing literature knowledge.

An important added value of a researcher in a company is the perspective that they can provide to the company's stakeholders who are too often blinded by the day-to-day operations. However, to keep this advantage, the researcher must be careful not to get themselves pulled into day-to-day emergencies. 


\section{How to Develop an Impactful Action Research Program: Insights and Lessons from a Case Study Victoria Lakiza and Isabelle Deschamps}

\section{Understand the system... to focus on the right change levers}

Being part of the team also helps gain a more comprehensive understanding of the system and its pressures (Horowitz, 2014), which is paramount in order to fully grasp the issues and factors influencing the subject of study. A deeper understanding of challenges faced in industry provides an opportunity to go beyond best practices by developing fully customized tangible solutions while bringing back new knowledge to academia. More importantly, it can help reduce the chances of developing localized or short-term solutions at the expense of the bigger picture and the long-term goals.

\section{Iterate... to bridge the gap between research and practice} Qualitative field research is a highly iterative process (Strauss \& Corbin, 1998). "Theory and practice flow in parallel with continuous literature review, data collection, and analysis and interpretation feeding one another" (Lakiza, 2018). This continuous interaction between knowledge transfer and knowledge development creates a true bilateral conversation between research and industry, thus helping bridge the gap between them. This iterative process, which has no precise beginning to data analysis (Stake, 2000), can be divided into three parts: observe, consolidate and validate (see Figure 1).

\section{Putting the principles into action}

Observing in action gives access to crucial information that might not be captured by regular research methods (Saunders et al., 2011). Field research provides plenty of opportunities to observe in formal and informal contexts. The informal observations made during lunch breaks or casual discussions among employees are particularly interesting as they may bring up perspectives that have no place in the company's formal setting but may be crucial to the study (Katzenbach et al., 2019).

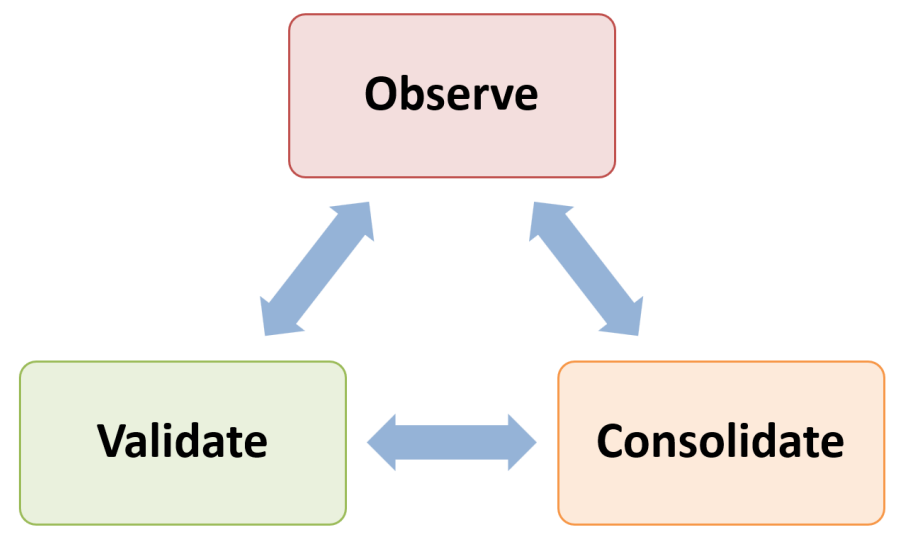

Figure 1. A continuous iterative process: observe, consolidate, validate
Action research provides access to a large amount of data that must be regularly consolidated in order to avoid getting lost. In addition to data analysis, consolidation implies raising the data to a higher conceptual level to help make sense of it (Holton, 2010). During the research, data consolidation helps regularly redirect the next steps based on how the project unfolds, to confirm or infirm various observations and to assess what else the researcher must learn through observation or literature. At the end of the research project, data conceptualization helps build frameworks and leads to new research propositions (Suddaby, 2006).

When collecting and consolidating data from the field, there is often a need to validate certain observations that could be interpreted differently. Validation can be done by returning to the literature for additional knowledge or by triangulating data through various data collection methods. In qualitative field research, triangulation is essential to achieve reliable results (Saunders et al., 2011; Stake, 2000; Yin, 2013).

Based on this case study and on the cumulative insights from their experience over the three years of the action research program, the authors propose a summary of the potential benefits of each guiding principle cited above, for both industry and research, in Table 1.

\section{Six Success Factors for an Action Researcher to Implement a Relevant Methodology}

Inductive action research has to be carefully implemented through an explicit research methodology, using multiple and complementary data collection and analysis methods. In this section, the main steps of the field research are shared, illustrating how each of the four guiding principles described in the previous section was applied, implemented, and adapted over time, as summarized in Table 2.

The researchers' applied research and professional experience, as well as their open-minded and flexible attitude, played a crucial role in the successful deployment of this multi-faceted action research methodology. Such a methodology requires multiple adjustments to the responsiveness of the management team under study during the longitudinal project. In retrospect, the steps taken in this research project are grouped by six success factors (described below) that helped the action researchers put the odds on their side when faced with ambiguity and organizational complexity. These factors were derived from the researchers' cumulative experience, both from prior research and change management 


\section{How to Develop an Impactful Action Research Program: Insights and Lessons from a Case Study Victoria Lakiza and Isabelle Deschamps}

Table 1. Benefits of the guiding principles to industry and research

\begin{tabular}{|c|c|c|}
\hline Principle & Benefits to Industry & Benefits to Research \\
\hline \multirow[t]{2}{*}{ Build trust } & $\begin{array}{l}\text { - Access to customized solutions based on } \\
\text { state of art literature }\end{array}$ & $\begin{array}{l}\text { - Access to higher quality data that could not be } \\
\text { obtained through surveying "from a distance" }\end{array}$ \\
\hline & $\begin{array}{l}\text { Higher levels of adoption of processes, } \\
\text { methods, and tools coming from } \\
\text { academia }\end{array}$ & $\begin{array}{l}\text { - Opportunity to uncover new research topics of } \\
\text { interest to industry by finding out "what we don't } \\
\text { know that we don't know" }\end{array}$ \\
\hline Understand the system & $\begin{array}{l}\text { Help stakeholders better connect to each } \\
\text { other and understand how their work fits in } \\
\text { the bigger picture }\end{array}$ & $\begin{array}{l}\text { Possibility to go beyond generic best practices, as a } \\
\text { more holistic understanding of a specific context can } \\
\text { help uncover new inhibiting/success factors }\end{array}$ \\
\hline Be part of the team & Access to specialized knowledge & $\begin{array}{l}\text { Access to root causes and deeper issues related to a } \\
\text { specific research topic }\end{array}$ \\
\hline \multirow{3}{*}{$\begin{array}{l}\text { Iterate } \\
\text { (Observe-Consolidate - } \\
\text { Validate) }\end{array}$} & $\begin{array}{l}\text { Progressively help stakeholders uncover } \\
\text { their blind spots through validation }\end{array}$ & $\begin{array}{l}\text { - Uncover blind spots that are difficult to access } \\
\text { with regular research methods }\end{array}$ \\
\hline & & $\begin{array}{l}\text { - (Re)direct research based on needs and } \\
\text { continuous findings }\end{array}$ \\
\hline & \multicolumn{2}{|c|}{$\begin{array}{l}\text { Close the gap between research and practice through continuous interaction between knowledge } \\
\text { transfer and knowledge development }\end{array}$} \\
\hline
\end{tabular}

Table 2. Application of the guiding principles throughout the main case study steps

\begin{tabular}{|c|c|c|c|c|}
\hline Case Study Steps & Build Trust & $\begin{array}{l}\text { Understand } \\
\text { the System }\end{array}$ & $\begin{array}{l}\text { Be Part of } \\
\text { the Team }\end{array}$ & Iterate \\
\hline \multicolumn{5}{|l|}{ Analysis of data collected during phase I } \\
\hline \multicolumn{5}{|l|}{ Preliminary system mapping } \\
\hline \multicolumn{5}{|l|}{ Project charter interviews } \\
\hline \multicolumn{5}{|l|}{ Support in strategic planning workshop development } \\
\hline \multicolumn{5}{|l|}{ Support of the fellow researchers' projects } \\
\hline Workshop on the stakeholders' innovation KPI requirements & & & & \\
\hline \multicolumn{5}{|l|}{ System mapping workshop } \\
\hline Innovation Quotient questionnaire & & & & \\
\hline Feedback discussions following a draft innovation KPIs proposal & & & & \\
\hline
\end{tabular}




\section{How to Develop an Impactful Action Research Program: Insights and Lessons from a Case Study Victoria Lakiza and Isabelle Deschamps}

experience, and from insights gained during this multiyear case study.

\section{Be prepared and informed}

This specific case study was part of phase II of the longitudinal field study in the case company. Therefore, before starting the research in the field, it was possible to access data and analysis from phase I as well as perform a preliminary literature review. A preliminary stakeholder mapping exercise inspired by FSG's Guide to Actor Mapping (Gopal \& Clarke, 2016) was also carried out with the goal to understand key stakeholder dynamics within the company as well as the company's reality and positioning within its industry. This preparation helped the researcher start conversations, build trust, and more easily integrate various teams during the first weeks in the field.

\section{Be clear and manage expectations}

For a successful action research partnership with a company, clear expectations on the researcher's role and mandate must be set and shared with the main stakeholders. To do so, a first draft of a project charter was developed and shared with the main stakeholders during individual interviews. Interviewing is a key tool for an action researcher as it "is the main road to multiple realities" (Stake, 2000) that might be invisible otherwise (Lakiza, 2018). It allows one "to find out from [people] those things we can't observe" (Patton, 1987). The interviews started with an introduction of the researcher's background to help build trust (Patton, 1987). The semi-structured interviews with open-ended questions were complemented with probing and follow-up questions to encourage the participants to elaborate (Denzin \& Lincoln, 2008; Lakiza, 2018; Stake, 2000). This approach favoured open and free discussion (Esterberg, 2002; Kvale, 1996), which generated a rich initial data set and helped build trust. Moreover, a collection of interviews helps build a better holistic understanding of a system than what any one individual can observe (Stake, 2000).

\section{Be involved with what matters to the company's em- ployees}

To become part of the team, the researcher must seize opportunities and get involved with projects that might be beyond the research scope but that are important to the company's key stakeholders. Visioning and strategic planning exercises were ongoing at the partner company and the VP of Engineering was interested in obtaining some help to align the process and develop strategic planning workshops with his directors and managers. In addition to contributing to trust building, developing and helping run these workshops and meetings was critical to the researcher's understanding of the company's culture by providing access to a more genuine work dynamic.

Throughout the 11 months on site, several other opportunities were taken to support the company's projects, including the research projects of the two fellow phase II researchers. Special care was taken to not get drawn into the company's day-to-day operations. When asked to do something beyond the research scope, the researcher always asked herself if she had specific knowledge and skills to contribute or is this something that would normally be done by a regular employee.

\section{Be patient, work in small learning cycles}

After two months of gathering data through interviews, meetings, and observation of the company's daily life, it was time for a first big consolidation and validation exercise. For this purpose, a workshop on the stakeholders' innovation KPI requirements was developed. During the workshop, a preliminary consolidation and analysis of some of the data collected so far were presented to see what resonated and how. Moreover, more detailed discussions were held during the workshop to better understand what kind of innovation KPIs can be useful to the employees in their given contexts. The exercise also helped bring the stakeholders onto the same page given that, during individual interviews, some incomplete and diverging perspectives had been noted.

This consolidation exercise raised many questions, sending the researcher for validation in the literature and for further observations through additional individual discussions. In the same time period, the development of ideas for innovation KPIs that might be relevant to the case company began. This process brought up the need to validate what is feasible in the company's context given its existing systems as well as its various communication processes. A system mapping workshop was developed to better understand the formal and informal communication tools, methods, and processes linked to innovation with the key stakeholders. This exercise was not only useful to the researcher but also to the company's stakeholders, most of whom do not have a good understanding of the system beyond their work group or department and do not fully understand how their everyday work fits in the bigger picture. The mapping exercise helped uncover structural problems they did not know they had. 


\section{How to Develop an Impactful Action Research Program: Insights and Lessons from a Case Study Victoria Lakiza and Isabelle Deschamps}

\section{Be flexible}

After four months in the field, it was clear to the research group that the company's organizational culture was not favourable to innovation. However, some of the key stakeholders strongly disagreed with this interpretation. As the research group believed that the company must address some of its cultural challenges to be able to improve its innovation management capabilities, it was necessary to validate the cultural assessment using an objective and proven tool. To do so, the researcher chose to administer the Innovation Quotient questionnaire developed by Rao and Weintraub (2013). This questionnaire assesses how innovative a company's culture is based on six building blocks. Respondents of different departments and hierarchical levels were able to choose between two ways of taking the survey: self-administered online or interviewer-administered in person. The latter had the potential for follow-up questions and discussions contributing additional insights. The results were clear and supported the researchers' initial assessment. This time, the stakeholders that initially strongly disagreed with this assessment were ready to face the facts. This helped them adjust their approach to improving innovation management at the company.

After five months, with enough understanding of the company's context, it was time to prepare a first proposal of innovation KPIs. This provided enough time to gather feedback, to figure out what is more appropriate in the context, and to iterate with an improved proposal. The feedback was mostly gathered through individual interviews. Several work sessions with a few key stakeholders were held to better adapt some of the KPIs to the company's needs and capabilities.

\section{Be open to unexpected results}

Several months later, the researcher finished her mandate, leaving the company with a proposal of five innovation KPIs fully customized to the company's context and current needs. The proposed KPIs were different from what could have initially been expected and, more importantly, answered a different need than what was initially expressed by the company (Lakiza \& Deschamps, 2018). While the original mandate asked for KPIs to measure the success of innovation endeavours, the company's innovation processes were not mature enough to be measured and its culture was not open enough to accept such KPIs. The final KPIs had the goal of helping the company develop behaviours more favourable to innovation in order to ultimately increase the maturity of their innovation process, focusing on what they currently needed and what could help them move forward as opposed to providing tools that they were not ready to use (Lakiza \& Deschamps, 2018). This result was unexpected, but very useful. It is a perfect illustration of how action research can help overcome the second limitation of traditional research (the incapacity of managers in using research findings to improve their organizations) and lead to better acceptance and use of research findings by the managers.

There was nothing on the importance of process maturity in the innovation performance measurement literature (Lakiza, 2018). This link would have been difficult to make if the researcher was not present full time at the company collaborating with a fellow researcher who did a process maturity assessment of that company's innovation processes. Such an assessment was also not planned for in his initial research plans; its need came up through the iterative process. "To discover an unexpected connection is to discover a new set of implications" (Weick, 1989). This opens doors to a plethora of new questions and research potential. The link with process maturity had a substantial impact on the research referenced in this article and its conclusions, becoming an integral part of the conceptual framework and propositions issued from the research project (Lakiza, 2018). This shows how the action research project was useful in overcoming the first limitation of traditional research (difficulties experienced by researchers in translating research findings into tangible solutions in industry) by producing more relevant research findings both for practice and academia.

The iteration principle was also applied at a larger scale to the different phases of the longitudinal research. During each phase, the understanding of the company's context and its real needs were deepened. The projects proposed for the next phase were adjusted accordingly. The work done during phase III was very different from what could have initially been forecasted based on phase I discussions. Indeed, the company's real needs were different from those expressed by its stakeholders. In addition, the lack of innovation management knowledge led its managers to seek tools and processes that were either not appropriate for them or that they were not ready to use.

\section{Conclusion}

In social science, the systems under study are open rather than closed (Henshel, 1971) and the correspondence between concepts and observables is loose (Weick, 1989). Thus, the contribution of social science "does not lie in validated knowledge, but rather in the suggestion of relationships and connections that had 


\section{How to Develop an Impactful Action Research Program: Insights and Lessons from a Case Study Victoria Lakiza and Isabelle Deschamps}

previously not been suspected, relationships that change actions and perspectives" (Weick, 1989). The central contribution of this article is to illustrate, through a case study, how it is possible to achieve this through action research. The authors suggest that such impacts can be attained by applying the four guiding principles described herein and systematically adapting them over time using the six success factors described and illustrated in the case study above.

As presented in Table 1, action research can provide multiple benefits to industry and academia, bridging the gap between these two worlds that live in different paradigms and speak different languages. Based on the field experience described herein, it is concluded that the application of these four guiding principles can help make an action research project useful to both these worlds. Several examples of how they were applied throughout the action research project in the case company were illustrated in this article. The guiding principles are derived from the authors' past and recent experience, and by no means are meant to be exhaustive. A comprehensive survey of what makes action research valuable, and how to better implement it and adapt the research methodology to the research context, would be of interest.

Moreover, this article provides insights to researchers and practitioners that would be tempted to learn more about and eventually apply longitudinal action research. It offers tangible recommendations for the implementation of the proposed guiding principles (see Table 2) in the form of steps and ways to behave and interact as a field researcher. In order to have an impactful research methodology that would provide value to academia and industry, the researchers must adapt and iterate as the case study unfolds. The authors discussed their methodology and, based on their cumulative experience, suggest six success factors, related to a general code of conduct to use Action Research properly: Be prepared, Be clear, Be involved, Be patient, Be flexible, and Be open.

The main limitation of this article is the fact that it is mainly based on the authors' experience and insights gained from a case study, although the conclusions and recommendations are supported by many proponents of action research cited in this article. The authors consider this article as an exploratory phase of a systematic search for factors to be applied for impactful action research. It would be important to support the propositions herein with a more extensive literature review and additional field studies using action research methodology in multiple industrial contexts. This would help develop more robust and generic guiding principles, and potentially success factors adaptable to the specific action research objectives and the profile of the company under study.

Another limitation is that the article outlines the benefits of action research when properly applied, but neglects to discuss at length its risks, costs, and limitations. Besides the benefits of the application of these guiding principles and success factors, this approach has inherent additional costs that were not the subject of discussion in this article, such as a longer data collection and analysis process and a stronger implication of the researcher in the process, not only in terms of their time, but also in terms of personal involvement. Furthermore, action research is not for everyone: beyond the researcher's experience and skills necessary to put in place the key success factors, the will and personal investment are significant. Moreover, it would be of interest to further explore the role of the researcher's background and experience, and how to develop a researcher's set of relevant skills.

The authors hope that this article can help bridge the research-practice gap by sharing tangible examples, success factors, and guiding principles that can help researchers design a productive action research project. Most importantly, the authors hope that this article and the practical experience and insights from the field that were shared will help make the value, the steps, and the success conditions of an action research project more tangible and accessible for researchers who want to try it. They also hope that the examples provided in this article can help companies see the benefits of working more with academia, notably through action research partnerships. 


\section{How to Develop an Impactful Action Research Program: Insights and Lessons from a Case Study Victoria Lakiza and Isabelle Deschamps}

\section{About the Authors}

Victoria Lakiza is a senior consultant, facilitator, and coach committed to unlocking the potential of people and organizations. She is passionate about change management, organizational transformation, and building bridges between different fields and perspectives. Victoria has a Master's degree in Industrial Engineering from Polytechnique Montreal in Canada. Her action research Master's project allowed her to deepen her knowledge and understanding of organizational change dynamics and of the role of performance measurement in promoting culture change while trying to bridge the gap between research and practice. Victoria's professional experience includes supporting a culture shift towards intrapreneurship, developing a complete performance measurement system, and managing an organizational restructuring and re-branding in an innovative engineering consulting company. Concurrently, she was co-leading a volunteer initiative aiming to accelerate sustainable innovations in organizations through the development of intrapreneurial leaders.

Isabelle Deschamps is a professional engineer, business manager, coach, and entrepreneur active in the areas of technology incubation, venture capital, intellectual property strategy, and hi-tech financing. In her 35-year career, she has been guiding innovation strategy and accompanying in both technological and organizational changes dozens of startups, SMEs, and $\mathrm{R} \& \mathrm{D}$ groups in information technologies, new materials, 3D print, cleantech, and medical devices. Isabelle is a recognized professor and researcher at HEC Montreal, ÉTS, and Polytechnique Montreal in Canada. She is a speaker and expert in technology entrepreneurship, innovation and product management, science and technology policy and ecosystems, and SME financing. Isabelle advises Canadian industrial clusters, $R \& D$ consortia, governmental agencies, and ecosystem members, such as the National Research Council Canada, Prima Quebec, Aero Montreal, and TechnoMontreal. She specializes in longitudinal and action research field studies, and she has published on the topics of technology implementation, innovation strategy and management, crisis management, open and collaborative innovation, industry research projects, and startup incubation. Isabelle is a metallurgist (Polytechnique Montreal) and holds an MBA (HEC Montreal) and a DBA (Harvard Business School) in Technology Management and Organizational Psychology.

\section{References}

Brodeur, J., Deschamps, I., \& Lakiza, V. 2017. NPD Implementation: Beyond Best Practices. Paper presented at the ISPIM Innovation Forum, Toronto, Canada, March 19-22, 2017.

Bryman, A. 2016. Integrating Quantitative and Qualitative Research: How Is It Done? Qualitative Research, 6(1): 97-113. https://doi.org/10.1177/1468794106058877

Denzin, N. K., \& Lincoln, Y. S. 2008. The Landscape of Qualitative Research. Thousand Oaks, CA: SAGE.

Esterberg, K. G. 2002. Qualitative Methods in Social Research. Boston, MA: McGraw-Hill.

Gopal, S., \& Clarke, T. 2016. Guide to Actor Mapping. Boston, MA: FSG. https://www.fsg.org/tools-and-resources/guide-actor-mapping

Henshel, R. L. 1971. Sociology and Prediction. The American Sociologist, 6(3): 213-220.

https://www.jstor.org/stable/27701765

Hlady-Rispal, M. 2016. Une stratégie de recherche en gestion. Revue Française de Gestion, 41(253): 251-266. http://doi.org/10.3166/rfg.253.251-266

Holton, J. A. 2010. The Coding Process and Its Challenges. The Grounded Theory Review, 9(1): 265-289.

Horowitz, M. 2014. The Dance of We: The Mindful Use of Love and Power in Human Systems. Amherst, MA: Synthesis Center Incorporated.

Katzenbach, J., \& Harshak, A. 2011. Stop Blaming Your Culture. strategy+business, 62: 35-42.

Katzenbach, J., Thomas, J., \& Anderson, G. 2019. The Critical Few: Energize Your Company's Culture by Choosing What Really Matters. Oakland, CA: Berrett-Koehler Publishers.

Kvale, S. 1996. InterViews: An Introduction to Qualitative Research Interviewing. Thousand Oaks, CA: SAGE Publications.

Lakiza, V. 2018. Relationships Between Performance Measurement Systems, Intrapreneurial Culture and Innovation Capabilities: A Longitudinal Field Case Study. Master's dissertation. Montreal: Polytechnique Montreal.

Lakiza, V., \& Deschamps, I. 2018. How to Develop Innovation KPIs in an Execution-Oriented Company. Technology Innovation Management Review, 8(7): 14-30. http://doi.org/10.22215/timreview/1168

Lindblom, C. E. 1987. Alternatives to Validity: Some Thoughts Suggested By Campbell's Guidelines. Knowledge, 8(3): 509-520. https://doi.org/10.1177/107554708700800305

Patton, M. Q. 1987. How to Use Qualitative Methods in Evaluation. Thousand Oaks, CA: SAGE.

Rao, J., \& Weintraub, J. 2013. How Innovative Is Your Company's Culture? MIT Sloan Management Review, 54(3): 29-37.

Robson, C. 2002. Real World Research (2nd ed.). Oxford: Blackwell Publishing.

Rousseau, D. M. 2006. Is There Such a Thing as "Evidence-Based Management"? Academy of Management Review, 31(2): 256-269. https://doi.org/10.5465/amr.2006.20208679

Saunders, M. N., Lewis, P., \& Thornhill, A. 2011. Research Methods for Business Students (5th ed.). Delhi: Pearson Education India. 


\section{How to Develop an Impactful Action Research Program: Insights and Lessons \\ from a Case Study Victoria Lakiza and Isabelle Deschamps}

Schein, E. H. 1999. Process Consultation Revisited: Building the Helping Relationship. Boston, MA: Addison-Wesley.

Schein, E. H. 2009. The Corporate Culture Survival Guide (2nd ed.). Hoboken, NJ: John Wiley \& Sons.

Stake, R. E. 2000. The Art of Case Study Research: Perspectives on Practice (2nd ed.). Thousand Oaks, CA: SAGE.

Strauss, A., \& Corbin, J. 1998. Basics of Qualitative Research: Techniques and Procedures for Developing Grounded Theory (2nd ed.). Thousand Oaks, CA: SAGE.

Suddaby, R. 2006. From the Editors: What Grounded Theory Is Not. Academy of Management Journal, 49(4): 633-642.

https://doi.org/10.5465/amj.2006.22083020

Tellis, G. J., Prabhu, J. C., \& Chandy, R. K. 2009. Radical Innovation Across Nations: The Preeminence of Corporate Culture. Journal of Marketing, 73(1): 3-23.

https://doi.org/10.1509/jmkg.73.1.003

Weick, K. E. 1989. Theory Construction as Disciplined Imagination. Academy of Management Review, 14(4): 516-531. https://doi.org/10.5465/amr.1989.4308376

Yin, R. K. 2013. Case Study Research: Design and Methods (5th ed.). Thousand Oaks, CA: SAGE.

Citation: Lakiza, V., \& Deschamps, I. 2019. How to

(cc)BY

Develop an Impactful Action Research Program: Insights

and Lessons from a Case Study. Technology Innovation

Management Review, 9(5): 34-43.

http://doi.org/10.22215/timreview/1239

Keywords: action research, innovation management,

success factors, guiding principles, research practice gap 


\title{
Employee-Driven Innovation: An Intervention Using Action Research Mats Holmquist and Anna Johansson
}

\author{
"We can bring the ideas, but we are not decision makers. ") \\ Employee participant in this study
}

\begin{abstract}
This article describes an intervention to design and test a method for employeedriven innovation and a model for learning among managers and development leaders. The empirical basis for the intervention focused on personal assistants in the home service within a municipality in Sweden. The intervention was carried out using action research in on a series of workshops with a group of employees, managers, development leaders. Using a "stage" and "stands" theatre metaphor, employees engaged in collective, innovative learning "on the stage" combined with observations and reflections from managers and development leaders "in the stands". This article contributes a method that can generate creative ideas among the employees and a model that can stimulate experience-based learning through observations. The intervention also shows that action research can be used to develop and test methods and models.
\end{abstract}

\section{Introduction}

In the public sector, there is a need for new forms of innovation that tackle unmet challenges such as climate change, aging societies, and a lack of resources (Bommert, 2010). Such forms must open the process of innovation to a variety of actors, overcome borders, and remove cultural restrictions. They must have the potential to improve idea generation, selection, implementation, and diffusion.

Employee-driven innovation is a new form of innovation that has only been researched to a small extent because the focus has been on research-driven, expertdriven, technology-driven, market-driven, and userdriven innovation (Høyrup, 2010). However, employees are a very important and effective resource for innovation that is often overlooked. They have strong potential for contributing to innovative processes because they acquire significant experience-based knowledge and information in their close contacts with customers and users at work (Høyrup, 2010). Bank and Raza (2014) found that inviting employees to increase their participation and engaging them in a conversation to collectively drive innovative solutions helps an organization's innovation process.
Among managers and development leaders, there is a demand for practical methods on how to work with bottom-up processes and engage employees in innovation. Action research can be a way to test and develop such methods. This article tells the story of a case study with that aim. The first part describes earlier research in three knowledge areas involved in the intervention: innovative employees, innovative organizations, and innovative management. The second part describes the intervention with the method design and the workshop process. The third part presents the results of the method with the three innovation teams.

In the fourth part, the employees evaluate their experiences with the innovation method and the managers and development leaders evaluate their experiences with the learning model. The fifth part discusses ethical considerations and the validity of the study. Finally, the final sixth part provides the conclusions and summarizes the key findings.

\section{Background}

Innovative employees

The environment and conditions in work life are changing, and a growing number of innovations will be 


\section{Employee-Driven Innovation: An Intervention Using Action Research}

\section{Mats Holmquist and Anna Johansson}

intangible and service-oriented (Alasoini, 2012). As a result, employees' knowledge about the wishes, expectations, and needs of users and customers, will become increasingly important. Alasoini (2012) identifies three trends that are driving this change. First, the market will change faster, requiring organizations to continuously gather information about users and customers. Second, the economy will be networked and innovations will be spread out to smaller organizations that, in the absence of $R \& D$ staff, will have to encourage their other staff to participate in the innovation process. Third, problem-solving skills and the competence to see larger opportunities will improve among employees.

Employees also benefit from participating in innovation. Well-being at work is positively affected by participating in innovation activities by stimulating employee intellect, creativity, initiative, and commitment (Alasoini, 2012). Mirvis and Googins (2018) add that this includes personal satisfaction and an enriched sense of meaning and purpose on the job. Organizational benefits include employee attraction and motivation and high degrees of workplace learning. Attracting and retaining talented employees are vital for organizations (Kesting \& Ulhøi, 2010), but decisions about major innovations are still in the hands of top managers or R\&D departments, and employees are typically excluded. Despite this exclusion, Kesting and Ulhøi (2010) argue that "employees have hidden abilities for innovation (Ford, 2001; Cohen et al., 1972) and that this potential can be made visible, recognized and exploited to the benefit of both the firm and its employees". However, there has been little research on how to realize this potential.

All employees in the organization have creative skills and problem-solving abilities that are important for innovation (Tidd \& Bessant, 2009). This means that their collective innovative potential is enormous. Høyrup (2010) sees employee-driven innovation as a humanistic and social approach to innovation that leverages the expertise, experience, ideas, creativity, and skills of employees. However, this participative, bottom-up process needs to be supported, recognized, and organized, and it has to be integrated with policies and top-down processes. But Wihlman, Hoppe, Wihlman, and Sandmark (2016) show that this is difficult: there are barriers to creating an innovative culture in the public sector, such as traditions, old structures, and a lack of communication.

\section{Innovative organizations}

What makes a new work routine an employee-driven innovation? Kristiansen and Bloch-Poulsen (2010) state that it must create value for the organization, facilitate the organization of work, and improve the quality of work life for the employees. However, according to those authors, these three criteria are often in conflict. Innovation from the managerial point of view tends to focus on the first criteria and so it becomes a "form of modern rationalization" (Kristiansen \& Bloch-Poulsen, 2010). To make employee-driven innovation possible, Kristiansen and Bloch-Poulsen emphasize the importance of creating a constructive dialogue where everyone feels free and safe to express their opinions. The goal should not be for participants to seek consensus, but rather to encourage the expression of ideas, reservations, and criticism - thus, both negative and positive inputs.

Ireland and Hitt (1999) show that many good developmental ideas remain just ideas; they never apply in the organization and do not lead to change. This failure is more due to ineffective implementation of innovations than on the innovations per se. Lack of understanding around the innovation concept is a major hindrance to the implementation of the policies (Wihlman et al., 2016). For innovation to take place, new knowledge must translate into organizational learning and change (Brown \& Duguid, 1991). To be realized, an innovative idea requires an organization with high absorptive capacity (Cohen \& Levinthal, 1990).

An innovative organization should be characterized by organizational learning and an innovative climate that supports ideas and accepts risks (Claver et al., 1998). Innovation processes are social processes of human action. Innovative learning can occur when groups begin to reflect on established routines, structures, and actions in the organization (Ellström, 2001). It sparks transformational change and novel solutions that challenge existing practices. Ellström uses practice-based innovation and that means that implementing new methods, working procedures, routines, and services are based on the experience, knowledge, and skills that employees have acquired at work.

\section{Innovative management}

Smith, Ulhøi, and Kesting (2012) argue that driving innovation means both coming up with an idea and being involved in its implementation. They identify four relevant factors for employee-driven innovation: leader 


\title{
Employee-Driven Innovation: An Intervention Using Action Research
}

\author{
Mats Holmquist and Anna Johansson
}

support, autonomy, collaboration, and organizational norms of exploration. Leader support is important for employees to feel safe to come up with new ideas that question existing practice and are different from management's view. It is also crucial for motivation, implementation, and allocation of necessary resources. Autonomy in defining and prioritizing one's own goals, in expressing social identity, and in organizing one's own behaviour increases creativity and the possibility of introducing unexpected opportunities. Collaboration means working together and sharing information and knowledge. Group interaction and sharing ideas with others are important for creativity because they stimulate employees to make additional associations and facilitate innovative learning. Norms of exploration refer to the managerial attitude toward change and the internal climate for innovation. Most important are trust, openmindedness, work task flexibility, and a learning climate. They will have a significant impact on employee creativity and innovative behaviour.

Organizations need specific innovative management capacity (Robertson et al., 2012), a higher-order dynamic capacity to coordinate capabilities, knowledge, and action. But employee-driven innovation is difficult to manage in practice (Birkingshaw \& Duke, 2013). Everyone has ideas about job improvement, but most of them never go further, and those that do often get tied up by formal procedures and bureaucracy. Birkingshaw and Duke (2013) identify four enablers: 1) time out to give employees space for creative thoughts, 2) expansive roles to move beyond the assigned job, 3) competitions to stimulate action, and 4) open forums to give a sense of direction and foster collaboration.

If management wants to take advantage of employees' innovative ideas, they need to release control and change to a bottom-up perspective (Jalonen \& Juntunen, 2011). They have to accept the paradox of being in charge but not in control. Instead of reducing uncertainty, they should stimulate ongoing interaction processes. Innovation requires constant support. Jalonen and Juntunen (2011) identified four pro-innovation conditions in complex welfare services: 1) creating trust, 2) increasing communication responsiveness, 3) utilizing connectivity and interdependencies, and 4) pursuing diversity. Management needs to develop a process strategy characterized by a development-oriented leadership (Ellström, 2018) with an open and enabling pattern of leading and organizing development. In this strategy, many managers are looking for methods on how to stimulate employee-driven innovation. The intervention described in this article is motivated by this need.

\section{Case Study: An Intervention Using Action Research}

The case examined in this article focused on personal assistants in the home service within a municipality in Sweden. The background in this case was that the political committee in the municipality had taken a decision that the social administration should work more actively with innovation. Two development leaders were motivated, took the assignment, and contacted the local university in Halmstad for support. To this point, the case was in line with Borins' (2002) research results, illustrating that bottom-up innovations in the public sector need support from both politicians and senior public servants to create a creative organizational climate. At the same time, a European Union project was underway to encourage a more competent and innovative welfare system, where this became one of the sub-projects. The aim was to learn new ways of working with organizational innovation that could be disseminated in social services. One researcher and the development leaders initiated and staged the action together. They decided to test two aspects: 1) an innovation method for employee-driven innovation that could explore and use employees' ideas about social services in the future and 2) a learning model for experience-based learning through observations and reflections from managers and development leaders.

The innovation method was to assemble a working group of eight personal assistants, their unit manager, and two action researchers. This group represented the actors "on stage" and they participated in three workshops with collective, innovative learning (Dixon, 1999; Ellström, 2001) over a period of six months. The "stage" was physically a table surrounded by chairs.

The learning model extended the metaphor to assemble a group of around ten unit managers and development leaders as observers "in the stands". This group observed the innovation process to learn the method. Those in the stands experienced what happened on stage and made reflections on the method together with the action researchers after each workshop. The "stands" was physically an arc of tables with chairs on the side of the "stage". The design used a theatre metaphor to support organizational learning with a "stage" and "stands" that was inspired by the fishbowl method (Kane, 1995), which is a small-group teaching technique in which a number of persons are engaged in a discussion while observers form a circle around them. 


\title{
Employee-Driven Innovation: An Intervention Using Action Research
}

\author{
Mats Holmquist and Anna Johansson
}

The workshops were directed, facilitated, and documented by action researchers from Halmstad University. They took an active part in the practical workshops and conducted theoretical analyses (Gustavsen, 2001). The intention of using action research was to combine traditional scientific values as subject-specific, theoretical, and general knowledge with a creative, innovative, and development-oriented ambition requiring flexibility, proximity, and mutual relationships with the participants (Bennich et al., 2016).

The method was based on a development approach inspired by the search conference (van Beinum, 1998), where the formative and democratic dialogue (Gustavsen \& Engelstad, 1986) between employees and researchers about the future and opportunities to construct it was a tool to create relevant ideas. The democratic dialogue broke down the border between the researcher and the researched and followed explicit rules: everyone on stage should be active, no one is allowed to dominate, all opinions are allowed, and different opinions are an asset and must be respected regardless of who expresses them. Together the actors searched for innovative ideas with reciprocal respect for the employees' practical knowledge and the researchers' theoretical knowledge. Ample documentation between the workshops contributed to the systematic learning process.

One aim with the intervention was to increase employee participation in the organization, and the development leaders wanted to engage a unit with lower status in the organization (and in the public's eye). The unit manager was positive and chose one of his work groups that seldom met and had a low creative climate. This presented its own challenge, but participating in a process like this could be a chance for a new start for the workgroup. Of course, this process also raised some ethical considerations. For example, it could be hard for an employee to tell their manager that they do not want to participate, especially if their colleagues want to. The action researchers therefore placed great emphasis on creating and maintaining the democratic dialogue during the entire process, but did not notice any problems in the group. On the contrary, it was a very open and creative climate during the workshops, which surprised the unit manager.

\section{The workshop process}

At the first workshop, the employees mapped their view of trends they could see in social services and how this could affect their future work. This was first done in one big group with all participants from the stage, and then in smaller groups where each group continued working with possible development areas based on the trends they had discussed. Each development area was then discussed among the participants on stage. The joint discussion led to a decision to focus on three development areas. The stage group was then divided into three groups, where each group worked to develop more concrete ideas based on one of the development areas. At this point, it was important that the focus for the work was on vision and dreams about the future, not about problems and negative aspects with the daily work of today. At the end of the first workshop, the participants were given a mission to think of more concrete ideas to be continued with during the second workshop.

At the second workshop, the process continued with ideas about the future and ended with concrete development proposals. Each idea was discussed with questions such as: How could this be achieved? What should we do to get there? The questions led to several concrete proposals, and the participants voted on which proposal they wanted to continue work with. Each participant had three votes, including the unit manager. The unit manager also had a casting voice and the opportunity to decide if a proposal with few votes should be continued. This first voting round helped the participants to prioritize the proposals they had worked with. Some of the proposals did not receive enough votes this time and were saved for another time or forum. A second voting round was conducted where each participant had one vote each. They now voted for which one of the remaining proposals they wanted to work with until the third workshop. Based on how the participants had voted, they were divided into innovation teams. Each team was led by an innovation coach (the unit manager or a development leader). Each team's task for the third workshop was to work with their proposal and design an action plan that could be put into practice as soon as possible.

At the third workshop, the innovation teams presented their action plans, and the next step for each plan was discussed. At the end of the workshop, an evaluation was held, first one with the participants from the stage and then one with the participants from the stands (including the unit manager from the stage). The method and the result of the process were discussed.

A few months after the last workshop, the researchers met the unit manager and one of the development leaders to discuss the learning model and the innovation method and to find out what had happened with the action plans since the last workshop. The method required a development-oriented leadership with a facilitating 


\title{
Employee-Driven Innovation: An Intervention Using Action Research
}

\author{
Mats Holmquist and Anna Johansson
}

competence that practices a process strategy. In this case, it was performed by external action researchers, but the aim was to teach managers and development leaders in the organization to practice it themselves in the future.

\section{Results}

The discussions of trends and future work in the first workshop led to a focus on three development areas:

1. Attractive profession: focus on maintaining staff and managers by creating a more attractive view of the profession, both within the organization and in the broader society.

2. Career/development: find new/different tasks and better value existing competence among the personal assistants.

3. Better working conditions: create a better work climate, both social and physical.

During the second workshop, the development areas were explored further, leading to three action plans designed by innovation teams, each named after their major subject/theme: 1) Trainee team, 2) Rotation team, and 3) Flexibility team. At the third workshop, each innovation team presented their action plan for the other participants and all participants on the stage discussed the plans in terms of "Goal", "How should it be done?", and "Moving on".

\section{Trainee team}

The Trainee team's goal was to make personal assistants an attractive profession and to find ways to attract potential employees. By working on creating a better understanding of what the work really entails, it should be easier to attract potential employees with the desired attitude towards the work. This, in turn, will lead to development for the organization as well as for the care recipient. The unit manager and the employees discussed, during the whole innovation process, the substantial difficulties experienced with attracting and retaining employees. As one participant put it: "People don't know what this work is about."

The Trainee team had been in contact with an upper secondary school who educated its students in health and social care. The school had shown interest in cooperation with the organization because their students need practical experience during their education and this could be organized together with the personal as- sistants. The team pointed out three main advantages with this type of cooperation: 1) students who practice as personal assistants can be offered work during the summer and, in that way, can help solve staffing challenges that arise during the vacation period, 2) students could be offered work after their exams, and 3) it would be an opportunity for learning and experience for the ordinary employees who will work as mentors for the students.

The next step for the Trainee team was to form a smaller group with the unit manager, one or two of the employees, and a development leader (a participant "in the stands") who could continue the work to establish a more formal cooperation with the school (and perhaps even with other educational actors in health and social care). It was decided that this should be made by creating courses for the mentors in order to give the mentors competence in pedagogy and methodology in mentorship. One other suggestion was that the personal assistant, perhaps with their care recipient, could visit the school and inform students about what the work is, what they do, and what practice opportunities are available.

\section{Rotation team}

The Rotation teams' focus was on making it possible for the employees to test different aspects of the work. The employees worked as one unit with the same care recipient. There were very few opportunities to shift to another care recipient or to try other duties. The participants discussed that this made it difficult for personal development, and they wanted opportunities to try different aspects of the work.

The Rotation team pointed out several advantages with a rotation model: 1) it would give personal development and alternation, hopefully leading to employees finding the work more attractive and hence increase staff retention in the organization, 2) it would at the same time lead to security and continuity, because the employees could then be used in more than one position, which will reduce the use of temporary workers, 3) it would give the employees a better understanding of the complexity of being a member in a large organization, and 4) it could be used as a way to reduce sick leave, because employees who cannot do their regular work might be able to work with something or someone else.

The Rotation team concluded that there were at least four aspects that needed to be solved: 1) You can't force rotation, it must be voluntary; 2) Employees also need 


\title{
Employee-Driven Innovation: An Intervention Using Action Research
}

\author{
Mats Holmquist and Anna Johansson
}

some introduction, they can't just switch places; 3) Someone has to pay for this extra time; and 4) The organization doesn't have the structure (e.g., communication channels between the units) necessary to help the employees and the unit managers to contact each other. But, the team also identified several opportunities. For example, the employees have a schedule with some percentage of "floating time", which is supposed to be used to fill gaps in the crew (e.g., when someone is sick), but it could also be used for rotation. At this moment in the process, some observers from the stands intervened to inform the Rotation team that there were plans in the organization to establish a unit who will work with staffing across the organization. With the establishment of this unit, it would become easier to find opportunities for employees who wish to rotate. The next step for the team was to present their ideas, thoughts, and plans to this new unit.

\section{Flexibility team}

The Flexibility team focused on employee schedules. This concrete idea started during a discussion about their work, which they described as lonely and outdistanced. They aimed for more participation and community. One way to meet this need was by becoming more involved in scheduling. Making a schedule was described as something concrete to "gather around". And, by making everyone in the unit involved, they also hoped for more understanding about the difficulties with scheduling. For example, a scheduler cannot fulfill everyone's wishes, but they can create understanding about necessary decisions. By creating a schedule with greater flexibility, they also wanted to generate greater continuity for the care recipient, a better working environment, and better cohesion - all that will lead to a better personal assistant.

The team had been working on a new schedule that met about $80 \%$ of all employees' wishes. By the time of the third workshop, the schedule was not yet complete, but the participants could all see the potential in it. The team had also used research on working time and consequences for health to reduce the risks for negative health consequences due to working 24/7. They also incorporated laws, rules, and guidelines regarding scheduling in their work to create an understanding that everyone's wishes could not be fulfilled.

Since this new schedule was partly a new way of making a schedule, it was considered as a test schedule. In case the test schedule did not work out, the team had also been working with a more traditional schedule that could act as a standby schedule. The next step was to let all employees of the unit see the new schedule and then start testing it after the summer vacation period.

\section{Evaluation}

In the organization's view, the aim of the process was twofold: 1) to increase participation among the employees and 2) to develop a model for working with innovations in the organization.

\section{Employee experiences with the innovation method}

At the end of the third and last workshop, the participants from the stage talked about the pros and cons and possible improvements with the innovation method. Several positive aspects were raised. The process was described as an "eye opener" that it had made the group grow. The level of engagement was described as seeing "bright eyes" among the participants. Putting the employees on stage meant that they did not feel vulnerable but valuable, causing them to open up their ideas. Maybe the fact that participants were selected rather than having volunteered also added to this impression it made them feel chosen.

The participants talked about how the innovation method had been a way for the unit to get to know each other, to develop, and to do something together. The process was described as a "slow process", which gave them the opportunity to talk to each other in a more relaxed way and that this helped the group to find new ways and new solutions without "falling in the same pit again". However, they accentuated the importance of following through with the action plans and the results from the process. There must be a willingness from the organization to realize the plans. One difficulty they identified with the method was the fact that the work of personal assistants needs to be done around the clock. It can be hard to find temporary workers to enable innovation processes.

The observers from the stands pointed out several positive aspects with the method, including that it promotes participation, it gives the participants an understanding of the complexity of a large organization, and it breaks down the borders between ordinary staff and managers and development leaders in the organization. They also said that the method makes the innovation process a shared responsibility: it does not come done to one single person's work - the process is carried out by and with the participants from the group. A possibility they saw was to use the method in other situations and involve representatives that could provide family and user perspectives. 


\title{
Employee-Driven Innovation: An Intervention Using Action Research
}

\author{
Mats Holmquist and Anna Johansson
}

Ultimately, the organization could not exploit the innovative results, nor could they use the innovation method as they had planned. In the reflections afterwards, the development leader blamed this outcome on a lack of time and resources for innovation. Other things were prioritized. She was frustrated that the intervention had yielded good results that they could not take advantage right away. The unit manager that had learned the method on stage was also frustrated because he did not receive support to follow up, apply, and spread his new knowledge and competence. He had to work with other acute tasks. We experienced that the organization had low absorptive capacity to complete the test and implement the good results.

\section{Managers' and development leaders' experiences with the learning model}

The observers from the stands said that it was a bit hard to just listen and not be involved. However, they also said that it made them realize that the specific issues that were discussed in this process, with this unit, can be found in other units or parts of the organization as well, and that the solutions developed can be used elsewhere in the organization. Several of the participants emphasized the listening aspect of their role: "[I] wish there was more time just to sit and listen."

The listening gave them the time to reflect and the fact that they, who usually lead organizational development, now had the opportunity to listen to the ones they usually work for, gave them another perspective on how communication and information were spread (or not spread) in the organization. They talked about how interesting it was to listen and see the engagement from the employees: "It's fun to see that it was the right decision to include the employees and that they had so much to bring to the innovation process."

However, they also talked about the lack of communication in the organization, that the process made it clear that there are communication gaps and that information does not always reach all the way through the organization. One of the participants from the stands said that being in the stands had given her many tips on how to communicate in her daily work. One difficulty mentioned, related to the lack of communication, was that there is a risk that the innovation teams will rush ahead, not knowing about other plans in the organization.

\section{Discussion}

\section{Ethical considerations}

One difficult question is if the method can be used in organizations with a closed culture where employees are quiet about critical views on things that do not function well at work. Is there a possibility that it can be misused by managers that have the power to punish critical employees with worse jobs and hinder their careers? If that situation exists, then employee-driven innovation is not the right strategy and top-down models of innovation are more suitable. In this case, the researchers did not know anything about the people on the stage and in the stands, but they did know that management was positive and the preparing contacts with the development leader and the unit manager were positive. The researchers also knew from research and their own experience that democratic dialogue is a strong tool for building bottom-up processer. The method integrated critical with innovative perspectives, and this affected the organizational culture in a creative and constructive direction that counteracted misuse in this case.

\section{Validity}

Finally, there is the question of validity in this form of action research. Anderson and Herr (1999) describe five different validity criteria in action research. Democratic validity means that all parties who have a stake in the action research should be directly or indirectly involved. But it also means that actions and discussions should be highly relevant to the local participants and those concerned with the action. Outcome validity means that the participants have to fulfil a spiral process, which may lead to a reframing of the problem in a more complex way. Catalytic validity is the degree to which the process reorients the participants' view of reality in order to change it. Process validity asks to what extent the adequacy of the process is determined. Dialogic validity is reached when the research is exposed for a critical and reflective dialogue with others who can suggest alternative interpretations of research data. Newton and Burgess (2008) add that, in action research that aims for practical improvement of practice, catalytic and outcome validity are primary to achieve the research goals. Process and democratic validity are secondary goals to ensure that the research falls within the domain.

In this case, the most important stakeholders were involved, but at different levels. The employees and the first line manager were highly involved on the stage. The development leaders, human resources support staff, and administrators were involved at a lower level in the stands. The relevance was given directly through the local employees who reflected on the same problem field but with different experiences, aspects, and perspectives. Although their manager participated and other leaders sat in the stands, the conversation climate 


\section{Employee-Driven Innovation: An Intervention Using Action Research}

\section{Mats Holmquist and Anna Johansson}

was surprisingly open and straightforward. Our impression was that the employees felt safe to speak freely and even dared to be critical about the organization and the management of their work.

One explanation was the design, which gave the employees the main role and the leaders a side role as active listeners. The aim was to support employee-driven innovation, and this gave the employees a kind of collective mission that inspired and strengthened them. Another explanation was that the facilitators of the process presented and used the principles of a democratic dialogue (Gustavsen, 2001).

The action researchers were directly involved and could give relevant feedback in the ongoing knowledge-building process. They made theoretical analyses to support progress for practical action. They combined what Stjernström, Lund, and Olin (2006) call critical distance with essential closeness. The role of an action researcher is not only to analyze the situation and promote new knowledge, but also to contribute to action with those involved. The critical and reflective dialogue was only done between the participating researchers; they did not organize any seminaries at the university as they could have done. The participants fulfilled a process that reoriented their perspective and led to innovative solutions that were taken further to decisions. Three workshops and innovation teams were enough to process the ideas into relevant plans, but then it stopped.

\section{Conclusion}

In this study, action research was used to develop an employee-driven innovation method and an organizational learning model that broke down the organizational hierarchy by putting the employees as main actors on the stage and the managers and development leaders as observers in the stands. This encouraged employee commitment and participation, and it provided the opportunity for them to innovate their own work. An experienced-based learning process was used in the stands, not only with respect to the method but also about the organization itself. By observing, listening, and reflecting, the managers and leaders learned about the function of the organization and the employees' needs.

A challenge for the organization was to exploit the results from the innovation method and implement the proposals. One action plan was implemented but two remained dormant due to a lack of time and resources. It seems like the organization focused more on increasing the participation and creating possibilities for employee-driven innovation - rather than on organizational development and implanting the action plans. The employee-driven innovation method was also difficult to absorb, despite the fact that the management demanded it. One reason for this, as pointed out by the development leader and the unit manager, was that when it came down to the management, they did not prioritize the innovation process. The daily work had to been done; there were always fires to put out. This finding highlighted the problem with organizational learning and the difficulties encountered when trying to organize and lead the learning process to acquire and absorb new knowledge and transform it into competitiveness.

The organization needs to develop an absorptive capacity, an ability to utilize new ideas, assimilate, and use them to develop their business. The employees owned the process in the workshops; their visions, thoughts, and ideas led to the innovation teams. But, once the innovation teams had formulated their plans, the organization needed to have the ability and capacity to implement them. After all, the employees can bring up the ideas but they are not the decision makers. The management who initiated the process are also in charge of its outcomes.

To sum up, the key findings from this study are as follows:

- Employees have an innovation potential that can be released if they have the space, conditions, and resources required.

- Managers and development leaders can learn new methods by observing them in practice.

- Employee-driven innovation can be stimulated through action research if there is strong support from management and the dialogue is democratic.

- Innovative ideas are not enough; the organization must also have sufficient absorptive capacity to achieve innovation.

\section{Acknowledgements}

This article was developed from a paper presented at the Swedish Interactive Research Association (SIRA) Conference in Mälardalen University at Eskilstuna, Sweden, on September 17, 2018. SIRA is a network of researchers interested in interactive action research. 


\section{Employee-Driven Innovation: An Intervention Using Action Research}

\section{Mats Holmquist and Anna Johansson}

\section{About the Authors}

Mats Holmquist has a background in Sociology and is now Associate Professor in Work Science at Halmstad University in Sweden. At the university, he has been working with a multi-disciplinary research group on innovation with a societal perspective for many years and is now working with a newly started multi-disciplinary research group on sustainable work environments and health. His doctoral thesis was about learning networks as a social support in the development process and was presented at Luleå Technological University in 2010. His research focus is on learning, innovation, and sustainability in development processes in and between organizations. Currently, his research covers social entrepreneurs, social innovations, and social enterprises; project work and effects; local innovation system; as well as health innovation.

Anna Johansson is a Lecturer at Halmstad University in Sweden. She holds a master's degree in Work Science from Gothenburg University, and her thesis was on motives for working with gender within elderly care in the public sector. Currently, she is teaching in organizational change, work organization, and work environments. She is particularly interested in organizational change in public organizations.

\section{References}

Alasoini, T. 2012. A New Model for Workplace Development in Finland. Rethinking Employee Participation and the Quality of Working Life in the Context of Broad-based Innovation Policy. International Journal of Action Research, 8(3): 245-265.

Anderson, G. L., \& Herr, K. 1999. The New Paradigm Wars: Is there Room for Rigorous Practitioner Knowledge in Schools and Universities? Educational Researcher, 28(5): 12-21. https://doi.org/10.3102/0013189X028005012

Bank, J., \& Raza, A. 2014. Collaborative Idea Management: A Driver of Continuous Innovation. Technology Innovation Management Review, 2(4): 11-16. https://doi.org/10.22215/timreview/764

van Beinum, H. 1998. On the Practice of Action Research. Concepts and transformation. International Journal of Action Research and Organizational Renewal, 3(1-2): 1-29. https://doi.org/10.1075/cat.3.1-2.02bei

Bennich, M., Svensson, L., \& Brulin, G. 2016. Interactive Research: A Joint Learning Process with the Unions. In E. Gunnarsson, H. P. Hansen, B. Steen Nielson, \& N. Sriskandarajah (Eds), Action Research for Democracy. New Ideas and Perspectives from Scandinavia: 27-38. London: Routledge.

Birkinshaw, J., \& Duke, L. 2013. Employee-Led Innovation. Business Strategy Review, 24(2): 46-51.

https://doi.org/10.1111/j.1467-8616.2013.00947.x

Bommert, B. 2010. Collaborative Innovation in the Public Sector. International Public Management Review, 11(1): 15-33.

Borins, S. 2002. Leadership and Innovation in the Public Sector. Leadership \& Development Journal, 23(8): 467-476. https://doi.org/10.1108/01437730210449357

Brown, J. S., \& Duguid, P. 1991. Organizational Learning and Communities-of-Practice: Toward a Unified View of Working, Learning and Innovation. Organizational Science, 2(1): 40-56. https://doi.org/10.1287/orsc.2.1.40

Claver, E., Llopis, J., Garcia, D., \& Molina, H. 1998. Organizational Culture for Innovation and New Technological Behavior. Journal of High Technology Management Research, 9(1): 55-68. https://doi.org/10.1016/1047-8310(88)90005-3

Cohen, W., \& Levinthal, D. 1990. Absorptive Capacity: A New Perspective on Learning and Innovation. Administrative Science Quarterly, 35(1): 128-152.

https://doi.org/10.2307/2393553

Dixon, N. 1999. The Organizational Learning Cycle: How We Can Learn Collectively. Bennington, VT: Gower.

Ellström, P.-E. 2001. Integrating Learning and Work: Problems and Prospects. Human Resource Development Quarterly, 12(4): 421-435. https://doi.org/10.1002/hrdq.1006

Ellström, E., \& Ellström, P.-E. 2018. Two Modes of Learning-Oriented Leadership: A Study of First-Line Managers. Journal of Workplace Learning, 30(7): 545-561. https://doi.org/10.1108/JWL-03-2018-0056

Gustavsen, B. 2001. Theory and Practice: The Mediating Discourse. In P. Reason \& H. Bradbury (Eds), Handbook of Action Research. Participative Inquiry and Practice: 17-26. London: SAGE. 


\section{Employee-Driven Innovation: An Intervention Using Action Research \\ Mats Holmquist and Anna Johansson}

Gustavsen, B., \& Engelstad, P. H. 1986. The Design of Conferences and the Evolving Role of Democratic Dialogue in Changing Working Life. Human Relations, 30(2): 101-116. https://doi.org/10.1177/001872678603900201

Høyrup, S. 2010. Employee-Driven Innovation and Workplace Learning: Basic Concepts, Approaches and Themes. Transfer: European Review of Labour and Research, 16(2): 143-154. https://doi.org/10.1177/1024258910364102

Ireland, R. D., \& Hitt, M. A. 1999. Achieving and Maintaining Strategic Competitiveness in the 21st Century: The Role of Strategic Leadership. Academy of Management Executive, 13(1): 43-57. https://doi.org/10.5465/ame.1999.1567311

Jalonen, H., \& Juntunen, P. 2011. Enabling Innovation in Complex Welfare Service System. Journal of Service Science and Management, 4(4): 401-418.

https://doi.org/10.4236/jssm.2011.44046

Kane, C. M. 1995. Fishbowl Training in Group Process. The Journal for Specialists in Group Work, 20(3): 183-188. https://doi.org/10.1080/01933929508411342

Kesting, P., \& Ulhøi, J. P. 2010. Employee-Driven Innovation: Extending the License to Foster Innovation. Management Decision, 48(1): 65-84. https://doi.org/10.1108/00251741011014463

Kristiansen, M., \& Bloch-Poulsen, J. 2010. Employee Driven Innovation in Team (EDIT) - Innovation Potential, Dialogue and Dissensus. International Journal of Action Research, 6(2/3): 155-195.
Mirvis, P., \& Googins, B. 2018. Engaging Employees as Social Innovators. California Management Review, 60(4): 25-50. https://doi.org/10.1177/0008125618779062

Newton, P., \& Burgess, D. 2008. Exploring Types of Educational Action Research: Implication for Research Validity. International Journal of Qualitative Research, 7(4): 18-30.

https://doi.org/10.1007/9789463004381_004

Robertson, P., Casali, G. L., \& Jacobson, D. 2012. Managing Open Incremental Process Innovation: Absorptive Capacity and Distributed Learning. Research Policy, 41: 822-832. https://doi.org/10.1016/j.respol.2012.02.008

Smith P., Ulhöi J. P., \& Kesting, P. 2012. Mapping Key Antecedents of Employee-Driven Innovations. International Journal of Human Resources Development and Management, 12(3): 224-36. https://doi.org/10.1504/IJHRDM.2012.048629

Stjernström, E., Lund, T., \& Olin, A. 2006. Critical Distance - Essential Closeness. In N. Mockler (Ed.), Local Research, Global Community: Action Research for a New Century, CARN Bulletin 11A: 17-23. Manchester, UK: Manchester Metropolitan University.

Tidd, J., \& Bessant, J. 2009. Managing Innovation. Integrating Technological, Market and Organizational Change. Chichester, UK: Wiley and Sons.

Wihlman, T., Hoppe, M., Wihlman, U., \& Sandmark, H. 2016. Innovation Management in Swedish Municipalities. European Journal of Workplace Innovation, 2(1): 43-62.

Keywords: dialogue, ideas, development, organizational innovation, learning 


\title{
Embedded Master's Students Conduct Highly Relevant Research Using Industry as Their Laboratory
}

\author{
Kristin Falk and Gerrit Muller
}

\begin{abstract}
"If you think competency is expensive, have you tried incompetency? ... ") In addition to getting good and motivated students, the company also gets working knowledge of the subject systems engineering. The company also benefits from assignments along the way, and the thesis is aimed at current issues in business. We have much to learn from these students.
\end{abstract}

\author{
Willy Holdahl \\ HR Director of GKN Aerospace Norway \\ Industry collaborator in the USN Systems Engineering program
}

\begin{abstract}
This article analyzes participatory action research conducted by Systems Engineering master's students embedded fifty percent in industrial companies for three years. The resulting papers authored by these students identify challenges and effective practices suitable for knowledge transfer between industry and academia. The analysis covers 181 completed master's projects, with a detailed analysis of 40 papers that have been published in international conferences and journals. The publication rate of about $23 \%$ shows that these students contribute actively to the body of Systems Engineering knowledge. This study analyzes master's projects at three levels - industrial problem and drivers; Systems Engineering methods; and research method feasibility - and provides valuable lessons learned by applying the industry-as-laboratory approach. Embedding students in industry has resulted in publications that do not suffer from the main challenges of participatory research such as delays, repeatability, and only action and not research. These insights are valuable both for industry and for academia in future work to enhance innovations.
\end{abstract}

\section{Introduction}

Systems Engineering as a profession emerged from the telecommunications and space programs in the United States in the 1950s. Motivating this emergence was the need for these systems to be safe, reliable, robust, and able to handle unforeseen events. Practicing systems engineers wrote the earliest Systems Engineering literature (Chestnut, 1967; Goode \& Machol, 1957), but it took nearly 20 years before academia began to offer explicit Systems Engineering educational opportunities and to produce textbooks. The subsequent literature has dealt not only with technological topics but also with the corresponding impacts on organizations that produce these complex systems.
Thus, research on Systems Engineering is still an emerging field. One challenge is that Systems Engineering is context dependent: the practice is dependent on both the engineering domain as well as the organizations and its surroundings. Another challenge is that valuable tacit knowledge remains largely undocumented within the companies and industries. Specifically, research on Systems Engineering implementation and best practices within the oil and gas industry is scarce. This raises questions about how to make this knowledge explicit and how to best apply Systems Engineering in different settings.

Systems Engineering master's students at the University of South-Eastern Norway (USN; tinyurl.com/y2e6h6za) are 


\section{Embedded Master's Students Conduct Highly Relevant Research Using Industry as Their Laboratory Kristin Falk and Gerrit Muller}

working with these questions to evaluate the effectiveness of the Systems Engineering body of knowledge in practice. To facilitate this process, USN - in close cooperation with the industry - created a new study model: the Industry Master's Program. Students in this program are embedded in a company for three years, working as an engineer $50 \%$ of the time and studying during the other $50 \%$. During the last half year, they use the industry-aslaboratory concept (Potts, 1993) while they conduct their research. The industry partners provide an active study and research environment that benefits all parties.

This article analyzes the prior research performed by students in the Industry Master's Program at USN by answering the following questions:

1. How well does action research work for master's students?

2. How can industry and universities facilitate participatory action research performed by master's students within the field of Systems Engineering?

The central case examined in this study is thus the Systems Engineering master's projects in the Industry Master's Program. We analyze this case at two levels: 1) industrial application including Systems Engineering knowledge and 2) research methods with a focus on research methods and feasibility.

The remainder of this article is organized as follows. First, we provide some background on Systems Engineering pedagogy, the Industry Master's Program and projects, and the role of action research in those projects. This is followed by sections describing the research method and their results, analyzing various aspects of papers produced by students in the Industry Master's Program, including: industrial value, research methods, elements that assist or hinder the research, as well as experiences and recommendations. The article ends with a discussion and conclusions.

This article is aimed at business managers and engineers wanting to develop their companies by close and fruitful collaboration with academia, and researchers and students wanting to learn more about applying the industryas-laboratory concept. We often find that we have to explain the concept when we meet new university colleagues who are unaware of this type of teaching and action research and when we meet people from industry who are unaware of its existence. We also need to provide in-depth explanations to the students in our program and to their industrial mentors.
We, the two authors of this article, have supervised 104 of the 181 completed master's projects within this program between 2010 and 2017. We have supervised 28 Industry Master's students that have published papers in peer-reviewed conferences and conferences proceedings, which is $27 \%$ of the students we have supervised in that period of time. The first author, Kristin Falk, is an industrial expert in the domain of Systems Engineering within offshore oil and gas (Muller \& Falk, 2018), and the second author, Gerrit Muller, is an expert in the Systems Engineering research field (Muller 2009, 2013; Valerdi, Brown, \& Muller, 2010).

In this article, we draw on our research and experience to provide new insights and perspectives and to add to the literature in the field of action research and industry-university collaboration.

\section{Background}

\section{Systems Engineering pedagogy}

Systems Engineers typically work as engineering managers, systems architects, or project managers in projects that develop complex systems. These engineers often encounter situations where they need to influence stakeholders to select a suitable solution (McKinney \& Contractor, 2013). The field of System Engineering differs from other engineering disciplines as it covers a broad scope, it involves humans, it involves ill-defined problems with many unknowns, and it involves problems without a single unique best answer (Muller \& Bonnema, 2013).

The broad scope of Systems Engineering fits well with an experiential learning model, where the student learns more than theory. Theories from the sociocultural view (Vygotsky, 1978, 1986) on learning by doing and reflection are highly relevant to this discipline. Vygotsky advanced a view that knowledge and understanding were socially constructed through interactions with others. Lave and Wenger (1991) emphasized that learning is a participation in practice fellowship. This also relates to Kolb's (2014) learning cycle: experiencing, reflecting, generalizing, and applying.

Figure 1 illustrates the synergy between industry, teaching, and research within Systems Engineering. The industrial domain focuses on the actual systems under development. The practitioners (or engineers) in the industrial domain apply engineering methods to realize these systems. Engineering methods are what we teach at universities. Research should give objective validation and evidence for these methods. To validate 


\section{Embedded Master's Students Conduct Highly Relevant Research Using Industry \\ as Their Laboratory Kristin Falk and Gerrit Muller}

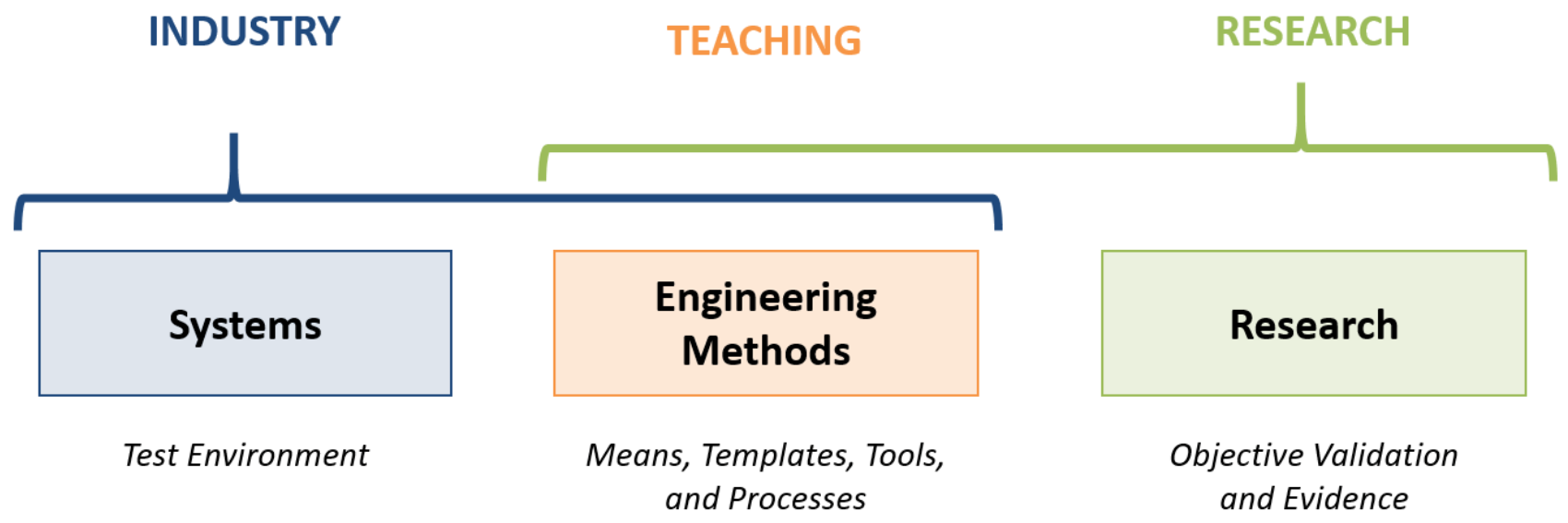

Figure 1. Industry, teaching, and academia synergy within the domain of Systems Engineering

the engineering methods during our research, we use the real-world systems as a test environment.

Garousi and colleagues (2016) presented (very) long lists of "best" and "worst" practices in industry-university collaboration. The best practices with the most references were:

- Run regular workshops and seminars.

- Base research on real-world problems.

- Ensure engagement and manage commitment.

- Be agile.

- Ensure that the research provides benefits to industry and solves the right problems.

As described in the next subsection, the Industry Master' model strives to support these practices.

\section{The Industry Master's model at USN}

In 1999, the Philips Research Department of Information and Software Technology and its group in Software Architectures were using Colin Potts' research model called "industry-as-laboratory". Potts (1993) observed that barely any research in software engineering transferred into practice. He hypothesized that most research focuses on the methods, techniques, tools, and concepts, without taking into account the practical context of using them. He promoted a research concept where researchers validate the research topics by applying them in practice.
In 2002, the Embedded Systems Institute (ESI; esi.nl) started a number of collaborative projects between academia and industry. The ESI staffed these projects, such as Boderc (redesign.esi.nl/boderc/), with a few research fellows, a significant number of PhDs, and some industry participants. These projects adopted the industry-as-laboratory research approach, scaling it up to a significant research effort. Muller and Heemels (2007) evaluated the research approach at the end of the Boderc project. Experiences with PhDs in the ESI period, around 2002, showed that it was quite challenging for PhD students to contribute within the industrial context. They continuously experienced opposing forces:

- The industrial problem, requiring pragmatic solutions quickly

- The academic environment, requiring depth and academic rigour

In 2006, the local university college in Kongsberg (now part of the University of South-Eastern Norway) established a new Industry Master's program in Systems Engineering. This program incorporates experiential learning as the pedagogic model for Systems Engineering through close cooperation between industry and academia. The industry offers paid part-time working positions to Systems Engineering students, which allow them to connect theory and practice to make this model work. Teachers and students share cases from their industrial experience as part of the courses. The university used the ESI experiences to model the master's projects. In retrospect, the working period before 


\section{Embedded Master's Students Conduct Highly Relevant Research Using Industry as Their Laboratory Kristin Falk and Gerrit Muller}

starting the master's project serves well to overcome some of the conflicts experienced in ESI.

The Industry Master's program at USN differs significantly from other master's studies in Engineering, at least in Norway, where students normally have very limited working experience. Some students do their final master's project thesis affiliated with a company but may struggle, as they need time to understand the context and help in defining relevant problems. Occasionally, students have relevant part-time jobs, industrial internships, or co-op placements between study, which afford them some of the same advantages as the USN master's students when doing industrial research.

The Industry Master's students go through a three-year course in reflective practice. According to the curriculum, the course should give the students knowledge of: reflection methods and learning cycle; knowledge of communication; frameworks for domain knowledge; academic writing; ability to reflect on work and education; and ability to develop themselves from a student into a professional employee. Muller (2015) documents how reflective practice is a core element in connecting theory and practice culminating in Industry Master's projects. As part of reflective practice, a program coordinator informs the students about the master's project at the very beginning of their study and guides them in their search for a topic through reflective practice workshops. At the end of the second study year, the students follow three workshops to select a topic, shape the master's project, and determine a research approach (indicated by the first three milestones in Figure 2). Three months before the start of the project, the coordinator assigns academic supervisors to students based on the topic. Students and their academic supervisors finalize the definition and research approach for each project before students begin to execute them.

The execution period of a master's project consists of a study load of 6 months of full-time effort (approximately 20 weeks) usually conducted in the final semester before graduation. When students are starting their master's project, they have been working at the company for two and a half years. By then, they know the company, the systems, the technology, the people, and the processes. During the first months of the master's project execution phase, the focus of the students is on the case and its industrial context. Students maintain regular contact with their academic supervisors, reflecting on the research itself. The fourth milestone indicates a workshop on academic writing, addressing the structure of the thesis and review of the research methods, among other topics.

During their master's projects, the students use the industry-as-laboratory approach, which is a sub-group of action research (Muller, 2013). The main triggers for the research should be "effective use of System Engineering methods in industrial practice." The idea is that action research enables students to understand and evaluate their respective company and its practices.

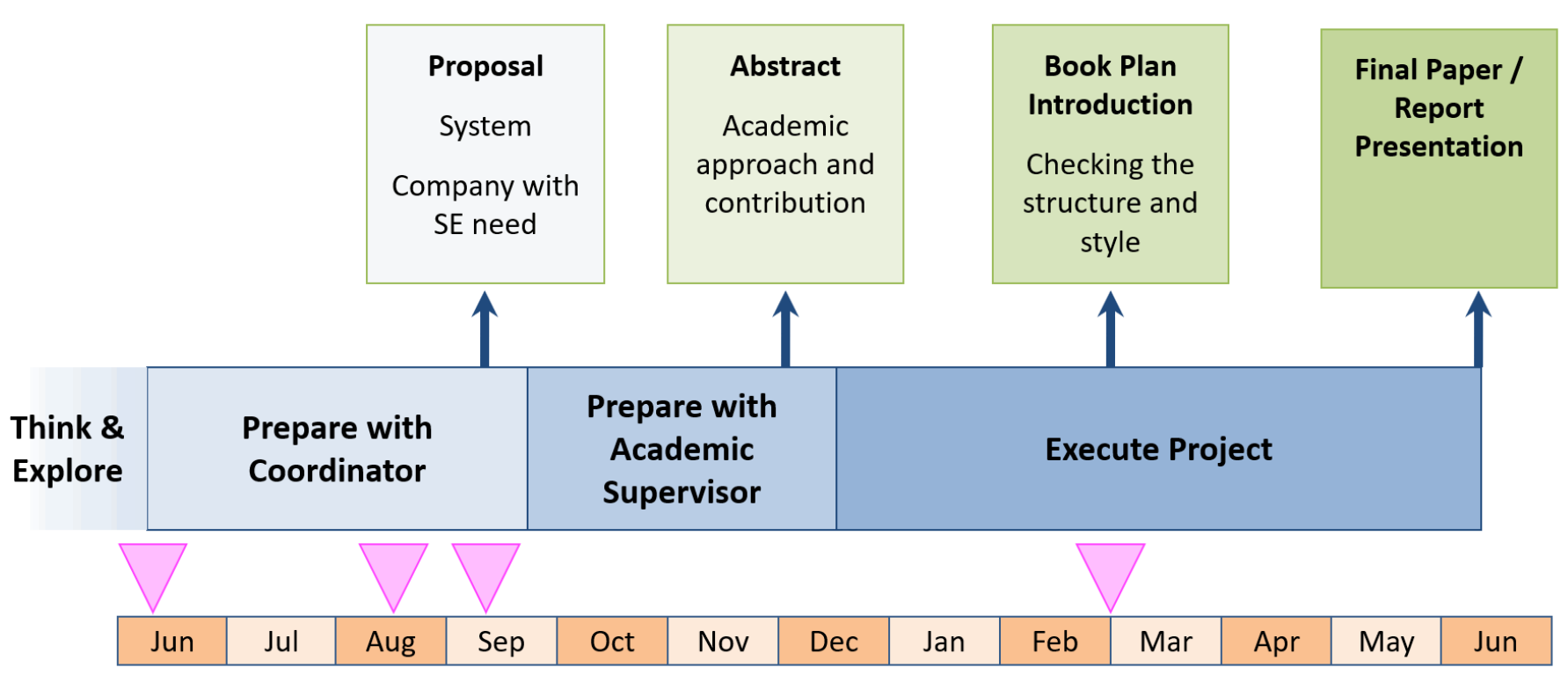

Figure 2. Master project preparation and execution phase (Muller, 2012) 


\section{Embedded Master's Students Conduct Highly Relevant Research Using Industry as Their Laboratory Kristin Falk and Gerrit Muller}

\section{Action research}

This article relates papers authored by the master's students to definitions and characteristics of action research as provided by O'Brien (2001):

\section{"Action research...aims to contribute both to the practical concerns of people in an immediate prob- lematic situation and to further the goals of social science simultaneously. Thus, there is a dual com- mitment in action research to study a system and concurrently to collaborate with members of the system in changing it in what is together regarded as a desirable direction. Accomplishing this twin goal requires the active collaboration of researcher and client, and thus it stresses the importance of co- learning as a primary aspect of the research pro- cess."}

Action research focuses on each of four phases - plan, act, observe, and reflect - and is conducted in iterations. Koshy (2005) provides a rather detailed description of action research and different methods. Tripp (2005) discusses different types of action research and claims that the researcher should be actively involved in the problem solving for it to be proper action research. Saunders and co-authors (2012) give a broad classification of action research. Interactive research has been described as "the idea of knowledge creation through cooperation between researchers and practitioners" by Ellström (2007). Research-Methodology.net (2018) listed three advantages of action research:

1. "High level of practical relevance of the business research"

2. Can be used with quantitative, as well as, qualitative data"

3. Possibility to gain in-depth knowledge about the problem"

They also listed three disadvantages:

1. "Difficulties in distinguishing between action and research and ensure the application of both"

2. Delays in completion of action research due to a wide range of reasons are not rare occurrences"

3. Lack of repeatability and rigor"
Beard and Wilson (2006) investigated how learning equals change, and how people learn and change. Reflective practice is very important in this process: "There are four distinct phases, which involve a concrete experience, thinking about the experience, generalizing and conceptualizing about the experience, and finally applying these ideas and thoughts to new situations. ... In the third stage, we make links and connections to our previous experience and knowledge. Without these links the experience may have little value in learning." Beard and Wilson (2006). This is similar to Kolb's learning cycle (experiencing, reflecting, generalizing, and applying) as applied in reflective practice for Systems Engineering students at USN (Muller, 2015).

Engaged scholarship is based on the management profession and can be performed in many ways; also in the form of action research. Van de Ven (2007) stated that, if we ground our research questions in practice and involve practitioners in problem formulation, theory building, research design, and problem solving, then management scholarship will flourish and the management profession will benefit. Furthermore, he argued that a deeper understanding of communicating knowledge across boundaries and a more engaged relationship between the researcher and their audience are needed if research findings are to have an impact in advancing science and practice. "It is one thing to write a research paper, and quite another to transfer, interpret, and implement study findings at the communication boundaries of both scientific and practitioner communities." (Van de Ven, 2007).

\section{Method}

The foundation of this research is a structural review of 40 papers published from Industry Master's projects. By published, we mean that the paper has been through peer review and published as a full paper. Thirty-three of the student papers were published in proceedings of the International Council on Systems Engineering (INCOSE) Annual International Symposium. This is the largest worldwide annual gathering of people who do Systems Engineering. The symposium attracts an international mix of professionals at all levels and includes practitioners in government and industry, as well as educators and researchers. The remaining papers were published in in journals and conference proceedings, as shown in Table 1. 


\section{Embedded Master's Students Conduct Highly Relevant Research Using Industry as Their Laboratory Kristin Falk and Gerrit Muller}

Table 1. Publication channels for published master's papers

\begin{tabular}{ll}
\hline Publication Channel & Type \\
\hline INCOSE's Annual International Symposium & Conference Proceedings \\
\hline International Journal of Information and Communication Engineering & Journal \\
\hline Sustainability & Journal \\
\hline International Conference on Industrial Engineering and Engineering Management & Conference Proceedings \\
\hline European Systems Engineering Conference (EUSEC) & Conference Proceedings \\
\hline Conference on Systems Engineering Research (CSER) & Journal / Proceedings \\
\hline
\end{tabular}

Figure 3 shows the flow of the research. The background for the papers stems from the Industry Master's model and the literature on action research. After a methodical review of the papers, the results are analyzed and discussed according to the following dimensions:

- Industrial value of the Systems Engineering methods and tools
- Research method related to theory and definition of action research

- Elements assisting or hindering the research

- Experiences and lessons learned (based on all completed master's projects, not just those resulting in publications)

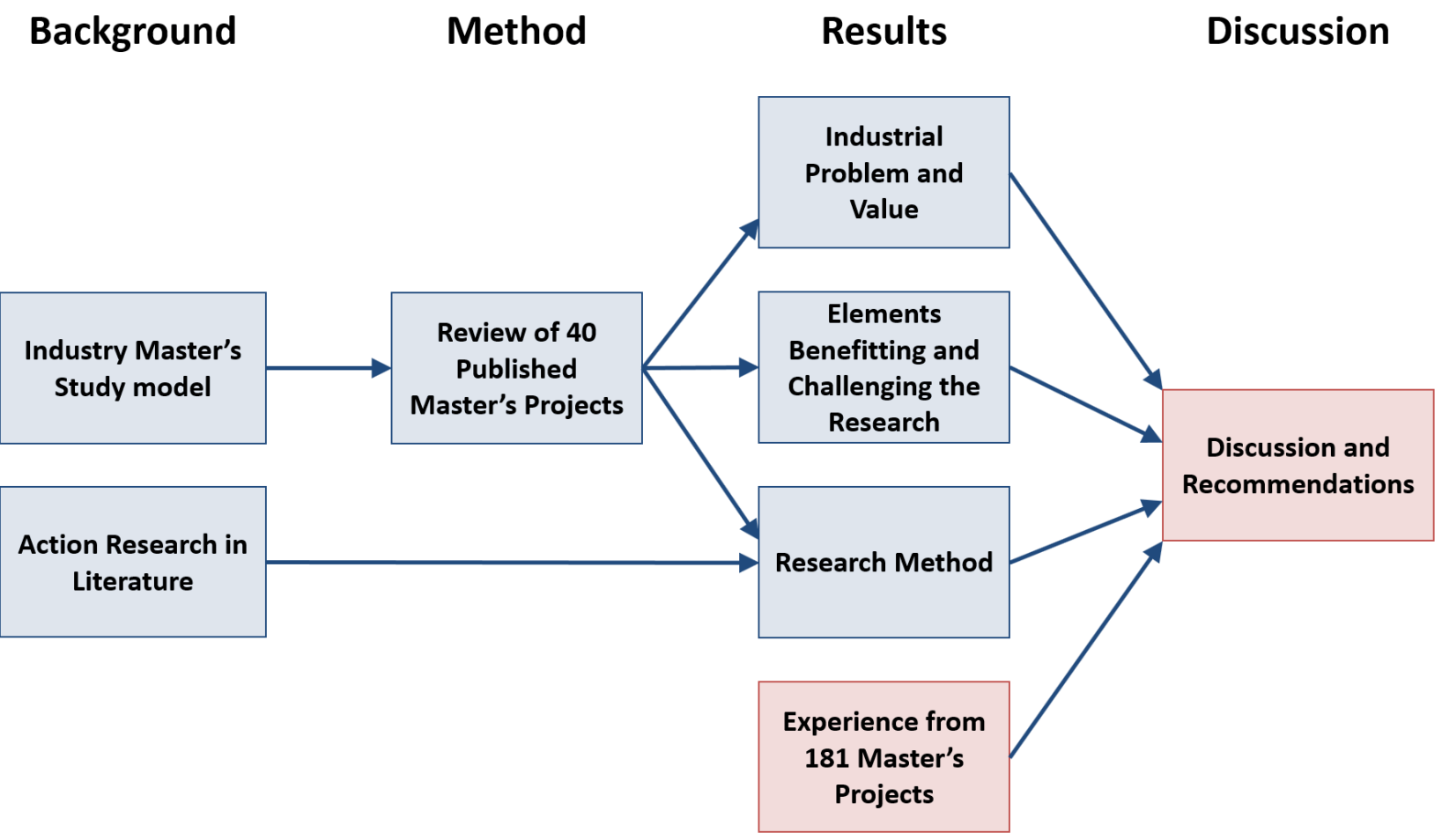

Figure 3. Research flow 


\section{Embedded Master's Students Conduct Highly Relevant Research Using Industry as Their Laboratory Kristin Falk and Gerrit Muller}

The underlying problem is identified for each paper and then is oriented according to our current research roadmap. The roadmap was derived from a number of meetings and workshops with industrial partners and contains the following industrial research triggers: autonomous systems, digital transformation, continuous innovation, effective manufacturing, connected world, and systems of systems. Benefits or qualities, defined by the research roadmap, are effectiveness in development, trustworthiness, human suitability, and changeability. In the early days, "reliability in harsh environments" and "innovation/evolvability" were guiding concepts or terms. Information about the main result and main conclusion was extracted from each paper. Appendix 1 lists the papers published by the master's students as analyzed in this work.

For each paper, we compared the research methods used to definitions and characteristics of action research, and we classified them on a scale from one to five. We also wrote down specific elements that could hinder or assist the effectiveness of action research. In addition, we examined whether the students had used the different phases of action research (i.e., plan, act, observe, and reflect) and whether the students used qualitative or quantitative research methods. Finally, we identified whether the students made use of interviews, workshops, literature, or historical data to support their research.

After scanning the papers to find elements assisting or hindering the effectiveness of action research, only $80 \%$ of the master papers clearly met the definition of action research (based on researchers understanding of paper). These were papers with a positive or neutral answer to both of the criteria: "The research aims at changing the practice" and "The research involves colearning (a group of practitioners)". Based on our experience and our systematic review of the published papers, we developed an in-depth discussion and recommendations related to how master's students can perform action research within industry.

When reading the papers, we also analyzed their readability and recorded their citation count from Google Scholar. By December 1, 2018, five papers had a Google Scholar citation count of seven or higher, and more than half of the papers had no citations. Only one of the papers from the population of 40 was identified as "very difficult" to examine, and four were "difficult" to analyze. In two of these five papers, the researchers struggled to see the practical relevance, whereas the other three contained insufficient details of the research method. Information related to industrial value was often hidden within the papers. The researchers had to make interpretations based on 20 years of industrial experience from innovation and management within the energy sector. The Systems Engineering tools, methods, and processes were the most easily available items to discover in our analysis, because there were typically mentioned in the abstract, body, and conclusion sections.

\section{Results}

Students in the Industry Master's program work in various industries. Figure 4 displays the industry affiliation of all 309 students enrolled in the program between 2006 and 2017. Of these, 181 students have graduated in the same period, and 42 of them have had their papers published.

Figure 5 displays the industry affiliation of the 40 published master's papers that we analyzed in detail. The energy industry has, by far, the most papers, representing almost half of the papers. The two other industries with more than one paper are manufacturing and maritime. Defense, maritime, manufacturing, consultancy, and automotive are the other main industries that have employed the students.

\section{Industrial value of the published papers}

Supervisors of master's projects ask the students to focus on a specific, relevant, and important problem in the company where they work. For example, they ask: "What makes the boss worried?" Thus, the immediate industrial needs rather than the longer-term drivers determine most, but not all the master project topics. Figure 6 shows the industry problems that the published papers have identified. Cost and then quality are the most common problems. In addition, at least five students have investigated problems related to time, risk and safety, and customer satisfaction.

As shown in Figure 4, 23 of the published master's project were within a single industry: energy. These papers focused on offshore energy, primarily subsea oil and gas. In this industry, there was a sudden drop in oil price in 2015, followed by an intense focus on cost and time. Seven out of eight publications from the 2016 and 2017 cohorts mention cost/time as the main problem. On the other hand, only one of the five publications from 2010 and 2011 mentions cost or time as a primary issue. Our findings give a strong indication that the papers deal 


\section{Embedded Master's Students Conduct Highly Relevant Research Using Industry as Their Laboratory Kristin Falk and Gerrit Muller}

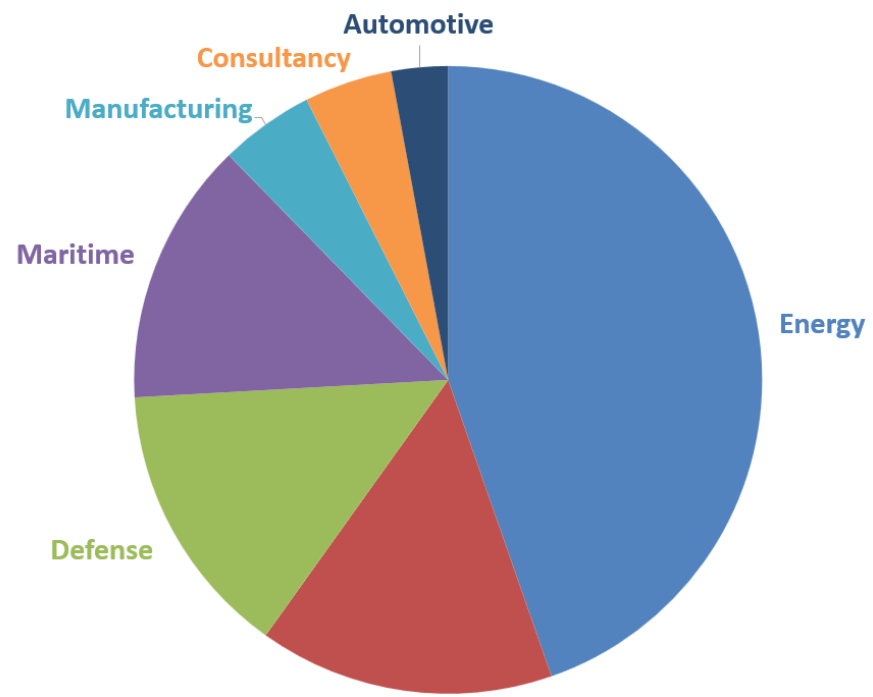

Miscellaneous

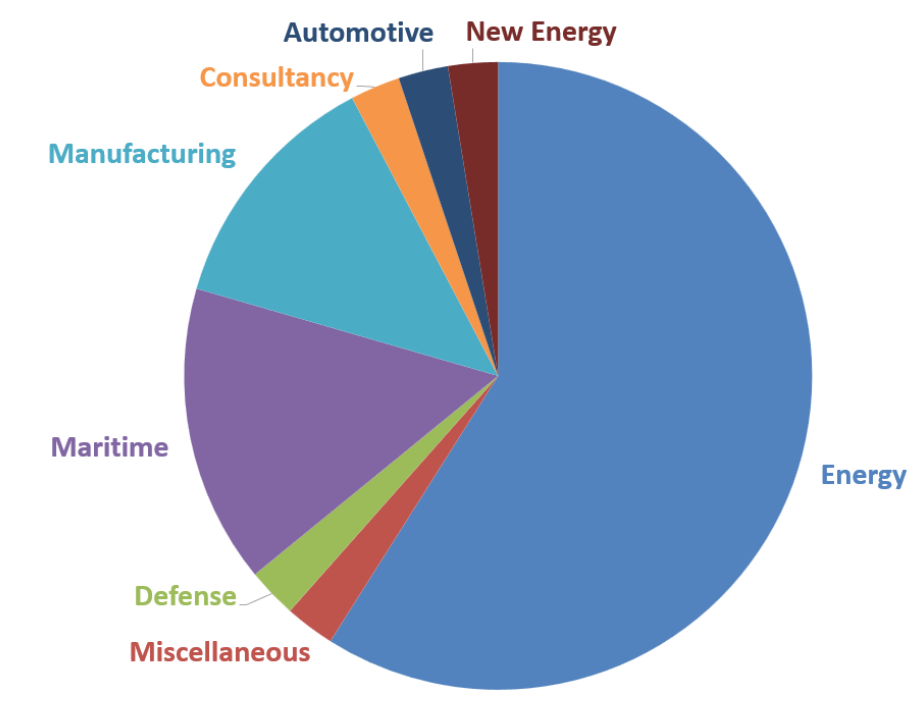

Figure 5. Industry affiliation of the 40 papers published by master's students between 2006 and 2017
Figure 4. Industry affiliation of all students enrolled in the Industry Master's program between 2006 and 2017

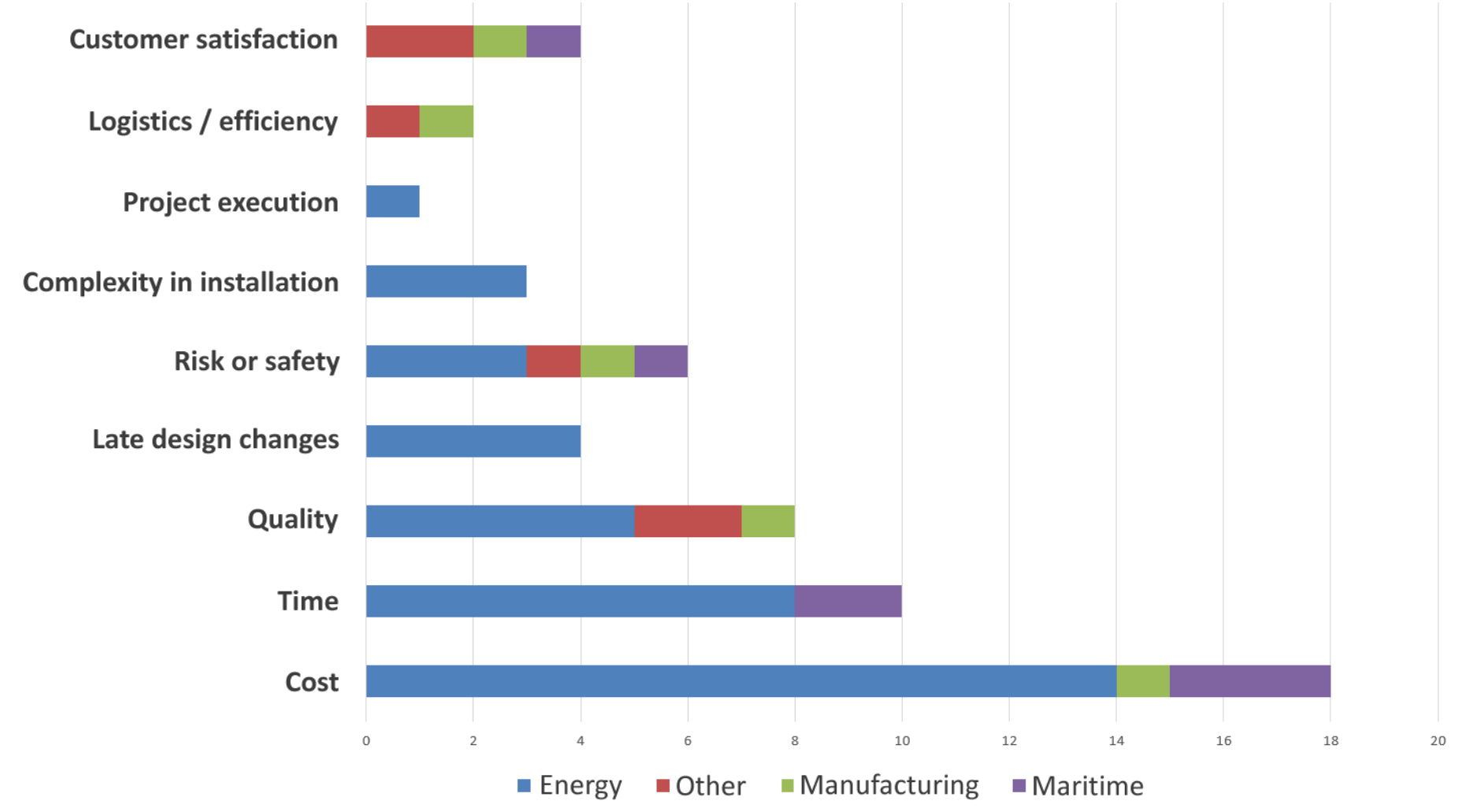

Figure 6. Problems that the published master's papers were attempting to solve, sorted by the different industries. One paper can address more than one problem. 


\section{Embedded Master's Students Conduct Highly Relevant Research Using Industry as Their Laboratory Kristin Falk and Gerrit Muller}

with real-world issues and real cases important to the industrial companies where the students are working during their entire master's studies.

Table 2 lists the most prominent key triggers of the research and qualities (benefits) of using the Systems Engineering methods and tools. Even though many papers were written prior to our current research roadmap, there is still a strong link between the papers and roadmap. Systems of Systems and Innovation are the most common research triggers. Digitalization and Autonomy are recent triggers. When it comes to qualities, effectiveness in development and trustworthiness are the most common. This finding originates from the former research agenda focusing on trustworthiness and effective methods.

Table 3 lists results and conclusions presented by the five papers with the highest Google Scholar citation counts as of December 12, 2018. The results and conclusions in Table 3 are rather tangible and easy to grasp. This is not
Table 2. Analysis of 23 energy papers with respect to key triggers for the research and benefits of using the Systems Engineering methods and tools

\begin{tabular}{lclc}
\hline Research Triggers & & \multicolumn{2}{l}{ Qualities (Benefits) } \\
\hline Systems of systems & 13 & $\begin{array}{l}\text { Effectiveness in } \\
\text { development }\end{array}$ & 10 \\
\hline Innovation & 6 & Trustworthiness & 9 \\
\hline $\begin{array}{l}\text { Digitalization and } \\
\text { autonomy }\end{array}$ & 3 & Human suitability & 2 \\
\hline $\begin{array}{l}\text { Efficiency in the } \\
\text { organization }\end{array}$ & 1 & Changeability & 2 \\
\hline
\end{tabular}

Table 3. Results and conclusions for the five papers with the highest Google Scholar citation count

\begin{tabular}{clll}
\hline Citations & Main Topic & Results (extracted from Abstract) & Conclusions (extracted) \\
\hline 20 & $\begin{array}{l}\text { Needs } \\
\text { Analysis }\end{array}$ & $\begin{array}{l}\text { Early capturing of customer needs and user } \\
\text { requirements could give "92\% reduction in } \\
\text { cost of late design changes" }\end{array}$ & $\begin{array}{l}\text { "Proper use of systems engineering ensures a } \\
\text { minimal amount of late design changes. The most } \\
\text { important systems engineering process in such a } \\
\text { context, is the capturing of customer needs and } \\
\text { definition of user requirements." }\end{array}$ \\
\hline
\end{tabular}

\begin{tabular}{|c|c|c|c|}
\hline 8 & $\begin{array}{l}\text { Concept } \\
\text { Modelling }\end{array}$ & $\begin{array}{l}\text { “...presents impact factors the architect can } \\
\text { use to increase a model's ability to assist } \\
\text { communication.” }\end{array}$ & $\begin{array}{l}\text { “...balancing and utilizing the right quantity of these } \\
\text { factors increase modeling value." }\end{array}$ \\
\hline 8 & $\begin{array}{l}\text { Concept } \\
\text { Selection }\end{array}$ & $\begin{array}{l}\text { "The application of Pugh Matrix in these } \\
\text { cases resulted in exploring more and farther } \\
\text { reaching alternate design than in the } \\
\text { normal practice." }\end{array}$ & $\begin{array}{l}\text { “...managers and engineers tend to skip the concept } \\
\text { phase and prefer to jump into a realization. The } \\
\text { perception is that Concept Selection is time } \\
\text { consuming; spending time on it cannot be afforded." }\end{array}$ \\
\hline 7 & A3AO & $\begin{array}{l}\text { "Using the A3 Dynamic Architecture } \\
\text { stakeholders were able to focus during } \\
\text { validation on one state at one time rather } \\
\text { than all the states combined." }\end{array}$ & $\begin{array}{l}\text { "Dynamic A3 Architecture can ease internal and } \\
\text { cross boundary communication, train new } \\
\text { employees, facilitate knowledge capture, and share } \\
\text { common understanding of the "system of interest". } \\
\text { A functional sequence diagram, which is a hybrid of } \\
\text { a state and functional diagram, can assist in early } \\
\text { validation of process applications." }\end{array}$ \\
\hline 7 & $\begin{array}{l}\text { Concept } \\
\text { Selection }\end{array}$ & $\begin{array}{l}\text { "The application of the Pugh Matrix in these } \\
\text { studies showed that if applied on the correct } \\
\text { level of detail as part of the concept } \\
\text { selection process, it is a powerful tool." }\end{array}$ & $\begin{array}{l}\text { "The involved engineers readily adopted the Pugh } \\
\text { matrix and they intend to continue using it, mainly } \\
\text { due to its ability to force structural thinking in } \\
\text { complex systems." }\end{array}$ \\
\hline
\end{tabular}




\section{Embedded Master's Students Conduct Highly Relevant Research Using Industry as Their Laboratory Kristin Falk and Gerrit Muller}

the case for the majority of the papers. Most of the papers concluded with more vague statements typically saying that the method or tool worked as intended, and was appreciated.

\section{Research method applied in the published papers}

All papers, except for one, made active use of qualitative research methods. Thirty percent also used quantitative research methods. About $80 \%$ of master's students used interviews or questionnaires. Some of them also held workshops. Interviews, questionnaires, and workshops were used to explore and gain deep understanding. They were also useful to validate the results. Thirty-five percent of the papers did not display a clear use of former literature as a part of the research. At least thirty percent used historical data actively, including data collected from former projects

About fifty percent of the papers were clearly iterative in their research method. We do assume that this was the case for others, but this was not explicitly stated in those papers. The "plan, act, observe, and reflect" procedures were used by about $75 \%$ of the papers, although some used only part of this reflective cycle.
As an example, Nilsen and co-authors (2018) made active use of the student's experience as an interface manager as a "substitute" for the plan and act phases. His observations had been ongoing during the previous three years while he was an employee and interface manager. He used these observations to provide the relevant data and discuss the relevant subjects. In addition, he used recordings from the prior six years and was able to perform a quantitative study combined with the qualitative in-depth analysis.

Figure 6 shows how the 40 papers align with the different characteristics of action research presented in the background section. The histogram indicates that most of the master's students were actively involved in problem solving, even though most of the papers are somewhat weak on repeatability and rigour and 11 displayed no repeatability at all. Even so, 14 of 40 papers displayed high repeatability and rigour. According to the literature, one of the characteristics of action research is that it often suffers from delays. Our results, presented in Figure 7 , are not conclusive on this point. For $50 \%$ of the papers, the students did not mention any delays. Only five of the papers indicate that they suffer
The author is actively involved in problem solving

The task displays repeatability and rigour

Action research completed without delays

Distinguishes between action and research, ensuring application of both

Researcher gains in-depth knowledge about the problem

High level of practical relevance of the research

The research involves co-learning (a group of practitioners)

The research aims at changing the practice
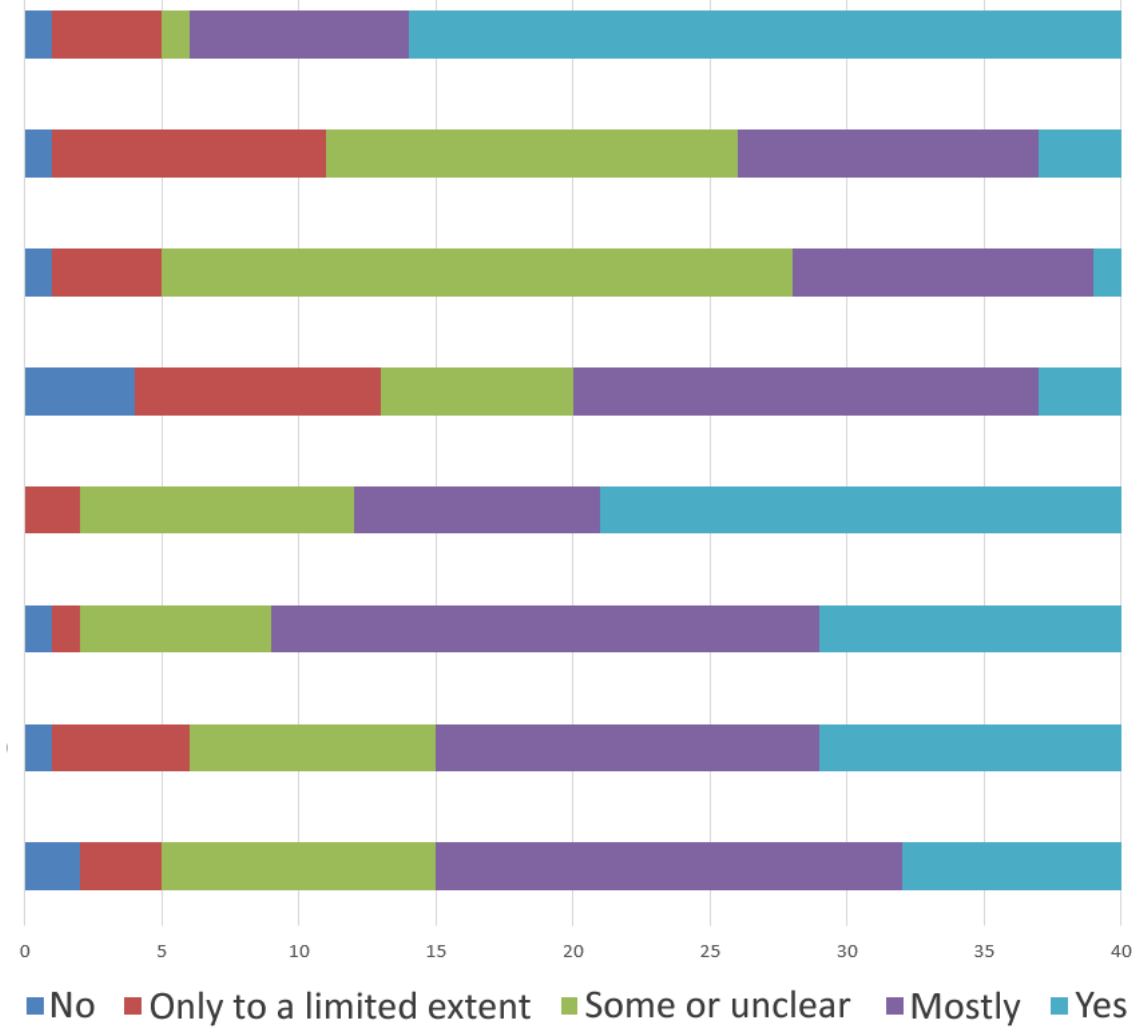

Figure 7. Histogram illustrating the extent to which the research methods in the published papers corresponded to the characteristics of action research 


\section{Embedded Master's Students Conduct Highly Relevant Research Using Industry as Their Laboratory Kristin Falk and Gerrit Muller}

from delay during their research execution, while 14 of the papers gave indications that delays were not a problem. According to our experience, the Industry Master's students are normally not delayed in completing their master's projects. However, we do see that some students need to change their research focus due to delays with products or projects that they had planned to research.

Distinguishing action and research is challenging for the master's students. Yet, only $20 \%$ of the published papers display clear difficulties in distinguishing between action and research, while $50 \%$ of the papers showed evidence of the application of both action and research. Also, our findings indicate that the students did seem to gain in-depth knowledge about the problem they were solving. The question related to the practical relevance was difficult for us to answer based on the papers alone. In general, we know from experience that the industry and academic supervisors are guiding the master's students toward relevant problems.

\section{Elements assisting or hindering the research}

Elements that seem to be hindering the effectiveness of action research include lack of communication and time, and lack of reflections. Notably, the employees in the industrial company prioritized productivity and did not want to "waste time". Some of them were said to be "Not willing to collaborate". Another statement from one of the papers was that "Personnel were not on board early enough" and others claimed that the communication around the research was ineffective or insufficient for the collaborating organization. Two of the papers mentioned the "meeting structure" as an issue. For example, one said: "When having interviews with three or more people we got off track easily, discussions around technical-, or organizational issues appeared." Other papers mentioned "limited time", "delayed industrial project", and "slow project progress and hard to get data due to confidentiality". One student reflected on the fact that he worked in a "single small project" as a limitation to his research. A few of the papers contain no or limited reflections and discussion.

Elements assisting the effectiveness of action research were strongly related to the students having worked for years in the company, but also "proper use of Systems Engineering and research methods." The papers revealed that the fact that the master's students "worked in a company" with "real projects, cases and problems" and with "access to stakeholders" as clear strengths in the research. This made them "very well involved with the subject". It is obvious from several of the papers that the students had been "actively involved for several years with the topic". One paper indicated that they had "very good support of the organization" where they performed their daily work. They often worked in "integrated teams". One paper mentioned the "team using the tool for some months". Another paper claimed that "Meetings with more than one stakeholder can also be beneficial, with cross fertilization, and creation of shared insight." Other elements that strengthened the research were selecting the "appropriate type of models" from Systems Engineering to solve the problem. Active use of "iterations" made the research more valuable as did "extensive use of questionnaires". Some of the strongest papers combined qualitative work with "quantification" and came out with quantified results.

\section{Further experiences and recommendations}

In our experience, it is crucial that the university understands and respects the industrial setting. At USN, we do this by hiring teachers with an industrial background. The supervisors at the university actively guide the students through their master's projects and encourage them to reflect on the subject of their research prior to starting it.

The majority of the master's project papers are not available in the public domain. There are a number of reasons for this, including insufficient quality and confidential content. In a selection of six unpublished papers, supervised by the main investigator, four of these projects were clearly participatory research containing results worth publishing. On the other hand, these papers contained confidential company information and would have needed significant re-writing to be cleared for publication. The remaining two papers suffered from having a simplistic problem and a simplistic solution. In both these latter two cases, the students spent most of their time learning new things on their own. Furthermore, both of these students were working in an industry focusing on downsizing instead of encouraging master's projects.

Supervision of the students is a continuous balancing act between encouraging students to be responsible (e.g., making it the students' responsibility to contact supervisors) and keeping their finger on the pulse of their students' work (e.g., supervisors "pinging" students that stay silent). A good model is to advise students to present and discuss content with their company supervisors bi-weekly, with a copy being sent to the academic supervisor. For example, the academic supervisor would make contact, or "ping" the student, 


\section{Embedded Master's Students Conduct Highly Relevant Research Using Industry as Their Laboratory Kristin Falk and Gerrit Muller}

if the period between contact gets longer than two weeks. Without this regime, we see that students too easily may fall in the trap of solving urgent problems at their companies that may not relate to their research.

Discussion of the content (i.e., What did they do? What was the impact?) is essential to keep the students on track. Simply submitting progress reports can easily hide a lack of real progress or progress that is actually in the wrong direction. The research period is quite limited (only 4 months, effectively). Frequently, the project scope, goal, and some research questions change due to insights gained along the way. Adapting the project to new insights is essential, but it creates uncertainty for the researchers and most stakeholders. However, ignoring new insights is often worse. The supervisors have to guide these adaptations and make sure that the project's line of reasoning keeps focused. They must also ensure that the project scope will fit the schedule and is appropriate for the level of study.

We advise the students to spend about two months out of the six analyzing and reporting their research. There is often too little time set aside for actual writing. As an example, a clever student worked in a project designing a new subsea system. The innovators loved the visual architecting tool he had developed and used it iteratively. The student was busy supporting the innovation to the end. As a result, his written master project report does not contain his new methods, nor does it reflect research that the student actually performed.

In all cases, the final paper has to present the findings in a clear concise top-down way. Hence, changes in the research during the execution should not be reported chronologically. Rather, the paper needs to explain how the project achieves the results. Any adaptations to the research approach are part of the research method, and the researcher may explain the adaptations in a reflection. Example of such change in direction is that the researcher discovers that analysis of the status quo takes so much time or that planned interventions are not feasible within the timescale of the project. However, the analysis of the status quo may still generate significant publishable value. An example of the value of status quo is Tranøy (2014), who did not validate his suggested improvements, but still has by far the highest Google Scholar citation count of all the industry master's student papers.

Finally, we found two recurring patterns in the last part of the execution project, the so-called U-turn and Z-turn:
- The U-turn is the effect that students start writing a chronological report. They have to make a mental Uturn to describe their lessons learned in a top-down fashion. That is quite a challenge because they have been embedded so much in the daily chaos of the industrial context.

- The Z-turn is the previous effect, where students discover, while U-turning, that they lost the research while being embedded: they did not collect sufficient data and observations to reach a proper evaluation. Hence, they need to make another swift repair action to collect evaluation data. This pattern typically appears despite regular advice from the students' coordinators and academic supervisors. A counter-measure to avoid a Zturn is to ask students for early initial evaluations.

\section{Discussion}

We have investigated how well action research works for master's students, and how industry and universities can facilitate participatory action research. We experience that the students improve the methods, learn from practice, and test the methods in a real environment. The article validates theory on action research, it presents an experimental learning model, and it analyzes an extensive list of papers validating Systems Engineering best practice. In addition, the article contributes by connecting theory on research and Systems Engineering to teaching and engineering practices.

The Industry Master's model at USN is completely dependent on collaboration between industry and academia. This is the case both for education and for research, as we have seen in this article. The model in Figure 1, which is designed to create synergies between industry, teaching, and academia within the domain of Systems Engineering, illustrates the ecosystem. This model supports the points of Garousi and colleagues (2016) with respect to "best practices" in industry-university collaboration. Reformulating these points to our context, we propose the following best practices:

1. Define real-world problems.

2. Provide benefits to industry and solve the right problems.

3. Manage engagement and commitment through the students and their work.

4. Be flexible and professional. 


\section{Embedded Master's Students Conduct Highly Relevant Research Using Industry as Their Laboratory Kristin Falk and Gerrit Muller}

5. Engage in workshops and seminars through courses and interactions with alumni.

Figure 6 presented the main findings from our structured literature review by relating the reviewed papers to theory on action research. A deeper analysis of the papers displayed that elements that seem to be hindering the effectiveness of action research include lack of communication and time, and lack of reflections. Elements assisting the effectiveness of action research were strongly related to the students having worked for years in the researching company, but also "proper use of Systems Engineering and research methods".

We offer the following recommendations for facilitating participatory action research using the industry-aslaboratory approach:

1. Define a research problem that is of high importance to the company. This makes the research relevant and significant with a high level of practical relevance. This is also supported by theory in Van de Ven (2007). Industry-as-laboratory has much in common with the engaged scholarship process applied in a management context.

2. Do research in a familiar context. This enabled the students to focus on the Systems Engineering methods instead of having to spend most of the time understanding the environment. Using students to perform action research is not new. Full-time students often do their final master's work affiliated with a company. These students typically need help in defining relevant problems and more time to understand the context. Having relevant jobs and internships or co-op placements prior to doing research helps students to understand context. This is the case, in our experience, even when the students worked in a domain different from where they are doing research. The Industry Master's students at USN are fully acquainted with both the company and context when they finish their master's paper after three years of work.

3. Hire supervisors with industrial experience that actively guide the students through the research. The working period before starting the master's project serves well to overcome opposing forces between the industrial domain, requiring pragmatic solutions early, and the academic environment, requiring depth and academic rigour. The supervisors are strongly pushing this distinction during the preparation and execution phases of the master projects. This push may explain why more than half of published master papers were clearly able to distinguish action and research. From our results, it seems that the Industry Master's students manage this rather well, but an evaluation from one of the students still characterized their master's project as a "roller coaster experience".

4. Make sure the research results are accessible to the practitioners. In the tradition of experimental learning and action research, the researchers do this by practicing and involving, not only by reporting.

5. Apply Kolb's reflective learning cycle during the research period. Unfortunately, there is limited time, and the students are not always able to apply the full methodology. If the goal is to change the practice, then theory states that action research is well suited to this. We do not have clear evidence that the brief master's projects change practices, but we do know that the companies acquire new knowledge through the students and their research.

6. Apply reflective practice in teaching to enhance learning and change. Recall that the Industry Master's students have been working for at least three years when finalizing their degree. During these three years, they have been simultaneously studying, including a course in reflective practice that teaches them how to reflect on and apply their learnings in the industrial context. Theory states that reflective practice supports action research. Moreover, action research enables students and researchers deep access into their respective companies.

A master's project is the closure of three years of practicing experimental learning with reflective practice as the core and the student's placement within the engineering workplace for most of that time. Even their homework and exams are partly performed in their company. Other, more human-centred or innovative disciplines such as medicine, education, and design have applied situated learning for centuries. They are learning by doing. These fields also actively apply action research as a tool to collect and develop knowledge. Technology disciplines apply situated learning on lower levels, such as with electricians and mechanics. However, at an engineering level, situated learning is not common. For Systems Engineering, having to deal with humans and business in addition to science, the selection of situated learning and action research seems like a natural step. What about other engineers - are they not dealing with people and innovations? We believe that a step towards more situated learning would be beneficial also in other engineering disciplines. 


\section{Embedded Master's Students Conduct Highly Relevant Research Using Industry as Their Laboratory Kristin Falk and Gerrit Muller}

A major contribution of this article is a unique collection of research on engineering practice from within the sponsoring companies. Since the researchers are also the engineers, actively involved in problem solving, they have been able to participate in the engineering practice and collect knowledge that is otherwise not available from the outside. This tacit knowledge is used by colleagues to learn, but it is also available to a broader community and as a way to share learning between companies, domains, and industries. For our case, the Systems Engineering theory originating from space and defense disperses into other industries such as energy and maritime through teaching. The master's students validate the body of knowledge in other industries and identify what is practiced in the industry and what works where. The students must select topics of importance to their companies, which results in relevant research topics. We see a tendency for companies with a high number of Systems Engineering students to change their practices and become aware of the tacit knowledge of their employees. The research papers, written primarily by the students, are to a certain extent also used as curriculum in courses.

\section{Limitations of the current research}

There will be biases in this research. For example, only one of the researchers performed all the review and structuring of the papers. The basis for the review was the written papers, primarily the abstracts, but she also had to go through the conclusions and research methods as well as discussions for most of the papers. The researcher had, prior to this research, read 15 of the papers in depth and been supervisor for five of the students. The researcher spent, on average, about 15 minutes per paper analyzing with a variance of 40 minutes. This was not enough time to read the whole paper. Thus, there will be reflections and methods hidden in the paper that we have not included in this analysis. We did analyze the abstract and conclusions in detail, however. Also, we acknowledge that, although the students are provided with a template, they may reflect and observe in sections other than the abstract or conclusion. Another limitation of the current research is that it is based only on Systems Engineering students working in a small selection of industries. Furthermore, the theory on action research is extensive. We have only tested towards a limited set of publications and ideas.

\section{Further research}

Each master's paper contains only a small contribution to the knowledge of Systems Engineering. If we combine them, the significance will increase. Several of the papers discuss the same methods such as requirements, A3AO, and concept selection. A combined analysis across all the topics should provide a deeper insight into a selection of appropriate methods. The published papers can also be used to investigate details of the separate Systems Engineering practices.

The master's program is still evolving and improving. We are striving to incorporate more of the research into teaching. When it comes to the effect of reflective practice and the form of research, it would be interesting to compare to other groups of students. We would also like to know more about the effect of situated learning, for example, to see if there has been a change of practice.

\section{Conclusion}

This article investigates experiences with action research for master projects over a ten-year period. We reviewed 40 published papers performed by master's students who used the industry-as-laboratory. The papers indicate that the students had a good understanding of the industrial problems they were solving. They identified key triggers for the research and achieved insightful results on the topic of Systems Engineering. We classify $80 \%$ of the papers to be within action research, meaning that the research aims at changing the practice and involves co-learning. Only about half of the papers clearly illustrated the iterative nature of action research, and $75 \%$ used the "plan, act, observe, reflect" cycle. Elements that seem to be hindering the effectiveness of action research include lack of time, communication, and reflections. Elements assisting the effectiveness of action research were strongly related to the students having worked for years in the researching company, but also "proper use of Systems Engineering and research methods."

This article also offers recommendations to industry and universities on how to facilitate participatory action research performed by master's students. In our situation, we embed the students for three years into an industrial setting within the field of Systems Engineering. This familiarizes students with context and enables them to contribute to the action part of research. The problem to solve is thereby important and relevant to industry. The supervisor can facilitate the research by preparing students and by close follow-up of the research process during the master's project. It is crucial that the students report and validate results - only then will the action become research. 


\section{Embedded Master's Students Conduct Highly Relevant Research Using Industry as Their Laboratory Kristin Falk and Gerrit Muller}

\section{Additional Resources}

- Master of Science in Systems Engineering at the University of South-Eastern Norway:

tinyurl.com/y2e6h6za

- Systems Engineering Master Project course material: gaudisite.nl/SEMP.html

- Published Master Project Papers from the Systems Engineering Program: gaudisite.nl/MasterProjectPapers.html

\section{About the Authors}

Kristin Falk is an Associate Professor at University College of Southeastern Norway, where she is responsible for the Systems Engineering Energy track, and fronting research on Systems Engineering. Kristin holds a $\mathrm{PhD}$ in Petroleum Production and a Master's in Industrial Mathematics, both from Norwegian University of Science and Technology. She has worked within the oil and gas industry for 20 years, both with major subsea suppliers and with small startups. She has worked in various roles within engineering and management, cooperating well with multidisciplinary teams. She has successfully taken products from research through qualification and commercialization, and she has led R\&D projects both in industry and academia. Her current research focus is subsea architecture, safety, engineering communication, and innovation within the Systems Engineering framework.

Gerrit Muller, originally from the Netherlands, received his Master's degree in Physics from the University of Amsterdam in 1979. He worked from 1980 until 1997 at Philips Medical Systems as a System Architect, followed by two years at ASML as Manager of Systems Engineering, returning to Philips (Research) in 1999. Since 2003, he has worked as Senior Research Fellow at the Embedded Systems Institute in Eindhoven, focusing on developing system architecture methods and the education of new system architects, receiving his doctorate in 2004. In January 2008, he became full Professor of Systems Engineering at University College of Southeast Norway in Kongsberg, Norway. He continues to work as a Senior Research Fellow at the Embedded Systems Innovations by TNO in Eindhoven in a part-time position.

\section{References}

Beard, C. M., \& Wilson, J. P. 2006. Experiential Learning: A Best Practice Handbook for Educators and Trainers. London: Kogan Page Publishers.

Chestnut, H. 1967. Systems Engineering Methods. New York: John Wiley \& Sons.

Ellström, P.-E. 2007. Knowledge Creation through Interactive Research: A Learning Perspective. Paper presented at the HHS-07 Conference, Jönköping University, Sweden, May 8-11, 2007.

Frank, M. 2014. Towards a 4-D Systems Engineering Cognitive Competency Model. INCOSE International Symposium, 24(1): 617-634. https://doi.org/10.1002/j.2334-5837.2014.tb03171.x

Garousi, V., Petersen, K., \& Ozkan, B. 2016. Challenges and Best Practices in Industry-Academia Collaborations in Software Engineering: A Systematic Literature Review. Information and Software Technology, 79: 106-127. https://doi.org/10.1016/j.infsof.2016.07.006

Goode, H. H., \& Machol, R. E. 1957. System Engineering: An Introduction to the Design of Large-Scale Systems. New York: McGraw-Hill Book Company Inc.

Kolb, D. A. 2014. Experiential Learning: Experience as the Source of Learning and Development. Upper Saddle River, NJ: FT Press.

Koshy, V. 2005. Action Research for Improving Practice: A Practical Guide. London: SAGE.

Lave, J., \& Wenger, E. 1991. Situated Learning: Legitimate Peripheral Participation. Cambridge, UK: Cambridge University Press.

McKinney, D., Arnold, E., \& Sheard, S. 2015. Change Agency for Systems Engineers. INCOSE International Symposium, 25(1): 1209-1231.

https://doi.org/10.1002/j.2334-5837.2015.00125.x

McKinney, D., \& Contractor, S. 2013. Systems Engineering Implications of Neuroscience Discoveries. INCOSE International Symposium, 23(1): 1418-1432.

https://doi.org/10.1002/j.2334-5837.2013.tb03096.x

Muller, G. 2009. Creating an Academic Systems Engineering Group; Bootstrapping Systems Engineering Research. Paper presented at the 7th Annual Conference on Systems Engineering Research, Loughborough University, UK, April 20-23, 2009.

Muller, G. 2012. Validation of Systems Engineering Methods and Techniques in Industry. Procedia Computer Science, 8: 321-326. https://doi.org/10.1016/j.procs.2012.01.067

Muller, G. 2013. Systems Engineering Research Methods. Procedia Computer Science, 16: 1092-1101. https://doi.org/10.1016/j.procs.2013.01.115

Muller, G. 2015. Reflective Practice to Connect Theory and Practice; Working and Studying Concurrently. Procedia Computer Science, 44: 679-688. https://doi.org/10.1016/j.procs.2015.03.008

Muller, G., \& Bonnema, G. M. 2013. Teaching Systems Engineering to Undergraduates; Experiences and Considerations. INCOSE International Symposium, 23(1): 98-111. 


\section{Embedded Master's Students Conduct Highly Relevant Research Using Industry as Their Laboratory Kristin Falk and Gerrit Muller}

Muller, G., \& Falk, K. 2018. What Can (Systems of) Systems Engineering Contribute to Oil and Gas? An illustration with Case Studies from Subsea. In Proceedings of the 13th Annual Conference on System of Systems Engineering (SoSE): 629-635.

Muller, G., \& Heemels, W. M. 2007. Five Years of Multi-Disciplinary Academic and Industrial Research: Lessons Learned. In Proceedings of the 5th Annual Conference on Systems Engineering Research (CSER), Hoboken, NJ, March 14-16, 2007.

Nilsen, M. A., Falk, K., \& Haugen, T. A. 2018. Reducing Project Cost Growth through Early Implementation of Interface Management. INCOSE International Symposium, 28(1): 96-114.

O'Brien, R. 2001. Um exame da abordagem metodológica da pesquisa ação [An Overview of the Methodological Approach of Action Research]. In R. Richardson (Ed.), Teoria e Prática da Pesquisa Ação [Theory and Practice of Action Research]. João Pessoa, Brazil: Universidade Federal da Paraíba.

Potts, C. 1993. Software-Engineering Research Revisited. IEEE Software, 10(5):19-28.

Research-Methodology.net. 2018. Action Research. ResearchMethodology.net. Accessed November 25, 2018: https://research-methodology.net/research-methods/actionresearch/
Saunders, M., Lewis, P., \& Thornhill, A. 2012. Research Methods for Business Students (6th ed). Harlow, UK: Pearson.

Tranøy, E., \& Muller, G. 2014. Reduction of Late Design Changes through Early Phase Need Analysis. INCOSE International Symposium, 24(1): 570-582.

Tripp, D. 2005. Action Research: A Methodological Introduction. Educacao e pesquisa, 31(3): 443-466. http://dx.doi.org/10.1590/S1517-97022005000300009

Valerdi, R., Brown, S., \& Muller, G. 2010. Towards a Framework of Research Methodology Choices in Systems Engineering. In Proceedings of the 8th Annual Conference on Systems Engineering Research, Hoboken, NJ, March 17-19, 2010.

Van de Ven, A. H. 2007. Engaged Scholarship: A Guide for Organizational and Social Research. Oxford: Oxford University Press.

Vygotsky, L. S. 1978. Mind in Society: The Development of Higher Mental Processes. Cambridge, MA: Harvard University Press.

Vygotsky, L. S. 1986. Thought and Language. (A. Kozulin, Trans. and Ed.). Cambridge, MA: The MIT Press. 


\section{Embedded Master's Students Conduct Highly Relevant Research Using Industry as Their Laboratory Kristin Falk and Gerrit Muller}

Appendix 1. Papers published by the Industry Master's students

\begin{tabular}{|c|c|c|c|c|c|}
\hline \# & Student Name & Year & Problem to Solve & Systems Engineering Topic & Industrial Domain \\
\hline 1 & Marianne I. Drotninghaug & 2010 & Logistics & Value of Systems Engineering & Manufacturing \\
\hline 2 & Even Engebakken & 2010 & Safety & Conceptual modelling & Manufacturing \\
\hline 3 & Jorn Breivoll & 2010 & $\begin{array}{l}\text { Cost and schedule } \\
\text { overrun }\end{array}$ & Trade study & Maritime \\
\hline 4 & Andreas Rasmussen & 2010 & Risk in early phase & Risk assessment & Maritime \\
\hline 5 & Volker Heierhoff & 2011 & $\begin{array}{l}\text { Resource } \\
\text { management }\end{array}$ & $\begin{array}{l}\text { Enterprise resource } \\
\text { management (ERP) }\end{array}$ & Energy \\
\hline 6 & $\begin{array}{l}\text { Dag Jostein Klever \& Halvard } \\
\text { H. Bjørnsen }\end{array}$ & 2011 & $\begin{array}{l}\text { Competitive } \\
\text { advantage }\end{array}$ & Concept selection & Energy \\
\hline 7 & Levi Vigdal & 2011 & Risk & Conceptual modelling & Energy \\
\hline 8 & Jan Magnus Røkke & 2011 & $\begin{array}{l}\text { Avoid late design } \\
\text { changes and rework }\end{array}$ & Requirements & Energy \\
\hline 9 & Elisabeth Hansen & 2012 & Efficiency in design & Lean & Automotive \\
\hline 10 & Rasmus Wibe Rypdal & 2012 & $\begin{array}{l}\text { Competitive } \\
\text { advantage }\end{array}$ & Project management & Manufacturing \\
\hline 11 & Bjørnar Wiulsrød & 2012 & Cost & A3AO & Maritime \\
\hline 12 & Jan Ove Mjånes & 2013 & Project execution & Lifecycle management & Energy \\
\hline 13 & Asgeir Øvergaard & 2013 & Cost & Automated software testing & Maritime \\
\hline 14 & Vickram Singh & 2013 & $\begin{array}{l}\text { Cost of late design } \\
\text { changes }\end{array}$ & A3AO & Energy \\
\hline 15 & Arne Kristian Bye & 2014 & $\begin{array}{l}\text { System } \\
\text { optimization }\end{array}$ & Concept election & Energy \\
\hline 16 & Eldar Tranøy & 2014 & Cost and time & Needs analysis & Energy \\
\hline 17 & Linda Lønmo & 2014 & Cost and time & Concept selection & Energy \\
\hline 18 & Anders Fuglesteg Nilsen & 2014 & $\begin{array}{l}\text { Customer } \\
\text { satisfaction }\end{array}$ & A3AO & Consultancy \\
\hline 19 & Bjørn Stalsberg & 2014 & $\begin{array}{l}\text { Customer } \\
\text { satisfaction }\end{array}$ & Modelling tools & Manufacturing \\
\hline 20 & Halvor Eide & 2016 & Cost and time & Trade study & Energy \\
\hline
\end{tabular}




\section{Embedded Master's Students Conduct Highly Relevant Research Using Industry as Their Laboratory Kristin Falk and Gerrit Muller}

Appendix 1 (continued). Papers published by the Industry Master's students

\begin{tabular}{|c|c|c|c|c|c|}
\hline$\#$ & Student Name & Year & Problem to Solve & Systems Engineering Topic & Industrial Domain \\
\hline 21 & Thomas Henanger & 2016 & $\begin{array}{l}\text { Complexity in } \\
\text { installation }\end{array}$ & Conceptual modelling & Energy \\
\hline 22 & Arne Rugaas & 2016 & $\begin{array}{l}\text { Cost due to late } \\
\text { design changes }\end{array}$ & Knowledge management & Energy \\
\hline 23 & Peter Callister & 2016 & Technical risk & Systems integration & Energy \\
\hline 24 & Herman Solli & 2016 & Cost & Concept selection & Energy \\
\hline 25 & Kok Yi Damien Wee & 2016 & Quality and cost & Requirements & Energy \\
\hline 26 & Alexander Svendsen & 2016 & Quality & A3 & Energy \\
\hline 27 & Arne Goderstad & 2016 & Quality & Trade study & Defense \\
\hline 28 & $\begin{array}{l}\text { Aksel Botne Sandberg \& Eirik } \\
\text { Klementsen (Outside of the } \\
\text { Industry Master's program) }\end{array}$ & 2016 & Commercialization & PESTEL/Porter & New Energy \\
\hline 29 & Lars Petter Bryn & 2017 & Cost and robustness & Conceptual modelling & Energy \\
\hline 30 & Simen Bergli & 2017 & Cost and quality & Qualification & Energy \\
\hline 31 & Anders Roe Nykaas & 2017 & $\begin{array}{l}\text { Complexity in } \\
\text { installation }\end{array}$ & Autonomous & Energy \\
\hline 32 & Simon Aasheim & 2017 & $\begin{array}{l}\text { Cost of late design } \\
\text { changes }\end{array}$ & Requirements & Energy \\
\hline 33 & Kristian Frøvold & 2017 & $\begin{array}{l}\text { Attractive } \\
\text { product/system }\end{array}$ & $\mathrm{A} 3 \mathrm{AO}$ & Maritime \\
\hline 34 & Magnus André Nilsen & 2018 & Cost and time & Interface management & Energy \\
\hline 35 & Sindre Løndal & 2018 & $\begin{array}{l}\text { Cost and time of } \\
\text { engineering }\end{array}$ & $\mathrm{A} 3 \mathrm{AO}$ & Energy \\
\hline 36 & Ole Kaare Ulsvik & 2018 & $\begin{array}{l}\text { Time and cost of } \\
\text { engineering }\end{array}$ & Standardization & Energy \\
\hline 37 & Kjersti Bakke & 2018 & Literature survey & Technology readiness levels & None \\
\hline 38 & Christoffer Jimmy Røsegg & 2018 & $\begin{array}{l}\text { Time and cost of } \\
\text { testing and } \\
\text { integration }\end{array}$ & Verification & Energy \\
\hline 39 & Maximiliano Moraga & 2018 & Legacy software & Conceptual modelling & Manufacturing \\
\hline 40 & Anders Viken & 2018 & $\begin{array}{l}\text { Time of } \\
\text { commissioning }\end{array}$ & A3AO & Maritime \\
\hline
\end{tabular}




\section{Embedded Master's Students Conduct Highly Relevant Research Using Industry as Their Laboratory Kristin Falk and Gerrit Muller}

\section{References for Appendix 1}

1. Drotninghaug, M. I., Muller, G., \& Pennotti, M. 2009. The Value of Systems Engineering Tools for Understanding and Optimizing the Flow and Storage of Finished Products in a Manganese Production Facility. EUSEC 2010: Stockholm.

https://www.gaudisite.nl/EUSEC2010_DrotninghaugEtAl_SEatManganeseProduction.pdf

2. Engebakken, E., Muller, G., \& Pennotti, M. 2010. Supporting the System Architect: Model-Assisted Communication. Systems Research Forum, 4(02): 173-188. https://www.gaudisite.nl/SRF2010-2_Engebakken_Muller_Pennotti_Modeling.pdf

3. Breivoll, J., \& Muller, G. 2010. Change Impact Analysis-A Case Study. In Proceedings of the 8th Conference on Systems Engineering Research: 668-677. https://www.gaudisite.nl/CSER2010_BreivollMullerPennotti_changeImpact.pdf

4. Rasmussen, A., Maritime, K., Muller, G., \& P Pennotti, M. 2010. Causal Loop Based Change Propagation and Risk Assessment. EUSEC 2010. Stockholm. https://www.gaudisite.nl/EUSEC2010_RasmussenEtAl_CausalLoop.pdf

5. Heierhoff, V., Arntzen, A. A. B., \& Muller, G. 2011. A Training Model for Successful Implementation of Enterprise Resource Planning. International Journal of Information and Communication Engineering, 5(12): 505-511.

https://www.gaudisite.nl/WASET2011_HeierhoffEtAl_ERPtraining.pdf

6. Muller, G., Klever, D. G., Bjørnsen, H. H., \& Pennotti, M. 2011. Researching the Application of Pugh Matrix in the Sub-Sea Equipment Industry. In Proceedings of the 9th Annual Conference on Systems Engineering Research (CSER).

https://www.gaudisite.nl/CSER2011_MullerEtAl_ResearchingPughMatrix.pdf

7. Vigdal, L. A. B., Muller, G., \& Pennotti, M. 2011. How Applying Models in Work Group Sessions Can Help to Retrieve Information for Making FTA and FMECA Analysis. INCOSE International Symposium, 21(1): 14-27.

https://www.gaudisite.nl/INCOSE2011_Vigdal_FTAandFMECAanalysis.pdf

8. Røkke, J. M., Muller, G., \& Pennotti, M. 2011. Requirement Elicitation and Validation by Prototyping and Demonstrators: User Interface Development in the Oil and Gas Industry. Systems Research Forum, 5(02): 89-108.

https://www.gaudisite.nl/SRF2011-2_Rokke_Muller_Pennotti_RequirementElicitation.pdf

9. Hansen, E., \& Muller, G. 2012. Set-Based Design-The Lean Tool that Eludes Us; Pitfalls in Implementing Set-Based Design in Kongsberg Automotive. INCOSE International Symposium, 22(1): 1603-1618.

https://www.gaudisite.nl/INCOSE2012_Hansen_Muller_SetBasedDesign.pdf

10. Rypdal, R. W., Muller, G., \& Pennotti, M. 2012. Developing the Modeling Recommendation Matrix: Model-Assisted Communication at Volvo Aero. INCOSE International Symposium, 22(1): 1870-1883. https://www.gaudisite.nl/INCOSE2012_RypdalEtAl_ModelMaker.pdf

11. Wiulsrød, B., Muller, G., \& Pennotti, M. 2012. Architecting Diesel Engine Control System Using A3 Architecture Overview. INCOSE International Symposium, 22(1): 1791-1805. https://www.gaudisite.nl/INCOSE2012_Wiulsr\%C3\%B8dEtAl_DieselEngineA3.pdf

12. Mjånes, J. O., Haskins, C., \& Piciaccia, L. A. 2013. Closing the Loop for Lifecycle Product Management in Norwegian Subsea Systems. INCOSE International Symposium, 23(1): 490-501.https://www.gaudisite.nl/INCOSE2013_Mj\%C3\%A5nesEtAl_SEprocess.pdf

13. Øvergaard, A., \& Muller, G. 2013.System Verification by Automatic Testing. INCOSE International Symposium, $23(1)$ : 356-367. https://www.gaudisite.nl/INCOSE2013_\%C3\%98vergaard_Muller_AutomatedTesting.pdf

14. Singh, V., \& Muller, G. 2013. Knowledge Capture, Cross Boundary Communication and Early Validation with Dynamic A3 Architectures. INCOSE International Symposium, 23(1): 84-97. https://www.gaudisite.nl/INCOSE2013_Singh_Muller_DynamicA3.pdf

15. Bye, A. K., \& Piciaccia, L. A. 2014. System Engineering Applied to Concept Design Optimization of Subsea Coolers. INCOSE International Symposium, 24(1): 599-616. https://www.gaudisite.nl/INCOSE2014_Bye_Piciaccia_SubseaCoolers.pdf

16. Tranøy, E., \& Muller, G. 2014. Reduction of Late Design Changes Through Early Phase Need Analysis. INCOSE International Symposium, 24(1): 570-582. https://www.gaudisite.nl/INCOSE2014_Tran\%C3\%B8y_Muller_ReductionOfLateDesignChanges.pdf

17. Lønmo, L., \& Muller, G. 2014. Concept Selection-Applying Pugh Matrices in the Subsea Processing Domain. INCOSE International Symposium, 24(1): 583-598. https://www.gaudisite.nl/INCOSE2014_Lonmo_Muller_ConceptSelection.pdf

18. Nilsen, A. F., \& Muller, G. 2014. 1.2. 1 Use Cases and Non-functional Requirements Presented in Compact System Description A3s. INCOSE International Symposium, 24(1): 1-15. https://www.gaudisite.nl/INCOSE2014_Nilsen_Muller_NFRinA3.pdf

19. Stalsberg, B., \& Muller, G. 2014. Increasing the Value of Model-Assisted Communication: Modeling for Understanding, Exploration and Verification in Production Line Design Projects. INCOSE International Symposium, 24(1): 827-842.

https://www.gaudisite.nl/INCOSE2014_Stalsberg_Muller_ModelingProductionLine.pdf

20. Eide, H. M., \& Haskins, C. 2016. Trade Study of Alternative Controls and Power Distribution Architecture in Subsea Processing. INCOSE International Symposium, 26(1): 2148-2163. https://www.gaudisite.nl/INCOSE2016_Eide_Haskins_Control.pdf

21. Henanger, T., Muller, G., \& Picacia, L. 2016. Managing Installation Tolerances through System Modeling and Tolerance Budgeting. INCOSE International Symposium, 26(1): 1176-1191. https://www.gaudisite.nl/INCOSE2016_HenangerEtAl_Tolerances.pdf

22. Rugaas, A. K., \& Zhao, Y. Y. 2016. Knowledge Roadmap across Design and Engineering: An User-Centric Didactic Approach. IEEE International Conference on Industrial Engineering and Engineering Management (IEEM): 686-690. https://doi.org/10.1109/IEEM.2016.7797963

timreview.ca 


\section{Embedded Master's Students Conduct Highly Relevant Research Using Industry as Their Laboratory Kristin Falk and Gerrit Muller}

23. Callister, P. S., \& Andersson, J. 2016. Evaluation of System Integration and Qualification Strategies Using the Technical Debt Metaphor; A Case Study in Subsea System Development. INCOSE International Symposium, 26(1): 1016-1028.

https://www.gaudisite.nl/INCOSE2016_Callister_Andersson_SMARTtechnicalDebt.pdf

24. Solli, H., \& Muller, G. 2016. Evaluation of Illustrative ConOps and Decision Matrix as Tools in Concept Selection. INCOSE International Symposium, 26(1): 2361-2375. https://www.gaudisite.nl/INCOSE2016_Solli_Muller_VisualConOps.pdf

25. Damien Wee, K. Y., \& Muller, G. 2016. Evaluating the Effectiveness of Applying a Requirements Management System for a Subsea Oil and Gas Workover System. INCOSE International Symposium, 26(1): 2346-2360. https://www.gaudisite.nl/INCOSE2016_Wee_Muller_Requirements.pdf

26. Svendsen, A., \& Haskins, C. 2016. Applying A3 Problem Resolution to New System Design to Improve Performance and Reduce Rework. INCOSE International Symposium, 26(1): 1161-1175. https://www.gaudisite.nl/INCOSE2016_Svendsen_Haskins_A3problemResolution.pdf

27. Goderstad, A. B., \& Haskins, C. 2016. Understanding Mission Objectives and Priorities with QFD. INCOSE International Symposium, 26(1): 283-299. https://www.gaudisite.nl/INCOSE2016_Goderstad_Haskins_QFD.pdf

28. Sandberg, A., Klementsen, E., Muller, G., de Andres, A., \& Maillet, J. 2016. Critical Factors Influencing Viability of Wave Energy Converters in OffGrid Luxury Resorts and Small Utilities. Sustainability, 8(12): 1274. https://doi.org/10.3390/su8121274

29. Bryn, L. P., \& Muller, G. 2017. Evolving Tolerance Management for Increased Robustness of Subsea Installation Operations. INCOSE International Symposium, 27(1): 242-256. https://www.gaudisite.nl/INCOSE2017_Bryn_MullerToleranceManagement.pdf

30. Bergli, S., \& Falk, K. 2017. Cause and Impact Analysis of Cost and Schedule Overruns in Subsea Oil and Gas Projects-A Supplier's Perspective. INCOSE International Symposium, 27(1): 309-321. https://www.gaudisite.nl/INCOSE2017_Bergli_Falk_CostAnalysis.pdf

31. Nykaas, A. R., \& Zhao, Y. Y. 2017. A Context-Enabled Systems Development Method: The Case of Semi-Autonomous Remotely Operated Vehicles in an Arctic Environment. INCOSE International Symposium, 27(1): 229-241.

https://www.gaudisite.nl/INCOSE2017_Nykaas_Zhao_ROV.pdf

32. Aasheim, S., \& Zhao, Y. Y. 2017. Developing the Stakeholder Requirements Definition Process—A Journey of Customization. 12th System of Systems Engineering Conference (SoSE): 1-6. https://www.gaudisite.nl/SOSE2017_Aasheim_Zhao_RequirementsDefinition.pdf

33. Frøvold, K., Muller, G., \& Pennotti, M. 2017. Applying A3 Reports for Early Validation and Optimization of Stakeholder Communication in Development Projects. INCOSE International Symposium, 27(1): 322-338. https://www.gaudisite.nl/INCOSE2017_Frovold_A3.pdf

34. Nilsen, M. A., Falk, K., \& Haugen, T. A. 2018. Reducing Project Cost Growth Through Early Implementation of Interface Management. INCOSE International Symposium, 28(1): 96-114. https://www.gaudisite.nl/INCOSE2018_Nilsen_Falk_InterfaceManagement.pdf

35. Løndal, S., \& Falk, K. 2018. Implementation of A3 Architectural Overviews in Lean Product Development Teams; A Case Study in the Subsea Industry. INCOSE International Symposium, 28(1): 1737-1752. https://www.gaudisite.nl/INCOSE2018_Londal_Falk_A3subsea.pdf

36. Ulsvik, O. K., \& Falk, K. 2018. Developing a Configure-to-Order Product in the Subsea Oil and Gas Domain. INCOSE International Symposium, 28(1): 209-225. https://www.gaudisite.nl/INCOSE2018_Ulsvik_Falk_ConfigureToOrder.pdf

37. Bakke, K., \& Haskins, C. 2018. Use of TRL in the Systems Engineering Toolbox. INCOSE International Symposium, 28(1): 587-601. https://www.gaudisite.nl/INCOSE2018_Bakke_Haskins_TRL.pdf

38. Røsegg, C. J., \& Falk, K. 2018. The Importance of Project Management in the System Integration, Verification and Validation Process. INCOSE International Symposium, 28(1): 226-244. https://www.gaudisite.nl/INCOSE2018_Rosegg_Falk_PMinVV.pdf

39. Moraga, M., \& Zhao, Y. Y. 2018. Reverse Engineering a Legacy Software in a Complex System: A Systems Engineering Approach. INCOSE International Symposium, 28(1): 1250-1264. https://www.gaudisite.nl/INCOSE2018_Moraga_Yang_LegacySoftware.pdf

40. Viken, A., \& Muller, G. 2018. Creating and Applying A3 Architecture Overviews: A Case Study in Software Development. INCOSE International Symposium, 28(1): 378-391. https://www.gaudisite.nl/INCOSE2018_Viken_MullerA3.pdf

The following published papers were not included in the analysis because they were not readily available at the time of the analysis:

- Bøhn, A.H. \& Arntzen Bechina, A.A. 2015. A Generic A3 Framework for Sharing Knowledge in a Systems Engineering Context. Society for Design and Process Science, 20: 334-341.

- Haugen, J. A., \& Arntzen Bechina, A. A. 2016. An Investigation of Cost Based Framework for Documentation Reuse. Society for Design and Process Science, 21: 18-24.

- Simonsen, J.Ø.G \& Arntzen Bechina, A. A. 2014. A Model of Knowledge Sharing Fostering the Learning Capability - A Case Study within the Aerospace Industry. Society for Design and Process Science, 19: 447-455.

Citation: Falk, K., \& Muller, G. 2019. Embedded Master's Students Conduct Highly Relevant Research Using Industry as Their Laboratory. Technology Innovation Management Review, 9(5): 54-73. http://doi.org/10.22215/timreview/1241

Keywords: participatory research, action research, experimental learning, situated learning, Systems Engineering, master's students, knowledge transfer, master project, lessons learned, industrial knowledge, industry as laboratory, innovations, systems of systems, energy 


\section{Q\&A}

\section{Bengt Wahlström}

\section{Q. What Can Action Research Learn from Business Environment Analysis?}

\begin{abstract}
A ing point for bridging the divide between academia and business, because action research does not accept the boundaries between the researcher and what is being researched and it seeks to bring in other types of knowledge fields. But there is a group that has long worked in the borderland between academia and practice: consultants. They already use and create theories in their quest to help organizations develop, and in my own 30 years as a consultant within business environment analysis, I have seen how insights from consultancy can help bridge the divide between academia and business. But, before answering what action research can learn from business environment analysis, an overview of each field is in order.
\end{abstract}

\section{Business Environment Analysis}

Business environment analysis is used to identify strategically relevant external and internal factors, both expected and unexpected, that can affect an organization's performance. Hence, business environment analysis, broadly speaking, is the process of interpreting signals from outside the firm and then through insights gained through this analysis - changing the company's operation and strategic intent to make the organization more viable.

Monitoring the outside world is a matter of survival for any organization. Argyris and Schön (1996) argue that everyone - from companies and organizations to regions and nations - must adapt to changes in the outside world and learn from others' successes and failures, as well as discover challenges and threats while watching what is happening. Hamrefors (2002) adds that observing and analyzing these signals are not enough. Without action, companies will lag behind the competition. The implementation of effective business environment analysis systems and processes helps organizations to go from signals, through to the analysis, and then to taking appropriate actions.

Pfeffer and Salancik (2003) divide the outside world into several levels. One level consists of the actors and activities outside the organization but with links to the business in question. Another level is the different actors that the organization interacts with, and a third level is how the organization itself perceives and interprets this outside world (see also Hoppe, 2009). In this sense, a business environment analysis consultant assists their clients in the process of discovering, interpreting, and taking advantage of various business environment changes at all these levels.

The interest in using business environment analysis has increased significantly over the years, which is in line with the ever faster and more dramatic changes occurring in the world. However, the link between these changes and the organization's activities is not always obvious. Rohrbeck and Gemünden (2011) note that a rapid development rate - where there are increasing numbers of innovations, unexpected technology shifts, and shorter product lifecycles - creates difficulties in adapting, and thus capturing, business environment information.

\section{Linking Action Research to Management and Consultancy Work}

The concept of action research was coined by Kurt Lewin (1946) to describe a problem-solving mechanism where researchers would engage in the emancipation of underprivileged groups by helping them research their own situation and future. Over the years, the concept of action research has developed and gained many different meanings in addition to Lewin's connection to social action and minority problems. Johansson and Lindhult (2008) argue that the term is now used in so many ways that it has lost its original meaning. They emphasize the concepts of pragmatic versus critical orientation of action research and note that, in Scandinavia, the pragmatic orientation is strong. It is characterized by a broad and open dialogue between everyone involved and where the researchers are partners in this dialogue. The researcher's role, among other things, is to support the concrete knowledgebuilding, which at the same time includes practice development. 


\section{Q\&A. What Can Action Research Learn from Business Environment Analysis?} Bengt Wahlström

In line with the conceptual shift that Johansson and Lindhult (2008) point to, action research has increasingly come to be used in management. French (2009) makes a comprehensive review of the literature concerning action research in connection with management and lists a number of arguments why action research is a methodology that fits practicing managers. Some examples are:

\section{"Action research integrates thought and action, allows practitioners to research their own profes- sional activities, improve practice at the workplace and helps managers to be multidisciplinary and work across technical, cultural and functional boundaries. It is also problem-focused, context specific and future-oriented." (French, 2009)}

French (2009) also summarizes, based on his literature review, the work with action research in a four-stage, spiral model: 1) develop a plan, 2) act to implement the plan, 3) observe the action and collect data, and 4) reflect on the action and re-plan.

Gummesson (2000) lists several action research characteristics that are relevant to management such that action research strives for holistic understanding and recognizes complexity. Furthermore, action research is useful when it comes to understanding, planning, and implementing change processes in companies and organizations. Coughlan and Coghlan (2002) use Gummesson (2000) to explain the difference between action research and consulting. Consultants working with action research need to be more thorough with surveys and documentation than in their usual consulting work. Compared with an action researcher, a consultant is used to working under greater limitations when it comes to time and budget. The consulting work is often linear: the consultant engages, analyzes, acts, and disengages. Action research, on the other hand, is cyclical and consists of data collection, feedback, data analysis, planning, acting, evaluating and then continuing to collect new data, etc.

An academic with a strong consultancy agenda is Kaplan, who in 1998 launched a special form of action research called "innovation action research", which is about researchers actively participating in helping organizations implement new ideas. According to Kaplan, a consultant/researcher helps the client focus on and test an emerging theory that could improve the organization's performance.

\section{Empirical Findings from Decades of Consulting}

For over 30 years, I have worked with over 400 different clients and held more than 2,500 seminars and lectures about business environment analysis. The knowledge structure of the assignments can be divided into several different categories, depending on the client's wishes and on the client's maturity level regarding the use of business environment analysis. The assignments also differ in length, from one-hour lectures to year-long collaborations. Single, short lectures and seminars, whose main purpose is to go over current trends and position these trends in relation to the client's business, are the most common. In other assignments, the goal is to teach the client certain methods and tools so that the client can develop their own business environment analysis on a regular basis. A third category of assignments are reports and investigations, where business environment analysis, including both expected and unexpected trends, is used to highlight a particular theme associated with the client's business. Some clients demand digital platforms that are filled with business environment analysis signals on a regular basis. As a consultant, I listen to the client's knowledge needs and adjust the delivery of the content to these needs. I also have written books that summarize new developments in business environment analysis, which can be related to Kaplan's (1998) descriptions of how more general knowledge from consultancy work is gathered and disseminated to a broader audience.

My work as a consultant means working with several parallel knowledge structures, each with different purposes and recipients. These knowledge structures can be divided into some main areas, such as content, method, presentation, and technology. Depending on the nature of the assignment, different parts of the knowledge structures are handled in parallel. Another type of parallel knowledge structure is that acquired knowledge that deals with my own practice can be directly translated into changed actions, while acquired knowledge of a client's business first may need some internal explanation before it can be useful.

Thus, the knowledge structures for different business environment analysis assignments vary according to the nature of these assignments, as shown in Table 1. 


\section{Q\&A. What Can Action Research Learn from Business Environment Analysis? Bengt Wahlström}

Table 1. Knowledge structures for different types of business environment analysis assignments

\begin{tabular}{|c|c|}
\hline Assignment & Knowledge Structures \\
\hline \multirow[t]{3}{*}{ Seminars } & $\begin{array}{l}\text { - Content (current, forward-looking trends, including "Black Swans", that is, unexpected trends) } \\
\text { (Taleb, 2008) }\end{array}$ \\
\hline & - $\quad$ Method (overview) \\
\hline & - Presentation technology (advanced digital slideshows) \\
\hline \multirow[t]{3}{*}{ Education } & - $\quad$ Method (in-depth review) \\
\hline & - Pedagogy (examples, learning from others) \\
\hline & - Presentation technique (basic, digital slideshow) \\
\hline Reports & - Content (focus on special topics, complemented with business environment analysis) \\
\hline \multirow[t]{2}{*}{ Investigations } & - Analysis (draw conclusions, make checklists, and suggest decisions and actions) \\
\hline & - Presentation (make the content accessible and comprehensible) \\
\hline \multirow[t]{4}{*}{ Digital platform } & - Technology (building the digital platform) \\
\hline & - $\quad$ Layout (make the portal's interface accessible) \\
\hline & - Content (fill the portal with relevant business environment analysis signals) \\
\hline & - Analysis (draw conclusions from the business environment analysis signals for decisions and actions) \\
\hline \multirow[t]{3}{*}{ Books } & - Content (long perspective, forward- and backward-looking) \\
\hline & - Narrative (coherent story through the book) \\
\hline & - Presentation (accessible, with summaries and oversized quotations) \\
\hline
\end{tabular}

When it comes to business environment analysis, the organization's knowledge needs are different for different actors within the organization, such as the person who orders the assignment, the organization's employees, and the project's external target groups. In the organizations I have worked with, there are often different groups with different agendas, goals, knowledge, and so forth. This creates a particularly challenging environment for anyone who wants to work with action research for organizational development purposes since there are almost always shared opinions about the goal and approach for a possible action research project. This reality also differs from many other versions of action research, which has significantly clearer and more homogeneous groups to work with, for example, underprivileged groups in vulnerable areas.

The potential client's understanding of the importance of business environment analysis is often lacking, hence, the business environment analysis must be made interesting, for example, by presenting signals that are so exciting that they become eye-openers, leading to further discussions. The participants can be extremely knowledgeable in their respective fields but may not have much knowledge about how unexpected and disruptive events in the outside world would affect the company. This means that the knowledge needs also vary depending on the nature of the assignments, as shown in Table 2.

Examples of the combination of action research and business environment analysis

All types of assignments, from short seminars to yearlong collaborations, contain different knowledge structures and knowledge needs with links to action research. These links between business environment consultancy work and action research are, however, easiest to discover in the longer assignments. The participation takes place in different ways, depending on the situated conditions, as the following client examples show: 


\section{Q\&A. What Can Action Research Learn from Business Environment Analysis? Bengt Wahlström}

Table 2. Examples of knowledge needs for different actors

\begin{tabular}{lll}
\hline Actors & Examples of Knowledge Needs \\
\hline $\begin{array}{l}\text { The person who orders } \\
\text { the assignment }\end{array}$ & - & Learn to understand the overall meaning of business environment analysis for their own organization \\
& - & Learn to see the link between business environment analysis and the organization's core business \\
\hline The organization's & - Learn the methods of business environment analysis \\
employees & - Learn how to work with a digital portal \\
& - Learn to work in a digital way at a more general level \\
\hline $\begin{array}{l}\text { The project's external } \\
\text { target groups }\end{array}$ & - Learn to better understand the outside world \\
\hline
\end{tabular}

1. A labour market organization ordered a business environment analysis education project that gave regular feedback from the client's employees. They used the tools in the project with their customers and reported how it worked. This information was then used to continuously develop the material.

2. A region ordered a business environment portal online but was not specifically involved in the project. They let it continue, as business environment analysis was considered necessary in some form. The participation was indirect and consisted of the business environment consultant being able to follow and analyze how the business environment analysis portal was used and then both content and function were developed in accordance with user behaviour.

3. A member organization ordered both an online portal and seminars. The manager encouraged the project and ensured that the users participated and gave continuous feedback. The result was continuous changes that adapted the project to the users' knowledge needs, for example, by moving from a business environment analysis portal to a newsletter and thereby improving the usability.

4. A transport sector company first bought a small business environment analysis education project, which, after the evaluation, grew into an in-depth project. Participation took place through feedback at various meetings and workshops to continuously developed the project.
The examples above clearly illustrate the difference between action research and consulting that Coughlan and Coghlan (2002) described. Consulting is linear whereas action research is cyclical and requires thorough surveys and documentation. In the examples above, there was no time for that kind of accuracy. Similarly, the four-step model described by French (2009) with its careful planning, data collection, reflecting, and re-planning - is not always something that can be used in the business environment analysis consultant's everyday life. However, Johansson and Lindhult's (2008) description of the researchers' role in supporting concrete knowledge-building can also be relevant in a consulting role. The same goes for Kaplan's (1998) innovation action research cycle. The conclusion is that, in some respects, it is reasonable to call my business environment analysis consultancy work action research, but there are differences that are interesting and that can add useful insights.

\section{What Action Research Can Learn from Business Environment Analysis}

With the literature overview, the examples, and my other experiences as a business environment analysis consultant as starting points, I have identified four insights about action research in connection to business environment analysis consultancy work, as described below. 


\title{
Q\&A. What Can Action Research Learn from Business Environment Analysis?
}

\author{
Bengt Wahlström
}

\section{Insight 1: The importance of the client's position in the organization}

Making a business environment analysis project a success is a challenge because the client's organization rarely has identified business environment analysis as business critical; business environment analysis is expected to primarily bring complementary skills. Therefore, it does matter who orders a business environment analysis project. The higher up in the organization the contact is, the greater the probability is that the project will be a success.

Contacts can come from three levels: top management, middle management, or individual employees. If the client is a top manager, the project automatically is set up with good conditions. However, problems may arise if the CEO orders the project but delegates implementation to a middle manager without stating why the project is needed. Then, there is the risk that the project will fade out and become largely irrelevant (like with the second example, the region).

The most common client is an interested middle manager who has received clearance from the CEO, who is either positive or uninterested. These business environment analysis projects are the easiest to operate successfully (like the example with the member organization above).

The business environment analysis projects with the greatest risk of failure are those ordered by an individual employee. He or she works, for example, in a development department, education department, marketing department, or human resources department. This type of project requires a purposeful anchoring process so that both middle management and top management are informed and positive or, at the very least, neutral. It is easier for individual employees to both anchor and successfully implement a business environment analysis project in a decentralized organization where many employees can act on their own (Brunson, 2006).

This practice differs from Kaplan (1998) who writes, "My personal journey started in the early 1980s, after several discussion with senior skilled managers...". Kaplan seems to have constant access to senior managers in major companies, and it is within these companies that their new ideas and innovations are tested. The reality for the consultancy work that I represent is different. In Sweden, small and medium-sized enterprises with up to 250 employees represent $99 \%$ of all companies and, in that group, the client's position in the organization is important.
French (2009) and Coughlan and Coghlan (2002) are not as clear as Kaplan (1998), but their models also seem to be based on an unproblematic relationship with the management of the participating organization.

\section{Insight 2: The importance of working with parallel knowledge structures}

Different business environment analysis projects address different knowledge structures. The seminars attempt to capture current trends, whereas the training assignments focus on methods and tools. The reports, investigations, and digital platforms almost always begin with the client's core business, which is then placed in relation to the outside world. In terms of the content, business environment analysis projects work with further parallel knowledge structures in the form of expected and unexpected trends and signals.

Hence, as a business environment analysis consultant, I must constantly work with parallel knowledge structures. A special challenge is to get the client to accept and analyze both expected and unexpected business environment trends and signals in parallel, where the unexpected trends often are perceived as disturbing.

Parallel knowledge structures can also mean that knowledge is developed by one group of participants, but another group coming later in the project will get the benefits. If we return to Kaplan (1998) for a comparison, Kaplan enters a company with a project focusing on a specific and clear knowledge structure, such as a balanced scorecard or activity-based costing.

\section{Insight 3: The importance of finding the client's different} knowledge needs

In my experience, many companies regard the outside world as somewhat diffuse and troublesome. Most companies are satisfied with monitoring Porter's (1980) five forces (competitors, customers, suppliers, substitutes, and new entrants); this means that the demand for additional business environment analysis activities is limited. Therefore, as a consultant, I must first identify the client's different knowledge needs that go beyond these five forces and then obtain acceptance of this description of reality so that it is possible to start a business environment analysis project. The easiest way to do this is by highlighting specific examples - mainly in globalization, digital transformation, or sustainable development - and linking these examples to the company's operations. Some examples include the following: How would the client be affected if were a full-scale trade war between the United States and China? What would it mean for a retail client if Amazon were to establish 


\section{Q\&A. What Can Action Research Learn from Business Environment Analysis?} Bengt Wahlström

themselves in their country? What effects would there be for the client if customers with climate change panic were to abstain from eating meat or refrain from flying in planes or buying cars? And, above all, what knowledge needs do these changes in the outside world lead to? By asking these kinds of questions, a potential client may become interested, and it is then possible to start a project.

Kaplan does not have to wrestle with these kinds of questions. Kaplan writes (1998): "The teaching cases provided a discipline where we could visit each company for several days, interview a broad set of managers and engineers, collect data, write up our findings and share them with company managers."

\section{Insight 4: The importance of nuance in innovation ac- tion research}

According to Kaplan (1998), innovation action research requires the researcher (i.e., the consultant) to actively engage in helping the organization implement a new idea. In my case, this is done by using business environment analysis. Kaplan (1998) goes on to state that such an engagement will lead to the researcher not only learning more about the idea itself and how to improve it, but also how to implement it in organizations. In my case, this is a good description of how knowledge from different individual assignments could be used in other organizations. However, as the above insights show, Kaplan's model was developed under very special circumstances based on contact with large, well-established companies, where the company being researched was aware of the problem and welcomed Kaplan's projects. These circumstances cannot be considered normal within most consultancy work. Hence, a nuanced interpretation of Kaplan's model must be made and additional aspects must be incorporated into the model for it to be relevant for other types of action research projects, especially those with companies that are small, sometimes insecure, and that need to be patiently convinced to participate in a project.

\section{Conclusion}

So, what can action research learn from business environment analysis? First, there is the importance of where in the organization the person ordering a business environment analysis is, because this relates to the possible success of the project. It is not necessary to have access to top management, but it is important to be in the right context and have contacts with those who have the power to change. Second, it is also important to be able to identify both the knowledge structures and knowledge needs of the client, but at the same time be aware that the client usually needs help discovering these structures and needs; otherwise, there will not be a project. And, finally, action research should not be conducted only in large and confident companies; it can be useful even in the small, often cautious companies that make up the majority of the business community.

\section{About the Author}

Bengt Wahlström is a doctoral candidate at Mälardalen University in Sweden, where he holds a Licentiate of Philosophy degree. He is also a consultant and an author and has for decades been one of the leading experts in Scandinavia within innovation, business environment analysis, and future strategy. Every year, he meets with thousands of participants to hold discussions, seminars, and training programmes on these issues. His numerous books have sold over 60,000 copies, have won awards in Sweden and abroad, and have been translated into many languages. 


\section{Q\&A. What Can Action Research Learn from Business Environment Analysis? Bengt Wahlström}

\section{References}

Argyris, C., \& Schön, D. A. 1996. Organisational Learning II: Theory, Method and Practice. Reading, MA: Addison-Wesley.

Brunsson, N. 2006. The Organization of Hypocrisy: Talk, Decisions and Actions in Organizations. Malmö, Sweden: Liber

Coughlan, P., \& Coghlan, D. 2002. Action Research for Operations Management. International Journal of Operations \& Production Management, 22(2): 220-240.

https://doi.org/10.1108/01443570210417515

French, S. 2009. Action Research for Practising Managers. Journal of Management Development, 28(3): 187-204.

https://doi.org/10.1108/02621710910939596

Gummesson, E. 2000. Qualitative Methods in Management Research. Thousand Oaks, CA: SAGE.

Hamrefors, S. 2002. Den Uppmärksamma Organisationen. Från Business Intelligence till Intelligent Business. Lund, Sweden: Studentlitteratur.

Hoppe, M. 2009. Myten om det rationella flödet - En studie av hur organisatorisk ledning formas genom omvärldsanalys och underrättelsearbete $i$ kunskapsintensiva företagsmiljöer. Turku, Finland: Åbo Akademi University Press.

Johansson, A. W., \& Lindhult, E. 2008. Emancipation or Workability? Critical versus Pragmatic Scientific Orientation in Action Research. Action Research, 6(1): 95-115.

https://doi.org/10.1177/1476750307083713

Kaplan, R. S. 1998. Innovation Action Research: Creating New Management Theory and Practice. Journal of Management Accounting Research, 10: 89-118.

Lewin, K. 1946. Action Research and Minority Problems. Journal of Social Issues, 2(4): 34-46.

https://doi.org/10.1111/j.1540-4560.1946.tb02295.x

Pfeffer, J., \& Salancik, G. 2003. The External Control of Organizations: A Resource Dependency Perspective. Stanford, CA: Stanford University Books.

Porter, M. E. 1980. Competitive Strategy: Techniques for Analyzing Industries and Competitors. New York, NY: Free Press.

Rohrbeck, R., \& Gemünden, H. G. 2011. Corporate Foresight: Its Three Roles in Enhancing the Innovation Capacity. Technological Forecasting and Social Change, 78(2): 231-243.

http://doi.org/10.1016/j.techfore.2010.06.019

Taleb, N. N. 2008. The Black Swan: The Impact of the Highly Improbable. New York, NY: Penguin.

Keywords: action research, business environment analysis, consultancy, consultants, organizations 


\section{Author Guidelines}

These guidelines should assist in the process of translating your expertise into a focused article that adds to the knowledge resources available through the Technology Innovation Management Review. Prior to writing an article, we recommend that you contact the Editor to discuss your article topic, the author guidelines, upcoming editorial themes, and the submission process: timreview.ca/contact

\section{Topic}

Start by asking yourself:

- Does my research or experience provide any new insights or perspectives?

- Do I often find myself having to explain this topic when I meet people as they are unaware of its relevance?

- Do I believe that I could have saved myself time, money, and frustration if someone had explained to me the issues surrounding this topic?

- Am I constantly correcting misconceptions regarding this topic?

- Am I considered to be an expert in this field? For example, do I present my research or experience at conferences?

If your answer is "yes" to any of these questions, your topic is likely of interest to readers of the TIM Review.

When writing your article, keep the following points in mind:

- Emphasize the practical application of your insights or research.

- Thoroughly examine the topic; don't leave the reader wishing for more.

- Know your central theme and stick to it.

- Demonstrate your depth of understanding for the topic, and that you have considered its benefits, possible outcomes, and applicability.

- Write in a formal, analytical style. Third-person voice is recommended; first-person voice may also be acceptable depending on the perspective of your article.

\section{Format}

1. Use an article template: .doc .odt

2. Indicate if your submission has been previously published elsewhere. This is to ensure that we don't infringe upon another publisher's copyright policy.

3. Do not send articles shorter than 2000 words or longer than 5000 words.

4. Begin with a thought-provoking quotation that matches the spirit of the article. Research the source of your quotation in order to provide proper attribution.

5. Include an abstract that provides the key messages you will be presenting in the article.

6. Provide a 2-3 paragraph conclusion that summarizes the article's main points and leaves the reader with the most important messages.

7. Include a 75-150 word biography.

8. List the references at the end of the article.

9. If there are any texts that would be of particular interest to readers, include their full title and URL in a "Recommended Reading" section.

10. Include 5 keywords for the article's metadata to assist search engines in finding your article.

11. Include any figures at the appropriate locations in the article, but also send separate graphic files at maximum resolution available for each figure. 


\section{Issue Sponsor}

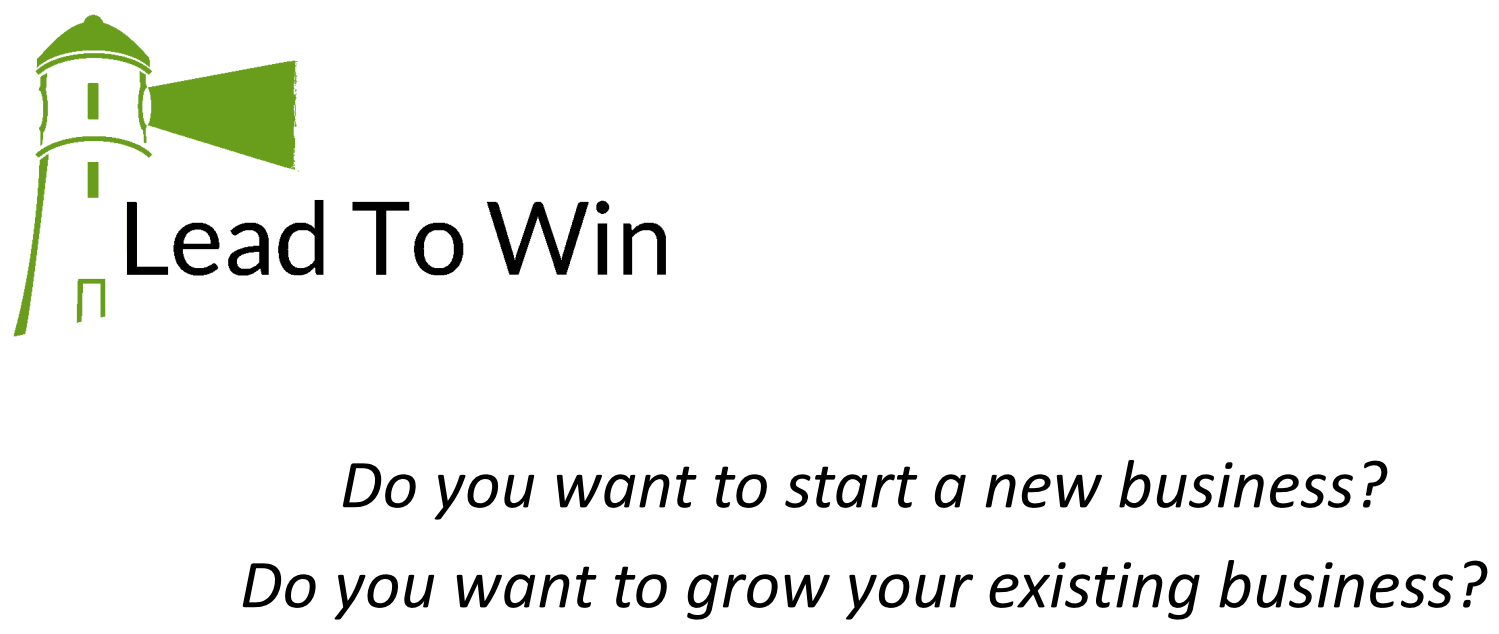

Lead To Win is a free business-development program to help establish and grow businesses in Canada's Capital Region.

Benefits to company founders:

- Knowledge to establish and grow a successful businesses

- Confidence, encouragement, and motivation to succeed

- Stronger business opportunity quickly

- Foundation to sell to first customers, raise funds, and attract talent

- Access to large and diverse business network

\section{Apply Now}

* Twitter

f Facebook

in Linkedin

E Eventbrite

9 Slideshare

- YouTube

-๑ Flickr 


\section{Academic Affiliations and Funding Acknowledgements}
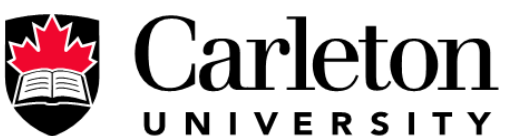

U N I V E R S I T Y

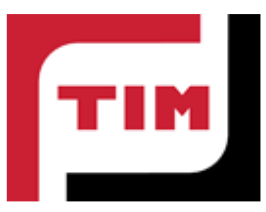

Technology Innovation Management (TIM; timprogram.ca) is an international master's level program at Carleton University in Ottawa, Canada. It leads to a Master of Applied Science (M.A.Sc.) degree, a Master of Engineering (M.Eng.) degree, or a Master of Entrepreneurship (M.Ent.) degree. The objective of this program is to train aspiring entrepreneurs on creating wealth at the early stages of company or opportunity lifecycles.

- The TIM Review is published in association with and receives partial funding from the TIM program. 